THE QUANTIFICATION OF THE FLY ASH ADSORPTION CAPACITY FOR THE PURPOSE OF CHARACTERIZATION AND USE IN CONCRETE

Zeyad Tareq Ahmed

Michigan Technological University

Follow this and additional works at: https://digitalcommons.mtu.edu/etds

Part of the Civil Engineering Commons, and the Materials Science and Engineering Commons Copyright 2012 Zeyad Tareq Ahmed

Recommended Citation

Ahmed, Zeyad Tareq, "THE QUANTIFICATION OF THE FLY ASH ADSORPTION CAPACITY FOR THE PURPOSE OF CHARACTERIZATION AND USE IN CONCRETE", Dissertation, Michigan Technological University, 2012.

https://doi.org/10.37099/mtu.dc.etds/789

Follow this and additional works at: https://digitalcommons.mtu.edu/etds

Part of the Civil Engineering Commons, and the Materials Science and Engineering Commons 


\title{
THE QUANTIFICATION OF THE FLY ASH ADSORPTION CAPACITY FOR THE PURPOSE OF CHARACTERIZATION AND USE IN CONCRETE
}

\author{
By \\ Zeyad Tareq Ahmed
}

\begin{abstract}
A DISSERTATION
Submitted in partial fulfillment of the requirements for the degree of DOCTOR OF PHILOSOPHY

(Environmental Engineering)
\end{abstract}

MICHIGAN TECHNOLOGICAL UNIVERSITY

2012

(C) 2012 Zeyad Ahmed 
This dissertation "The Quantification of the Fly Ash Adsorption Capacity for the Purpose of Characterization and Use in Concrete," is hereby approved in partial fulfillment of the requirement for the Degree of DOCTOR OF PHILOSOPHY IN ENVIRONMENTAL ENGINEERING.

Department of Civil and Environmental Engineering

Signatures:

Dissertation Advisor

David W. Hand

Department Chair

David W. Hand

Date 


\section{Table of Contents}

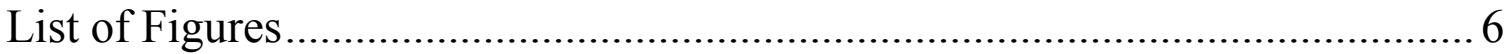

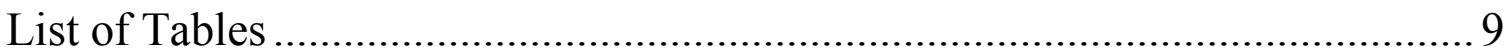

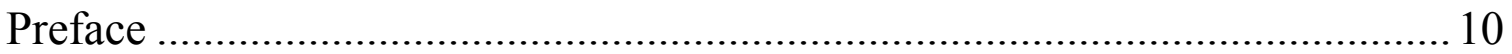

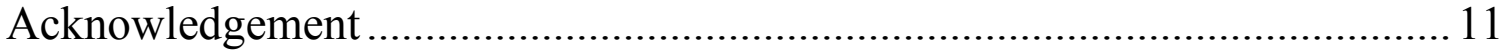

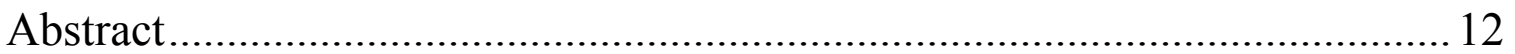

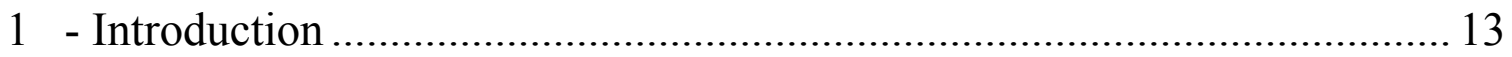

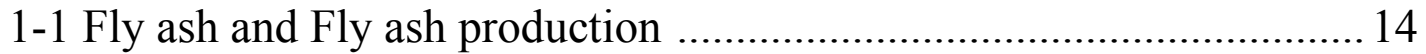

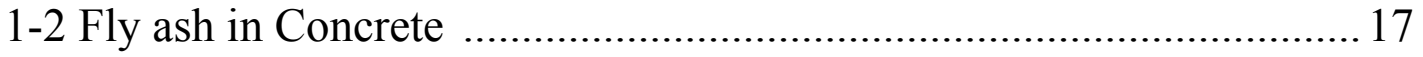

1-3 Air Entraining Admixtures (AEAs)................................................... 17

1-4 Interaction between fly ash and AEAs ................................................ 19

Factors affecting AEA adsorption on fly ash carbon ........................... 21

1-5 Measurement of the adsorption capacity of fly ash............................22

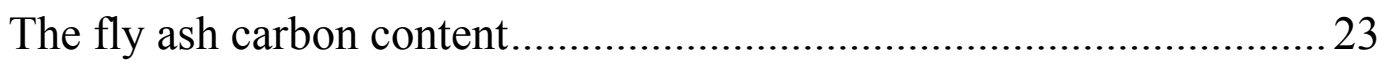

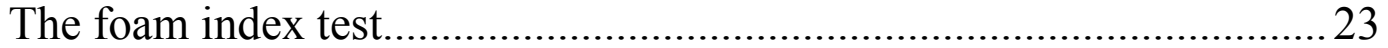

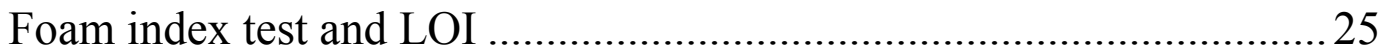

2 - Fly Ash Iodine Number for the Measurement of the Adsorption Capacity of Coal Fly Ash ...................................................................... 29

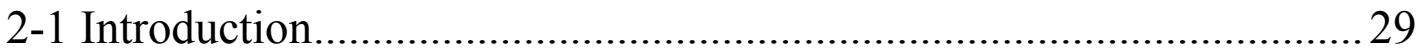

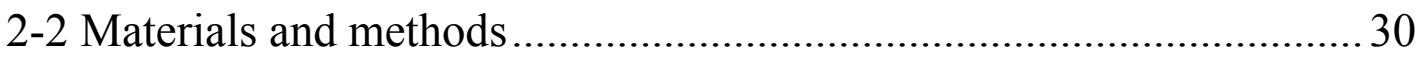

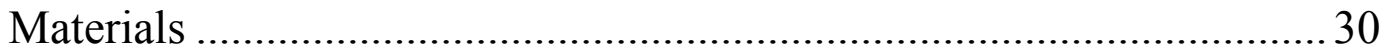

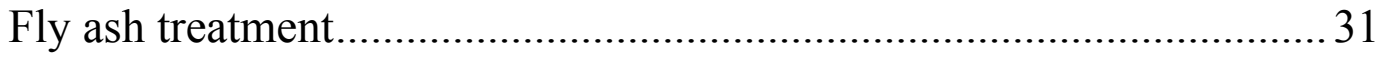

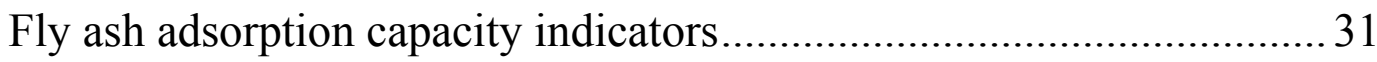

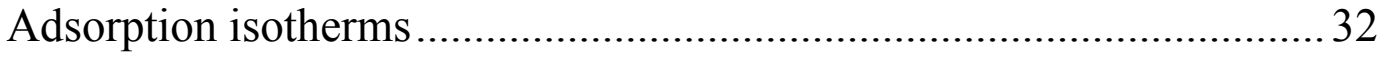

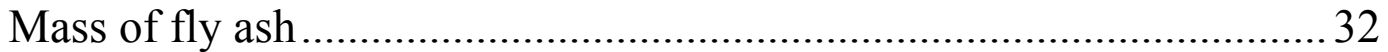

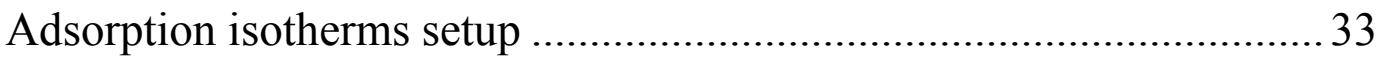

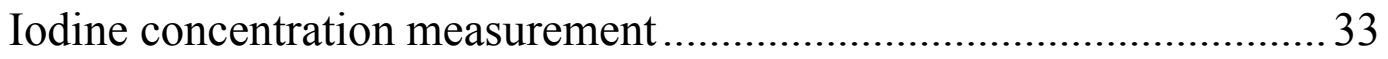

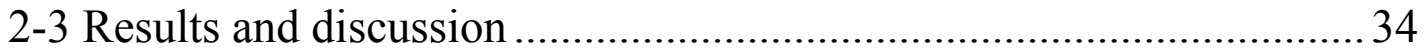

Impact of the fly ash treatment ............................................................ 34

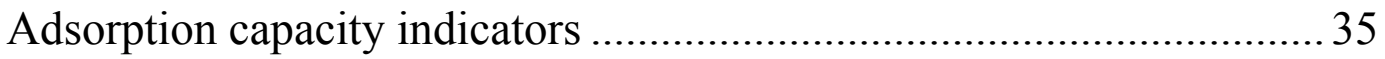




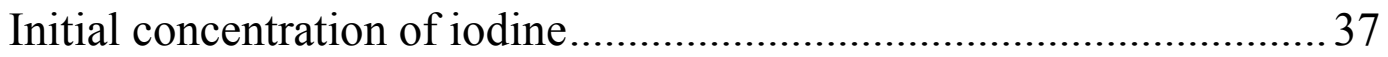

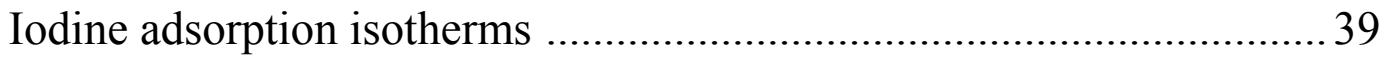

The target iodine concentration selection ................................................ 43

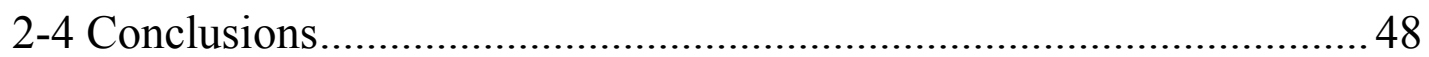

3 - Air Entraining Admixtures (AEAs) Partitioning and Adsorption by Coal

Fly Ash in Concrete.............................................................................. 49

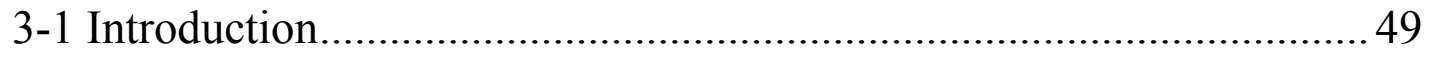

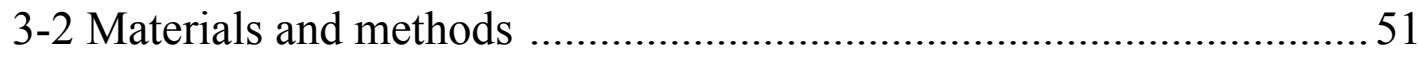

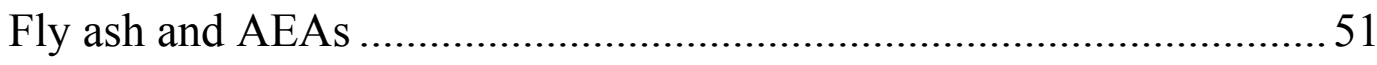

Measurement of AEA concentration ..................................................... 52

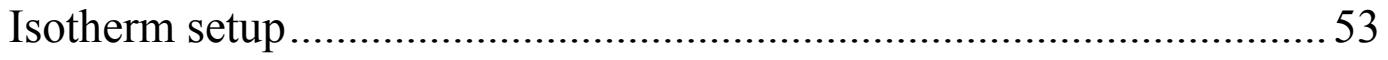

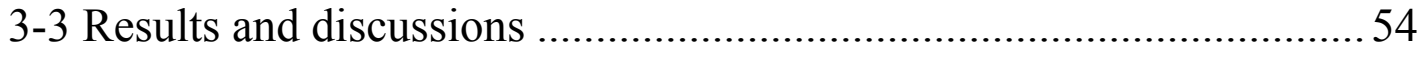

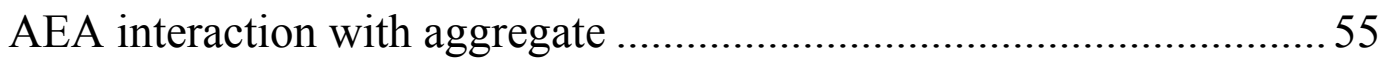

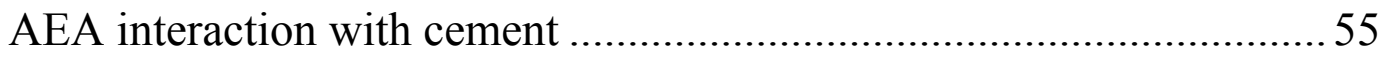

Factors affecting AEA partitioning coefficient ......................................5 57

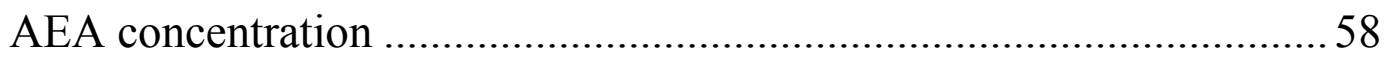

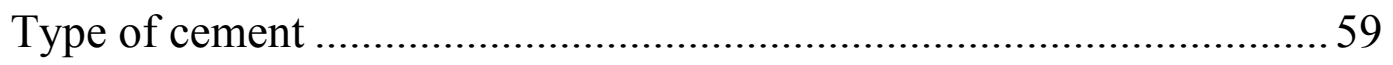

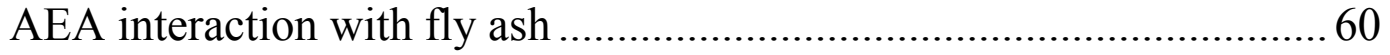

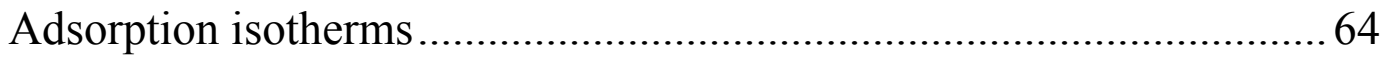

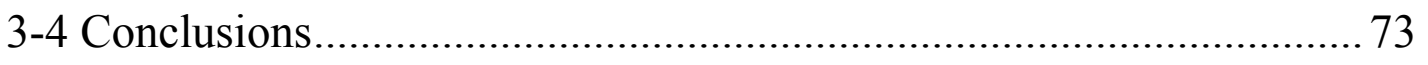

4 - Combined Adsorption Isotherms for the Quantification of Air Entraining Admixtures Adsorption by Fly Ash in Concrete .................................... 74

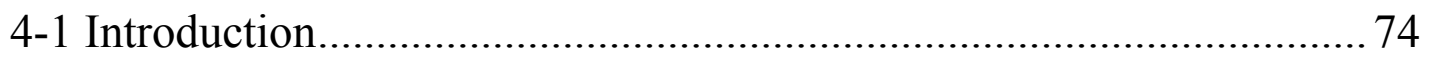

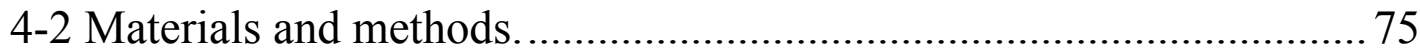

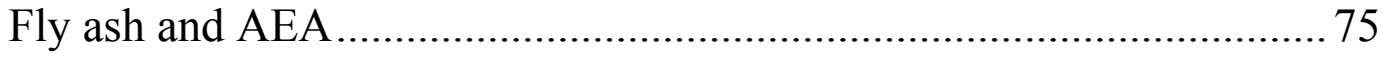

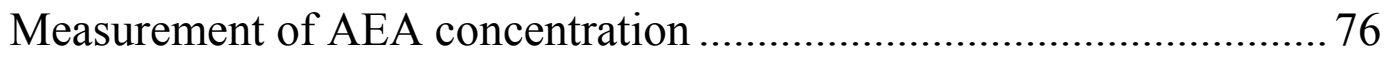

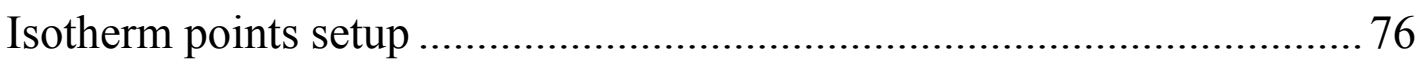

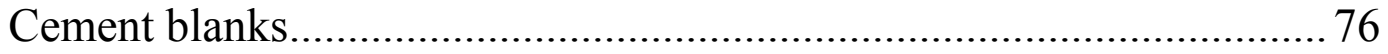

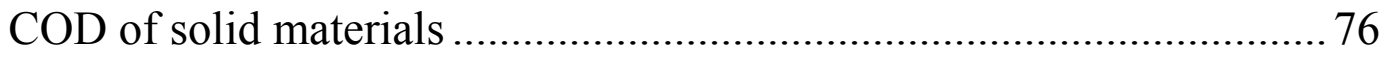

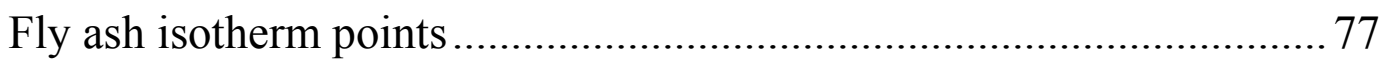

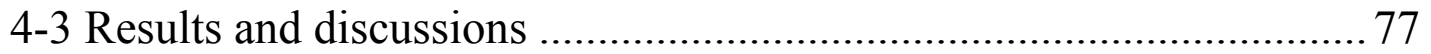




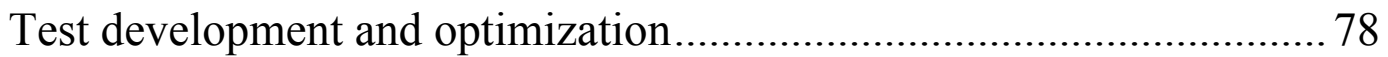

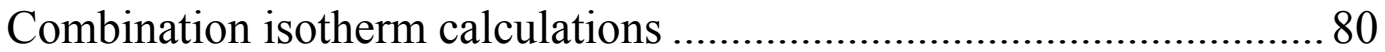

Combined Cement and Fly Ash Isotherm Results Analysis .................. 83

Adsorption Isotherms Utilization and AEA Dosage Adjustment........... 84

Effect of Temperature on Fly Ash Adsorption Capacity........................ 85

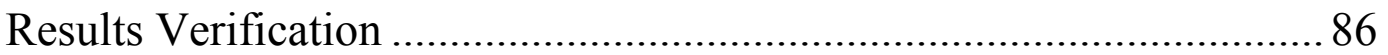

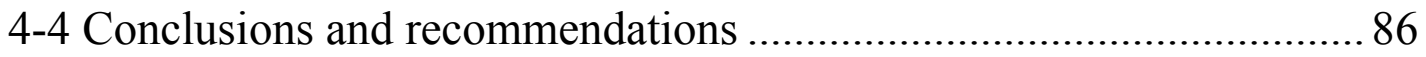

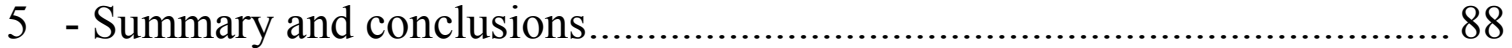

5-1 LOI Correlation to the Adsorption Tests ............................................ 88

5-2 Correlation among the adsorption capacity tests................................90

The foam index and the fly ash capacity ............................................... 91

The fly ash iodine number and the fly ash capacity ............................... 91

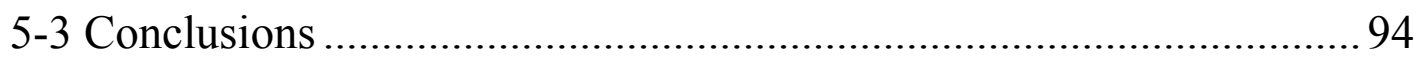

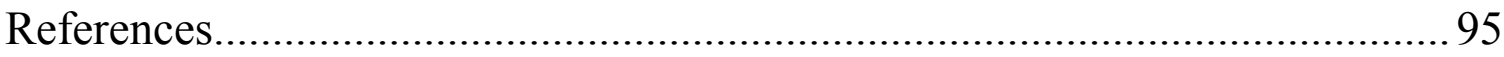

Appendix A. Direct adsorption isotherms results for various AEAs .............. 104

Appendix B. Copyright permissions …………............................................... 107 


\section{List of Figures}

Figure 1.1 Particle size distribution for various fly ash specimens.................. 15

Figure 1.2 SEM image of fly ash at 2000X magnification. ............................. 16

Figure 1.3 Air entraining admixture chemical nature .................................... 18

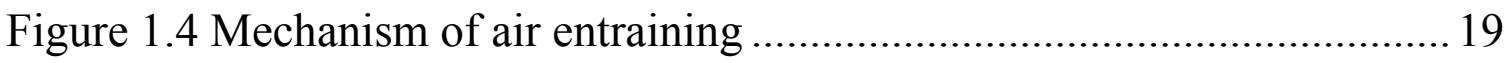

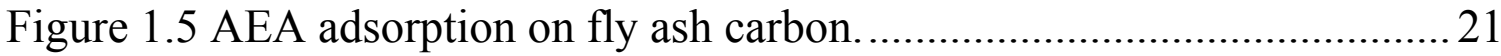

Figure 1.6 Foam index test versus LOI for five different studies .................... 26

Figure 1.7 Specific foam index test versus LOI for the studies presented in

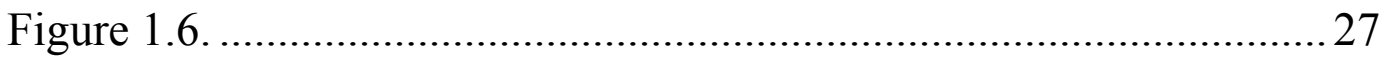

Figure 2.1. The effect of multiple treatment cycles on the adsorption behavior

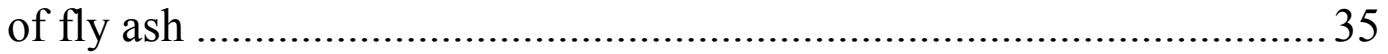

Figure 2.2 Correlation between LOI and foam index tests results for the fourteen fly ash types studied. Filled data points were chosen to illustrate inconsistencies between the LOI and foam index test results. ............... 37

Figure 2.3 Effect of iodine solution concentration on the adsorption isotherm

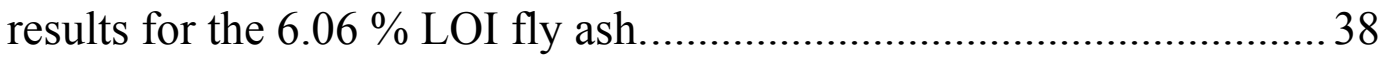

Figure 2.4 Aqueous phase iodine concentration versus fly ash mass for (a) $0.05 \mathrm{~N}$ and (b) $0.025 \mathrm{~N}$ initial iodine solution concentration. LOIs are shown in parentheses. 40

Figure 2.5 Adsorption isotherms for (a) $0.05 \mathrm{~N}$ and (b) $0.025 \mathrm{~N}$ iodine with 10 of fly ash types. LOIs are shown in parentheses. 41

Figure 2.6 The fly ash iodine number with target concentrations of $0.01 \mathrm{~N}$ and $0.005 \mathrm{~N}$ versus (a) LOI and (b) foam index for 10 types of fly ash ........ 43 Figure 2.7 Fly ash iodine number at $0.01 \mathrm{~N}$ and $0.005 \mathrm{~N}$ versus LOI ............... 44 Figure 2.8 Correlation between LOI and fly ash iodine number...................... 46

Figure 3.1 The correlation between AEA concentration in \% Vol. and COD $(\mathrm{mg} / \mathrm{L})$ 
Figure 3.2 AEAs partitioning between cement and water..............................57

Figure 3.3 AEA partitioning coefficient for various AEA concentrations .......58

Figure 3.4 Effect of type of cement on the AEA partitioning coefficient.........60

Figure 3.5 Low carbon fly ash $(0.39 \%$ LOI) interaction with three types of AEAs 61

Figure 3.6 Interaction between high carbon fly ash and six different AEAs, AEAs concentrations expressed as mg/L of COD ................................. 62

Figure 3.7 Interaction between high carbon fly ash and six different AEAs, AEAs concentrations expressed as ratio to the initial AEA concentration $(\mathrm{C} / \mathrm{Co})$ 62

Figure 3.8 AEA cement partitioning coefficients for six AEAs at various concentrations equilibrated with $20 \mathrm{~g}$ of portland cement. 66

Figure 3.9 High carbon fly ash isotherm with $0.8 \%$ MB VR ......................... 70

Figure 3.10 High carbon fly ash isotherm results with six AEAs.................... 71

Figure 3.11 High carbon fly ash isotherm results with six AEAs. Capacity expressed as ml AEA per $\mathrm{g}$ fly ash and concentration as \%vol. in water .72

Figure 4.1 Combination isotherm results of $0.8 \% \mathrm{MB}$ VR, fly ash 39 , and various masses of portland cement 79

Figure 4.2 Combined adsorption isotherms for MB-VR with eight fly ashes .. 84 Figure 4.3 The effect of temperature on the adsorption capacity of fly ash ..... 86 Figure 5.1 LOI correlation to fly ash iodine number, foam index, and fly ash capacity measured using the direct adsorption isotherms. 89

Figure 5.2 The relationship between the fly ash iodine number, the foam index, and the capacity of fly ash at $0.4 \%$ vol. MB VR concentration measured using direct adsorption isotherms 90 
Figure 5.3 The correlation between the fly ash iodine number and various concentrations of the vinsol resin admixture MB VR ........................... 93 


\section{List of Tables}

Table 2.1 Selected fly ash specimens and their properties.............................36

Table 2.2 Freundlich isotherm parameters for $0.025 \mathrm{~N}$ iodine isotherms with

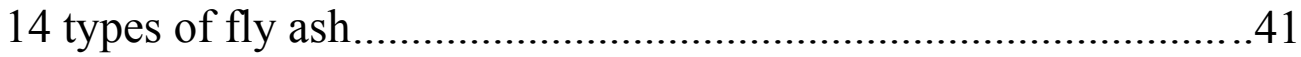

Table 2.3 Results of the fly ash iodine number, LOI, and the foam index for

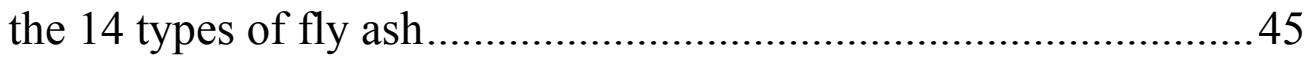

Table 3.1 Fly ash specimens and their properties..........................................51

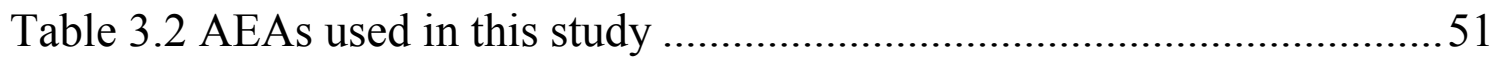

Table 4.1 Fly ash specimens and their properties......................................... 75 


\section{Preface}

This research project is part of a National Cooperative Highway Research Program (NCHRP 18-13) funded by the Transportation Research Board of The National Academies. Chapter two, three, and four of this dissertation are to be submitted as journal publications upon the approval of the final project report. The author of this dissertation has conducted the laboratory work, analyzed, and collected all the data presented in this dissertation. 


\section{Acknowledgement}

I wish to express my gratitude to my advisor, Dr. David Hand for his guidance and close supervision. I would like to thank him for his generosity in sharing his expertise, willingness to teach, and mostly his patience during my studies. His help and friendship turned this research into a pleasant journey, and I will remain his student who is eager to learn more from him for the rest of my life.

I would like to thank my committee members, Dr. Neil Hutzler, Dr. Martin Auer, Dr. Lawrence Sutter, and Dr. Stephan Hackney for taking interest in my work and for their assistance and valuable suggestions.

I am very grateful to Mrs. Shelle Sandell for her help and support which affected my work, study and my life at the MTU. I would like to thank Mr. David Perram for his scientific and technical support.

I would like to thank The National Cooperative Highway Research Program, the Transportation Research Board of The National Academies for funding this project (NCHRP 18-13). I also like to thank the National Science Foundation for granting me S-STEM scholarship (Grant No. 0806569) for two years.

I am also very grateful to my friends who supported me during tough times especially Mike, Meredith, and Melanie, and to my family especially my wife Hala for her unlimited encouragement and support. 


\begin{abstract}
Fly ash has been shown to be an effective replacement for portland cement in concrete mixtures. However, many fly ash materials contain unburned carbon from the combustion process. Unburned carbon in fly ash adsorbs air entraining admixtures (AEAs) reducing their effectiveness in providing a specified air void system in concrete materials. Measurement tools and methods for characterization of the adsorption properties of fly ash materials are necessary for beneficial use of fly ash materials in concrete. In this research, two methods were developed to measure and quantify the adsorption capacity AEAs on fly ash materials. The first method is the fly ash iodine number, a simple laboratory procedure that measures the adsorption capacity of fly ash based on iodine adsorption. The second is the application of direct adsorption isotherms. This test can be used to quantify the amount of AEA adsorbed by fly ash in concrete.
\end{abstract}

When the iodine number test is combined with the direct adsorption isotherms, the AEAs dosage predictions can be made by simply measuring the fly ash iodine number of the fly ash, then use the fly ash iodine number-direct adsorption correlation to predict the amount of AEA adsorbed, which represent the required dosage adjustment.

These two tests provide a robust, simple, and practical methodology for engineers to use in the specification of AEA quantities required for concrete mixes when Portland cement is replaced by fly ash. 


\section{1 - Introduction}

More than one fourth of the world production of primary energy is from coal (1). In 2010, the United States produced 4.13 billion megawatthours of electricity with 1.85 billion megawatthours from coal (2), generating 67.7 million tons of fly ash. Only $38 \%$ of this fly ash was beneficially used (3), the remainder was land filled as solid waste.

Currently the primary market for fly ash utilization is for use in concrete to improve durability and to reduce the amount of portland cement used in concrete mixtures. Increased fly ash utilization in concrete is challenged and limited by the tendency of fly ash to adsorb organic chemicals, most notably air entraining admixtures (AEAs), thereby adversely affecting other concrete properties. This adsorption property, on the other hand, can be favorable for other uses for fly ash. In both cases, the lack of an adequate test method to assess fly ash adsorption capacity limits increased fly ash use.

Air entraining admixtures interact with cement, aggregate, and fly ash in a complex manner due to the complex composition of AEAs and to the presence of various types of minerals in the concrete mix. Residual carbon in the fly ash adsorbs some components of the AEAs, reducing their availability to function in the concrete mixture, leading to a failure to produce the required air content in the concrete (4) (5) (6) (7) (8) (9). Implementing low temperature combustion techniques to reduce the mono-nitrogen oxides (NOx) emissions has increased the amount of unburned carbon and introduced high adsorption capacity fly ashes (10) (11). The adsorption capacity of fly ash is governed not

only by the amount of carbon content but also by other properties such as the particle size, surface chemistry, and positioning of carbon in the fly ash particle. 
The foam index test and carbon content measured by loss on ignition (LOI) have been used as indicators of AEA adsorption. These tests, however, do not provide a direct or accurate measurement of the adsorption capacity. A direct measurement of the adsorption capacity of fly ash would be a valuable tool for increased utilization in concrete as well as other beneficial uses.

In this research, two methods for the quantification of the fly ash adsorption capacity were developed and examined. The first method, the fly ash iodine number, is a simple laboratory procedure that measures the adsorption capacity of fly ash using iodine adsorption. This procedure is extremely important for the characterization and specification of fly ash because it can be used to determine the suitability of the fly ash for use in concrete or other applications. The second testing method, the direct adsorption isotherms, measures the amount of AEA adsorbed by the fly ash of interest. This procedure can be performed on specific concrete mixtures to obtain an accurate measurement for the adsorption of the AEA by the fly ash in the concrete mixture. Both tests combined together can be used to predict the AEA dosage adjustment required to compensate for AEA adsorbed by the fly ash.

\section{1-1 Fly ash and Fly ash production}

Fly ash is a fine residue generated from the combustion of pulverized coal. Fly ash particles sizes are typically between 10 and 100 microns (12). Particles below $1 \mu \mathrm{m}$ and above $150 \mu \mathrm{m}$ may also exist, but the highest contribution to the mass of fly ash is from particle sizes less than $38 \mu \mathrm{m}$ as shown in Figure 1.1. Fly ash particles are typically spherical since they have gone through combustion at very high temperatures (4). Figure 1.2 shows the spherical nature in a scanning electron microscopy (SEM) image of fly ash at 2000X magnification (12). 


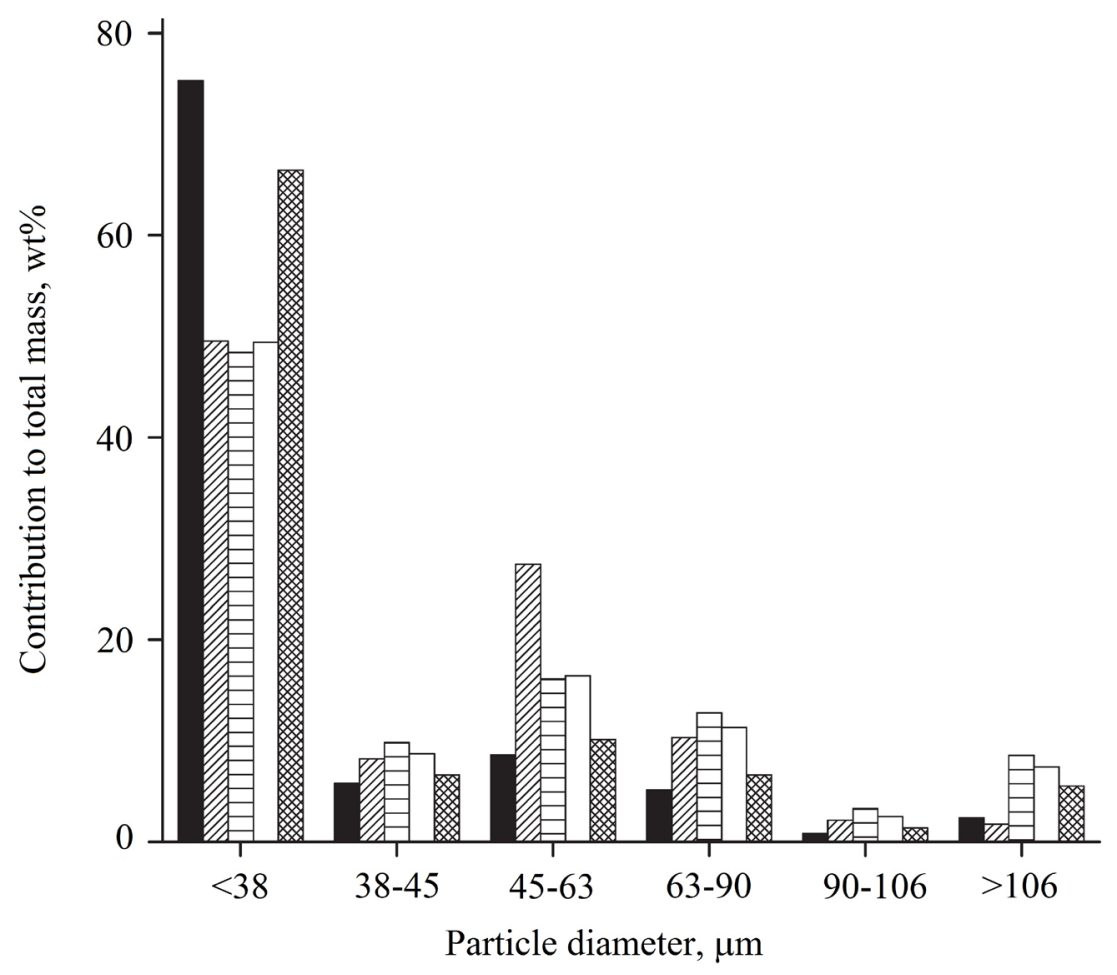

Figure 1.1* Particle size distribution of various fly ash specimens. Courtesy of Perdersen et al. (4) *Permission seen in Figure B-1

Fly ash contains a mixture of silicon, aluminum, Iron, and calcium oxides. Traces of magnesium, potassium, sodium, titanium, and sulfur may also exist. The composition of fly ash depends mainly on the type of coal burned, the coal loading rate, and the burning conditions. The composition of fly ash may vary even for the same production line at different times (5) due to the change in loading and burning conditions. 


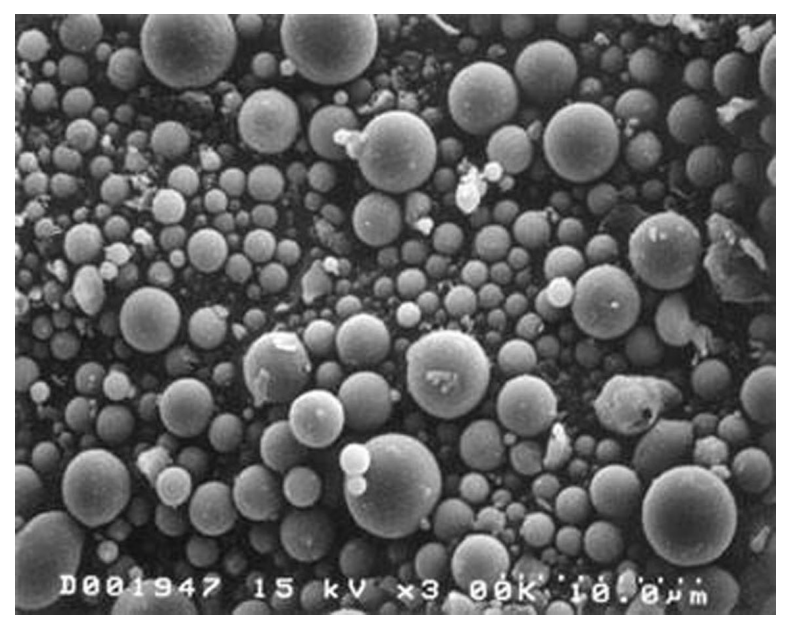

Figure 1.2* SEM image of fly ash at 2000X magnification. Courtesy of the Federal Highway Administration (12) *Permission seen in Figure B-2

Using high rank coals (i.e. anthracite or bituminous) produces fly ashes with high contents of $\mathrm{SiO}_{2}, \mathrm{Al}_{2} \mathrm{O}_{3}$, and $\mathrm{Fe}_{2} \mathrm{O}_{3}$. Using sub bituminous and lignite, which are lower rank coals, produces fly ashes with lower contents of $\mathrm{SiO}_{2}$, $\mathrm{Al}_{2} \mathrm{O}_{3}$, and $\mathrm{Fe}_{2} \mathrm{O}_{3}$. According to the American Society of Testing Materials (ASTM C618) (13) fly ash that contains a $\mathrm{SiO}_{2}+\mathrm{Al}_{2} \mathrm{O}_{3}+\mathrm{Fe}_{2} \mathrm{O}_{3}$ content of more than $70 \%$ is classified as Class $\mathrm{F}$ fly ash. Fly ash that has $\mathrm{SiO}_{2}+\mathrm{Al}_{2} \mathrm{O}_{3}+\mathrm{Fe}_{2} \mathrm{O}_{3}$ content of 50\%-70\% is classified as Class C fly ash. The American Association of State Highway Transportation Officials (AASHTO) M 295 (14) has a similar classification.

Fly ash contains some unburned carbon; this unburned carbon has adsorption capacity and can have surface adsorptive properties similar to activated carbon (15) and adsorb various chemical compounds. However, the adsorption capacity of fly ash carbon is much less than the adsorption capacity of activated carbon. The carbon activation process produces activated carbons with a high specific surface area $\left(800-1200 \mathrm{~m}^{2} / \mathrm{g}\right)$ and a high volume of micropores, which 
the main source of the active adsorption sites. On the other hand, the specific surface area of fly ash carbon is about $25-58 \mathrm{~m}^{2} / \mathrm{g}$, and the very limited pore volume it possesses is in the macropore (16) or mesopores range (6).

\section{1-2 Fly ash in Concrete}

Fly ash is used in concrete as a pozzolanic and supplementary cementitious material. Pozzolans are siliceous or siliceous and aluminous materials that by themselves do not possess significant cementitious properties but react with calcium hydroxide and water to form cementitious products (17). In addition, using fly ash in concrete improves workability, lowers heat evolution during hydration, increases hardened concrete strength, lowers permeability, increases resistance to aggressive admixtures, lowers creep and shrinkage and improves pore size distribution (4) (18) (6). For a typical structural concrete, the amount of fly ash used can supplement cement and replace from $15 \%$ to $35 \%$ of the mass of cement. Replacement is documented to be up to $70 \%$ for some construction needs such as roller compacted pavement and parking lots, dams, and walls (4) (18). Class F fly ash can be used to up to $80 \%$ of the total dry weight of autoclaved aerated concrete (19). Since both a high cost and high carbon footprint of concrete results from cement, enormous environmental and economical benefits can be gained by replacing cement with fly ash. However, the problem with using some types of fly ash is that the unburned carbon can affect the concrete causing discoloration, mixture segregation, and poor air entraining behavior which is the focus of this research.

\section{1-3 Air Entraining Admixtures (AEAs)}

Air entraining admixtures are organic or synthetic compounds, usually in liquid form, used to entrain a controlled amount of microscopic air bubbles 
distributed uniformly in the mixture. AEAs typically contain ionic and nonionic surfactants made of natural sources such as wood resins and tall oil or synthetic chemicals. AEAs are used to entrain $4-6 \%$ air void content to obtain freeze-thaw resistance; AEAs also improve mixture stability and control concrete density (20) (21).

The basic chemical nature of AEA is shown schematically in Figure 1.3. Typically any AEA contains two groups, the first which is represented as the head, is the ionic part that has strong attraction to the solvent (water) and is called hydrophilic. The second part which is referred to as the tail is non-ionic and has little or no attraction to the water and is called hydrophobic (22).

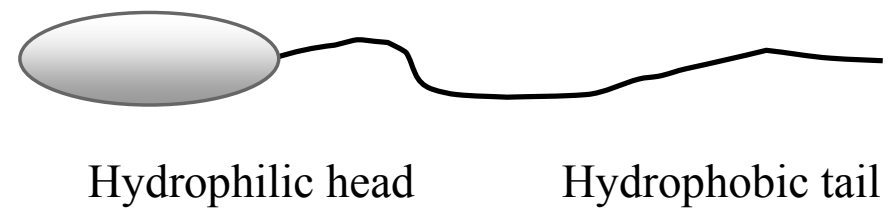

Figure 1.3 Air entraining admixture chemical nature

When AEAs are added to a concrete mixture, the hydrophilic ionic polar groups sorb strongly to the ionic cement particles leaving the hydrophobic nonpolar end of the surfactants toward the solution as shown in Figure 1.4. Air bubbles are formed during agitation and mixing of the concrete mixture, the hydrophobic non-polar ends of the surfactant molecules stabilize these air bubbles and prevent them from coalescing into large bubbles (4) (20) (23). The entrained air bubbles present in the mixture have diameters less than $0.25 \mathrm{~mm}$ and can be as small as $10 \mu \mathrm{m}$ (20). Bruere (24) studied air entrainment in cement and silica pastes and concluded that for sufficient air entrainment two 
conditions must be satisfied. First, the AEA should be adsorbed on the solid particles with non-polar ends pointing toward the water to give hydrophobic character to the cement particle and make it adhere to the air bubbles. Second, the concrete mixture must maintain enough liquid phase concentration of the AEA to entrain air during mixing. Another important observation of stable surface foam formation is that even though the AEA visually precipitates from the cement solution, it retains its ability to form stable foam. However, after filtration the filtrate lost this ability, which means that the precipitated portion of the AEA actively contributes to the foam formation (24) (20).

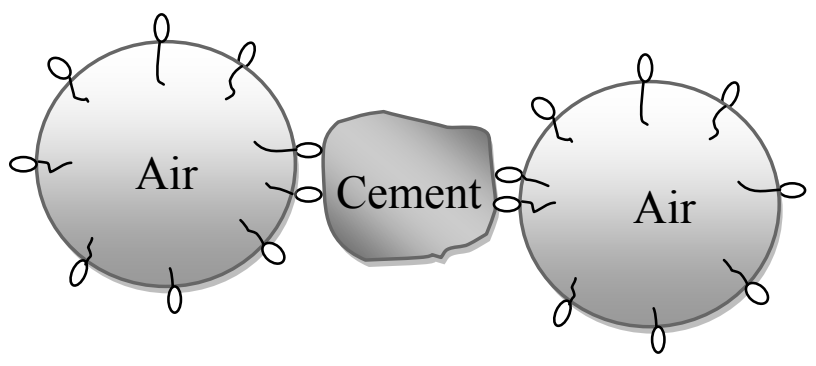

Figure 1.4 Mechanism of air entraining

\section{1-4 Interaction between fly ash and AEAs}

The impact of fly ash on the quantity of AEA required to entrain the desired amount of air bubbles is a major problem facing the utilization of fly ash in concrete (4) (5) (6) (7) (8) (9). Without prior knowledge of the adsorption capacity of a given fly ash, the AEA dosage required for a given air void specification is unknown. The consensus is that the carbon content of fly ash is the cause of this phenomenon. The unburned carbon adsorbs some of the AEAs from the solution and reduces the already low liquid phase concentration of AEA in the mixture. As a result the mixture fails to have the desired air content (5) (6) (25) (15) (26) (27). Increasing the AEA dosage may counteract the loss 
of AEA because of adsorption by fly ash. However, the variation in fly ash properties may cause an unacceptable variation in the air void content of the concrete mixture (15). The type of AEA has a significant effect on the AEA loss due to adsorption (8). Some AEAs have less adsorption potential than other AEAs because of their chemical composition and therefore function better with fly ash.

Non-polar surfaces of the carbon in fly ash provide active adsorption sites and these sites adsorb AEAs reducing the amount of the available liquid phase concentration of AEAs required for bubble formation. The AEAs adsorbed onto the carbon's non-polar active sites do not participate in air entrainment for two reasons. First, the hydrophobic part of the AEA will be adsorbed into the solid phase and will not be in contact with the air/water interface. Second, AEAs may travel and be adsorbed inside the carbon particle pores as shown in Figure 1.5, thus being sheltered from the air/water interface. 


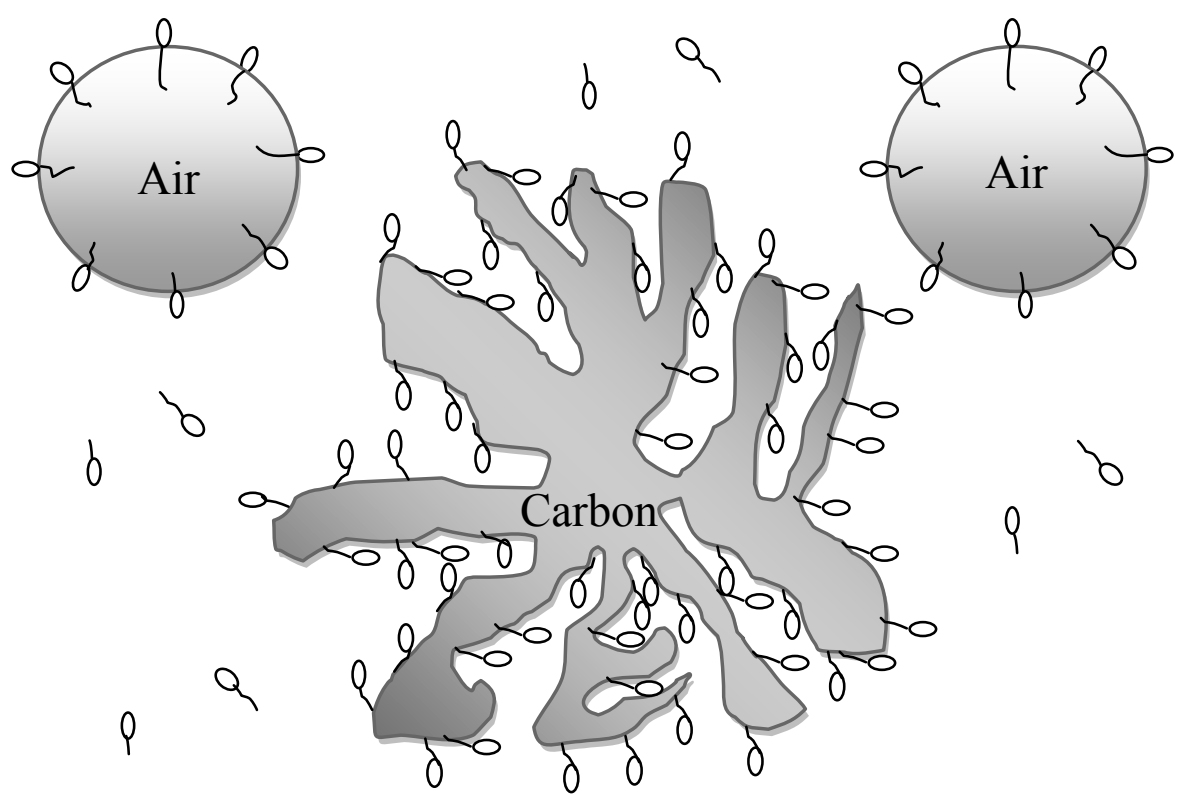

Figure 1.5 AEA adsorption on fly ash carbon

\section{Factors affecting AEA adsorption on fly ash carbon}

AEA type, quantity, surface chemistry, and specific surface area of the carbon on the fly ash can affect the fly ash adsorption capacity. The carbon content is usually low in class $\mathrm{C}$ fly ash but can be high in class F fly ash. The injection of Powdered Activated Carbon (PAC) in the off gas stream for mercury removal could produce ashes with very high adsorption capacity. According to ASTM C618 (13), the loss on ignition (LOI), which is a measure for the carbon content, must not be greater than $6 \%$ otherwise the fly ash cannot be used in concrete. Although ASTM C618 specifies 6\% as a maximum, problems with air entrainment have been reported for fly ashes with carbon content less than 3\% wt. (26).

There are three distinct carbon types in fly ash, inertinite, isotropic cock, and anisotropic cock (6). Inertinite is the oxidized form of carbon; the other two are non-oxidized forms. Other research groups classified carbon in fly ash into 
submicron carbon (soot) and porous carbon black or char (25) (10). Although both types are usually present in any given fly ash, the fraction of soot increases with increasing fineness of the fly ash (28). The non-oxidized form of carbon has a non-polar surface similar to the activated carbon surface and can physically adsorb hydrophobic compounds. Changing the fly ash surface chemistry by oxidation (beneficiation) has been proposed by many researchers because oxidation increases the oxygen content of the carbon surface and reduces the adsorption capacity (29) (30) (31) (32). Thermal post treatment and ozone oxidation have been studied and patent claims have been filed for fly ash treatment by ozone oxidation (33) (34).

$\mathrm{Ca}^{++}$and $\mathrm{Mg}^{++}$ions can form insoluble products with AEAs (23). Most of the AEA lost from the liquid phase is due to adsorption, but some of the AEA may also form insoluble products through bonding with $\mathrm{Ca}^{++}$and $\mathrm{Mg}^{++}$ions. Insoluble products may participate in air entrainment either directly or after redissolving in water. Baltrus et al. (35) reported a significant decrease in AEA adsorption after washing fly ash with deionized water. When AEA was added to the washing solution that contained the washed ions from fly ash, AEA precipitate immediately formed. Precipitation was also noticed when high calcium content fly ash was mixed with a diluted solution of an AEA, the AEA was instantaneously sorbed onto the fly ash, the precipitate formed, and then slowly went back into solution. In cement paste, the AEA sorbed on the cement particles surfaces and little if any AEA precipitate formed (23) (35). Gebler and Klieger (9) reported that $\mathrm{SO}_{3}$ and total alkalis such as $\mathrm{Na}_{2} \mathrm{O}$ reduce air loss and decreased the AEA concentration requirements. Kulaots (36) reported that less AEA is required for portland cement mortars with higher alkalis. It also has been reported the fly ash particles size affect the required AEA dosage (7) (37), but others showed that it has a minor influence (5) (38). 


\section{1-5 Measurement of the adsorption capacity of fly ash}

There is currently no method for the direct measurement of the fly ash adsorption capacity, instead the carbon content measured by LOI and the foam index tests are used as a surrogate to the adsorption capacity measurement.

\section{The fly ash carbon content}

The carbon content of fly ash is often determined by the LOI test according to ASTM C311 (39). For the LOI procedure, a known weight of fly ash is burned in a muffle furnace for 15 minutes at $750 \pm 50^{\circ} \mathrm{C}$. Several modifications

of the test include increasing the time to 2 hours (40), 3 hours (41), and preheating at $140 \mathrm{C}$ and burning for several hours (42). Many factors can contribute to the weight loss of fly ash after burning. These include decomposition of carbonate $\left(\mathrm{CaCO}_{3}\right)$ and portlandite $\mathrm{Ca}(\mathrm{OH})_{2}$, the loss of water bound in clay minerals, and the burning of carbon. Depending on the composition of fly ash, the error between carbon content and LOI can be as low as $1 \%(37)$ and can be as high as $75 \%(42)$.

\section{The foam index test}

The foam index test is a dynamic test used to determine the relative amount of AEA required in concrete containing fly ash. The foam index test is a simple titration procedure in which a solution of fly ash and water or fly ash, water, and cement is titrated incrementally in a specified dose with diluted AEA. After each addition the container is closed, agitated for certain time, opened, and the foam formation at the surface of the solution is observed. During the first few increments, the AEA will rapidly sorb onto the various particles in the solution. This is due to the high driving force resulting from the high concentration gradient between the solid and liquid phase concentration of the AEA. Consequently, foam will not be observed. As the titration progresses, the 
sorption process slows down due to lower concentration gradient caused by the accumulation of AEA on the solid phase. The aqueous phase concentration of AEA increases as the AEA addition continues and at some point the AEA will be able to produce foam at the solution surface of the solution. The titration end point occurs when stable foam covering the whole surface of the solution is formed and remains stable for a given time. The amount of AEA used for titration in milliliters is reported as the foam index number. The foam index number can be reported as milliliters of AEA added per gram of fly ash or even milliliters AEA per gram of carbon and this is called specific foam index number. A blank of water and cement is often used to provide a baseline of comparison. Many different procedures were reported by various research groups. Variations in the procedures include the type and concentration of AEA, the container volume and dimensions, the amount of fly ash and water, the presence and amount of cement, the initial time of wetting, time period of shaking, frequency of shaking, and time the foam must remain stable.

Reported procedures include Baltrus and LaCount (35), Dodson (43), Freeman (26), FHWA (44), Gebler and Klieger (9), Grace (45), Gurupira (46), Harris (47), Külaots 98 (48), Külaots 03 (49), Külaots 04 (11), Meininger (50), Stencel (51), and Zacarias (52).

It is very important to emphasize that foam index test, because of its short time and the very low AEA concentration, is a dynamic test and it is not based on equilibrium state. Because of this, every single procedure detail (such as time of agitation, frequency of agitation, power of agitation, concentration of the AEA used, etc.) may result in significant effects on the results. The foam index test provides an estimation of the instantaneous adsorption capacity of fly ash. A high carbon fly ash adsorbs more AEA than low carbon fly ash, and 
therefore it has more adsorption capacity and more AEA is required to produce the stable foam. The foam index test may be used to determine if the fly ash is acceptable or not, however, there are presently no standards for judging the usefulness of fly ash based on foam index and furthermore, foam index will only reflect the quantity of AEA needed to form foam on the surface of the test solution, not the net amount of AEA adsorbed by the fly ash.

\section{Foam index test and LOI}

The correlation between LOI and foam index test have been studied by many researchers. Yu et al. (27) reported a very good correlation between LOI and Foam index test, while poor correlation was reported by Gao et al. (25) and Freeman et al. (26) as shown in Figure 1.6. Pedersen et al. (4) suggested that fly ash coming from the same plant exhibits good correlation between AEA adsorption and LOI but not for ashes produced from different plants. Gebler and Klieger (9) reported a better relation between organic matter in fly ash and foam index test. The organic matter was determined by using a soil test method that utilizes sodium dichromate and sulfuric acid. 


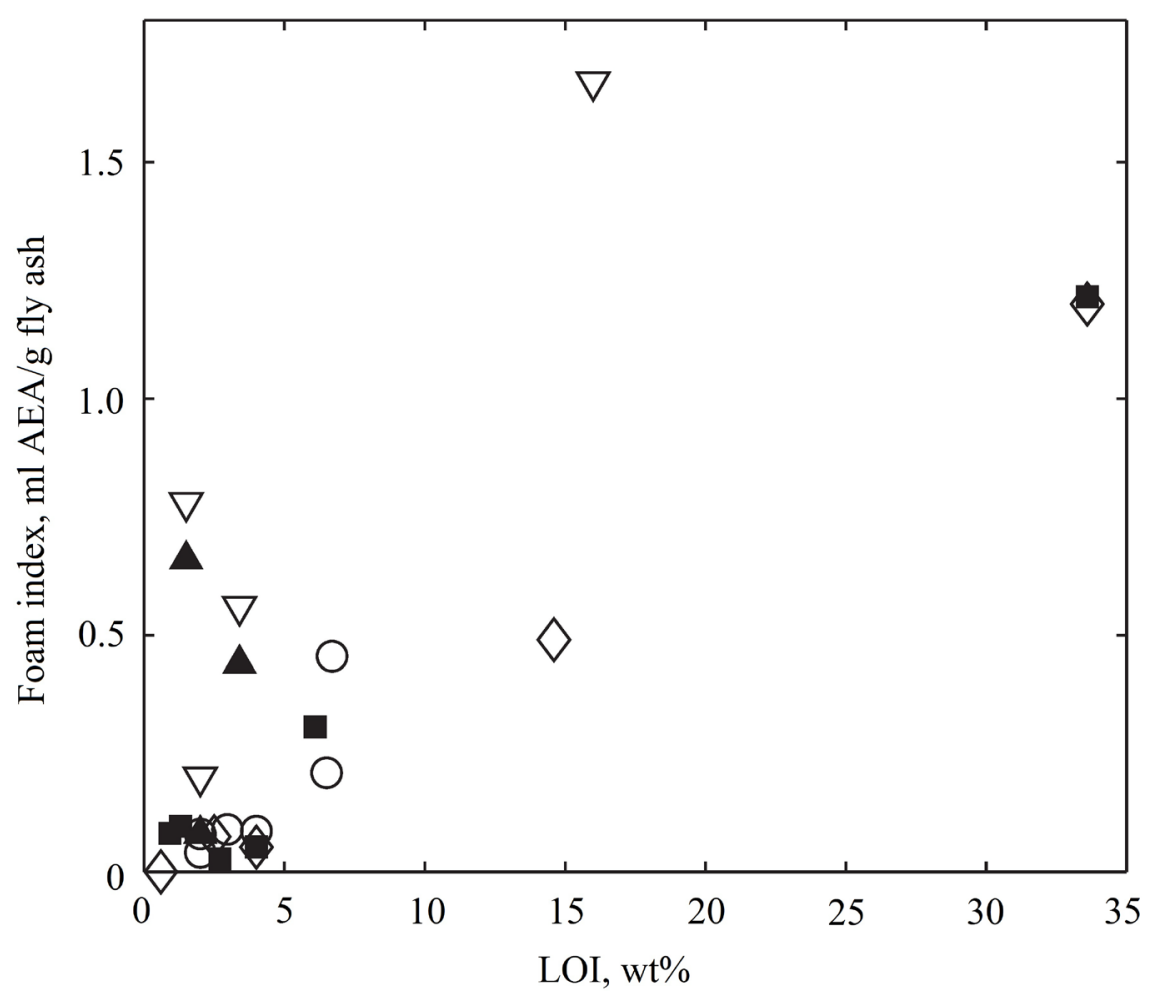

Figure 1.6* Foam index test versus LOI for five different studies, Courtesy of Perdersen et al. (4). ( $\nabla)$ Freeman et al. (26);( $)$ Yu et al. (27); (৫) Gao et al. (25); (ロ) Külaots et al. (11); and (o) Gao et al. (30) *Permission seen in Figure B-1

The relationship between the specific foam index and LOI is shown in Figure 1.7. The values of foam index are normalized per gram of carbon to eliminate the effect of the varying carbon content among different fly ash. High variation in adsorption is exhibited at low LOI values. The reason for this is twofold. The first is that at low LOI only a few drops of AEA are enough to produce the stable foam, which leads to the possibility of overshooting the exact amount required to produce the foam. The second factor may be attributed to the type of carbon that exists in the fly ash. Although class $\mathrm{C}$ fly ash has generally less carbon than class F, it may have more char than soot and shows more adsorption capacity per gram of carbon. 


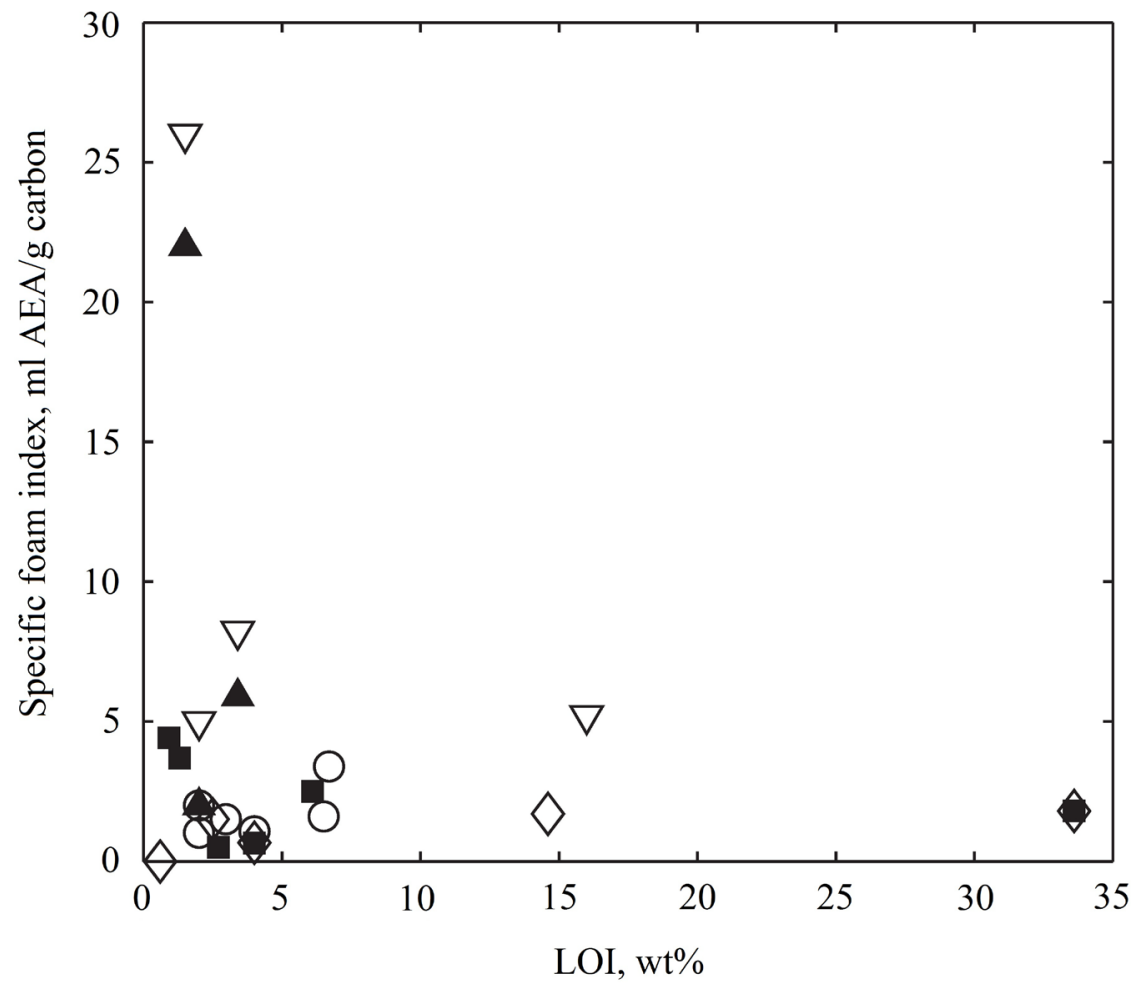

Figure 1.7* Specific foam index test versus LOI for the studies presented in

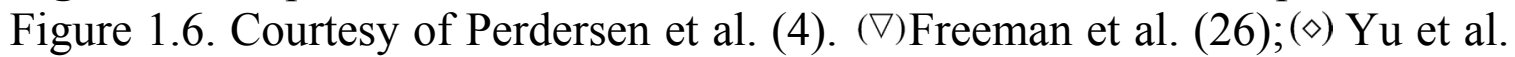
(27);(৫) Gao et al. (25);(ロ) Külaots et al. (11); and (o) Gao et al. (30) *Permission seen in Figure B-1

The interaction between fly ash in concrete and AEAs was studied, and procedures to standardize and characterize fly ashes in term of their potency to adsorb AEAs were developed using three different approaches:

1- Fly ash iodine number test for the determination of the fly ash adsorption capacity measured by iodine adsorption

2- Direct separate adsorption isotherms on fly ash and cement with AEAs

3- Combined adsorption isotherms for the quantification of AEAadsorption by fly ash 
Finally the iodine number results were combined with the direct adsorption isotherm results to develop correlation graphs, for each AEA studied. These graphs can be used to determine the amount of that AEA adsorbed by fly ash based on the fly ash iodine number. 


\section{2 - Fly Ash Iodine Number for the Measurement of the Adsorption Capacity of Coal Fly Ash}

\section{2-1 Introduction}

The iodine number test as presented in this chapter is a modified form of an existing ASTM test method (53) that was designed to quantify the highcapacity of activated carbons. In the ASTM test, the iodine number is defined as the mass of iodine adsorbed by one gram of activated carbon at an equilibrium solution concentration of $0.02 \mathrm{~N}$. The iodine number is a good indication of the microporosity of carbon (54) because the iodine molecule is very small. The existing ASTM test method utilizes a high initial concentration of iodine (i.e. $0.1 \mathrm{~N}$ ) along with a very short equilibration time (i.e. 30 seconds) to measure the adsorption capacity. To be used with fly ash, the existing ASTM test method required modification given the adsorbent (i.e. fly ash) has a relatively low adsorption capacity and also contains free lime and sulfur. The low adsorption capacity of fly ash does not cause a significant measurable reduction in the high iodine concentration used in the ASTM test method and therefore, a lower initial solution concentration is needed. The sulfur must be removed to prevent interference while the free lime is removed to prevent the isotherm solution basification. When lime basifies the solution, iodine converts into iodide, which yields false results since any reduction in iodine concentration is interpreted as adsorption. Removing sulfur and lime from fly ash will neither affect the properties nor the adsorption capacity of fly ash carbon (53).

In this chapter a modified iodine number test is proposed and in its modified form, is referred to as the fly ash iodine number test. This test makes it possible 
to characterize fly ashes based on their adsorptive capacity as measured by iodine adsorption. The fly ash iodine number test takes into consideration the relatively low, and therefore difficult to measure, adsorption capacity of fly ash and the various constituents that may be present in fly ash that can affect the results. In this test, a four point isotherm is utilized to measure the adsorption capacity. The test developed in this research was evaluated by comparing the results obtained with the loss on ignition (LOI) and foam index test results for the same fly ash samples. Results show that for a wide range of coal fly ashes the adsorption capacity can be effectively quantified. The fly ash iodine number test can replace current qualitative indicators of adsorption capacity, such as LOI and foam index tests, and can be directly used for the characterization and specification of fly ash. This test was developed using coal fly ash, and there is no reason to believe that it would not be suitable for ashes from other sources. However, the applicability of this test to ashes from non-coal based sources would need to be verified.

\section{2-2 Materials and methods}

\section{Materials}

All chemicals used in this research were ACS grade reagents and are the same as described in the existing ASTM test method (53). Hydrochloric acid was purchased from EMD Chemicals. Potassium iodide (99+\%), potassium iodate $(99.5 \%)$, iodine reagent $(99.8+)$, and sodium thiosulfate pentahydrate (99.5\%) reagents were purchased from Sigma Aldrich. Sodium carbonate $(99.5+\%)$ was purchased from EM Science. All filtration processes were performed using grade $1,11 \mu \mathrm{m}, 90 \mathrm{~mm}$ diameter, cellulose Whatman qualitative filter paper. MB-VR standard neutralized vinsol resin manufactured 
by Master Builders/BASF was utilized for all foam index tests used in this study.

\section{Fly ash treatment}

For the fly ash iodine number test, all fly ash test specimens must be pretreated before performing iodine adsorption isotherms. The purpose of the fly ash pre-treatment is to remove any sulfur and free lime from the fly ash. To remove sulfur and lime, many different pre-treatment scenarios were examined, and the easiest, most successful procedure was adopted (55).

The fly ash pre-treatment process consists of boiling the fly ash sample in a solution of $5 \%$ by weight $\mathrm{HCl}$ for 5 minutes. The mass of solution used should be at least four times the mass of fly ash treated. This quantity of solution ensures the removal of all sulfur content and maintains the resultant calcium chloride in solution. The mixture of fly ash and solution is filtered and rinsed with an excess of distilled water and dried in an oven at $103{ }^{\circ} \mathrm{C}$ to a constant weight.

\section{Fly ash adsorption capacity indicators}

For comparison, the LOI test was used in this research as a relative measurement of the carbon content. As previously stated, LOI is commonly used as a measure of carbon content and as a surrogate indicator of the adsorption capacity of fly ash. For this research, the LOI test was performed according to ASTM C311-11b (39) except the burning time was extended to 5 hours instead of 15 minutes. Foam index tests were performed according to a standard method developed as part of the larger research project (55), which in turn was adopted form the procedure published by Harris (47). 


\section{Adsorption isotherms}

Adsorption isotherms are used to quantify the affinity of an adsorbate (e.g. iodine or AEA) for an adsorbent (e.g. fly ash). It describes the equilibrium relationship between an adsorbate and an adsorbent at a constant temperature (56). The equilibrium adsorbent phase concentration of adsorbate can be determined from the mass balance on the two phases. The Freundlich isotherm equation is used to describe the behavior of heterogeneous adsorbents (57). The Freundlich adsorption capacity parameter (K), and Freundlich adsorption intensity parameter $(1 / \mathrm{n})$ can be determined from the isotherm data and then used to describe the equilibrium relation using Equation 2.1:

$$
\mathrm{q}_{\mathrm{A}}=\mathrm{K}_{\mathrm{A}} \times \mathrm{C}_{\mathrm{A}}^{1 / \mathrm{n}}
$$

Where,

$\mathrm{q}_{\mathrm{A}}=$ equilibrium adsorbent phase concentration of adsorbate $\mathrm{A}, \mathrm{mg} / \mathrm{g}$

$\mathrm{C}_{\mathrm{A}}=$ equilibrium concentration of adsorbate $\mathrm{A}$ in solution, $\mathrm{mg} / \mathrm{L}$

$\mathrm{K}_{\mathrm{A}}=$ Freundlich adsorption capacity parameter, $(\mathrm{mg} / \mathrm{g})(\mathrm{L} / \mathrm{mg})^{1 / \mathrm{n}}$

$1 / n=$ Freundlich adsorption intensity parameter, unitless

\section{Mass of fly ash}

Given the relatively low adsorption capacity of fly ash a large fly ash sample size, relative to the sample size required for the existing ASTM test method, is required to adsorb enough iodine to cause a significant drop in the iodine solution concentration. It was determined that using 10, 20, 40, and 80 grams of fly ash would be sufficient for most cases. The exceptions occur in the case of a very high carbon fly ash, where 40 and sometimes even 20 grams of high carbon fly ash can adsorb all iodine from the aqueous phase. In this case sample increments from 2.5-10 grams, or possibly less, must be used for determining the isotherm. 


\section{Adsorption isotherms setup}

All iodine adsorption isotherms were conducted in $250 \mathrm{ml}$ Erlenmeyer flasks. Ten grams of pre-treated fly ash sample is placed in the flask and $100 \mathrm{ml}$ of iodine solution is added. The flask is closed with a rubber stopper to minimize iodine volatilization. The flask is then placed on a stirring plate and the mixture is stirred for 5 minutes. After mixing, the solution is filtered and the volume of filtrate is measured using a graduated cylinder. The iodine concentration is immediately measured by titration with sodium thiosulfate. The same steps were repeated with 20,40 , and 80 grams of pre-treated fly ash samples. If any of these masses of fly ash caused the solution to be colorless, the test would be stopped and repeated with lower masses of fly ash such as 5 and 2.5 grams. It's preferred to have four points in the isotherm, although in the case of high carbon fly ash, two points are enough since the significant reduction in iodine concentration can be measured accurately.

\section{Iodine concentration measurement}

The aqueous phase iodine concentration was measured using the iodometric method as presented in Standard Methods (58) (4500-CI) and in the existing ASTM test method (53). The measurement is performed by titration with sodium thiosulfate using starch solution as an indicator of the titration end point.

The solid phase iodine concentration was determined by applying a mass balance on the system:

Total mass of iodine $=$ mass in aqueous phase + mass in solid phase

... Equation 2.2

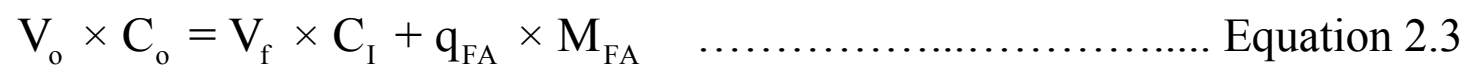




$$
\mathrm{q}_{\mathrm{FA}}=\frac{\mathrm{V}_{\mathrm{o}} \times \mathrm{C}_{\mathrm{o}}-\mathrm{V}_{\mathrm{f}} \times \mathrm{C}_{\mathrm{I}}}{\mathrm{M}_{\mathrm{FA}}}
$$

Where,

$\mathrm{q}_{\mathrm{FA}}=$ Solid phase iodine concentration, $\mathrm{mg}_{\text {iodine }} / \mathrm{g}_{\mathrm{FA}}$

$\mathrm{V}_{\mathrm{o}}=$ initial iodine solution volume, $\mathrm{L}$

$\mathrm{C}_{\mathrm{o}}=$ initial iodine solution concentration, $\mathrm{mg} / \mathrm{L}$

$\mathrm{V}_{\mathrm{f}}=$ final iodine solution volume, $\mathrm{L}$

$\mathrm{C}_{\mathrm{I}}=$ equilibrium iodine solution concentration, $\mathrm{mg} / \mathrm{L}$

$\mathrm{M}_{\mathrm{FA}}=$ Mass of the fly ash, $\mathrm{g}$

The difference between the initial and the final mass of iodine in the solution is the amount of iodine adsorbed by the solid-phase. The iodine solid-phase concentration is determined by dividing the amount of iodine adsorbed by the mass of fly ash used. If the loss of mass due to the fly ash treatment was significant, the fly ash capacity or the final fly ash iodine number must be corrected using the mass ratio of the not treated to the treated fly ash.

\section{2-3 Results and discussion}

\section{Impact of the fly ash treatment}

The impact of the fly ash pre-treatment on the iodine adsorption behavior was evaluated. The high carbon fly ash (FA31) was used in the development of the test because it has a high adsorption capacity and therefore, it was expected to best illustrate any differences in behavior resulting from the various pretreatment methods. A treatment cycle includes 5 minutes of boiling with stirring, followed by filtrating and rinsing with distilled water while the treated fly ash is still on the filter. Figure 2.1 displays the equilibrium liquid-phase iodine concentration as a function of the mass of fly ash used in the iodine number test for three different pre-treatment procedures, performed on the 
same fly ash. The first procedure utilizes one cycle of treatment with $5 \%$ wt $\mathrm{HCl}$. The second procedure utilizes four cycles of treatment with $5 \% \mathrm{wt} \mathrm{HCl}$. And the third procedure utilizes four cycles with $5 \% \mathrm{wt} \mathrm{HCl}$ followed by one cycle with distilled water. It is clear that neither treatment with multiple cycles of $\mathrm{HCl}$ nor treatment with distilled water after $\mathrm{HCl}$ treatment affected the adsorption behavior of fly ash. Therefore, pre-treatment with one cycle of $5 \% \mathrm{wt} \mathrm{HCl}$ treatment was considered sufficient and it was adopted for this test.

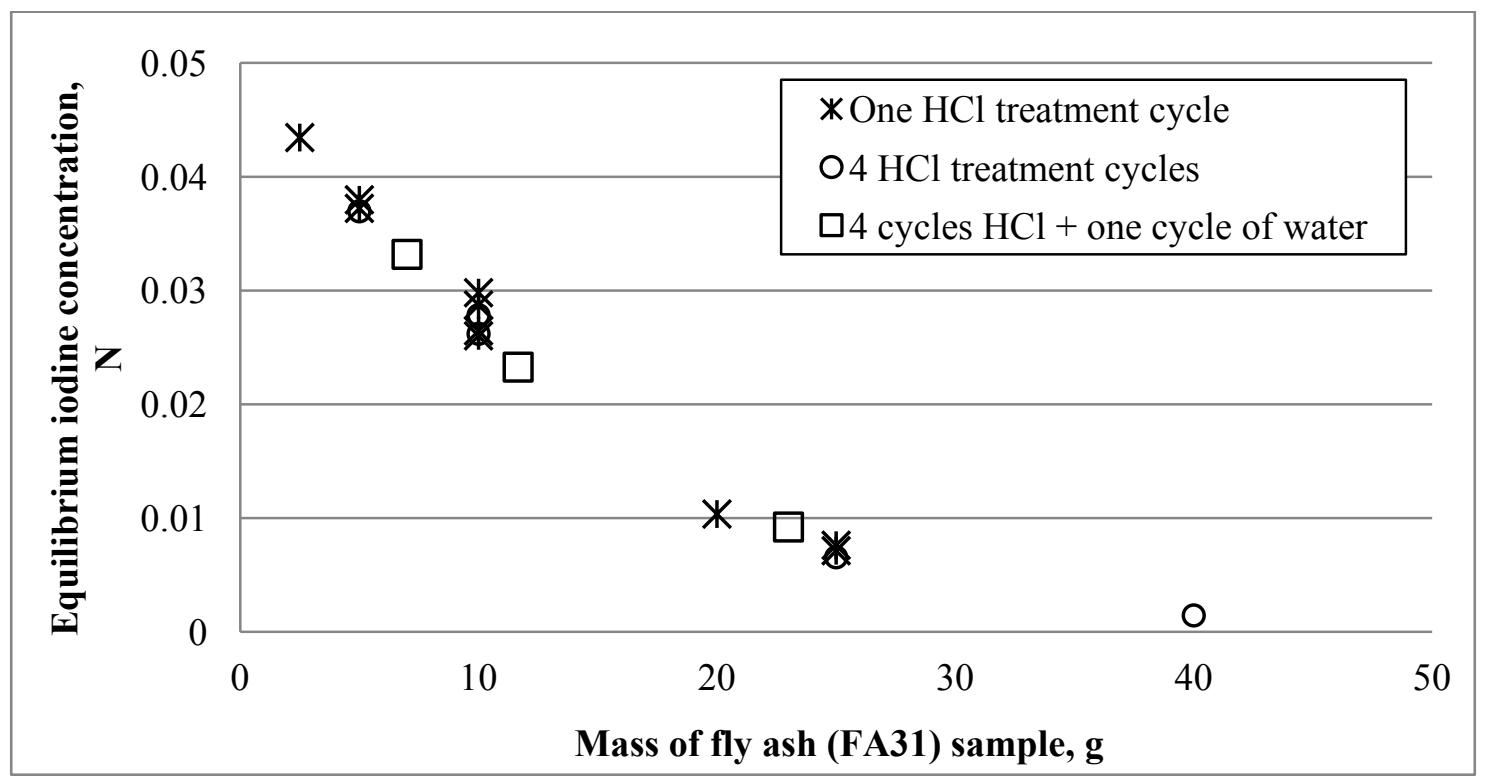

Figure 2.1 The effect of multiple treatment cycles on the adsorption behavior of fly ash

\section{Adsorption capacity indicators}

A suite of 10 coal fly ash specimens from various sources were selected to represent LOI's ranging from $0.39 \%$ to $23.3 \%$. These 10 ashes were used to develop the fly ash iodine number test procedure. The final test procedure was also performed on four additional fly ash specimens (FA1, FA8, FA15, and FA40). Table 2.1 illustrates the Fly ash ID, LOI, and some other properties of the 14 selected types of coal fly ash. 
Table 2.1

Selected fly ash specimens and their properties, wt $\%$

\begin{tabular}{|c|c|c|c|c|c|c|c|c|c|c|c|c|c|c|}
\hline $\begin{array}{c}\text { Fly } \\
\text { ash ID }\end{array}$ & $\begin{array}{c}\text { FA } \\
1 \\
\end{array}$ & $\begin{array}{c}\text { FA } \\
7 \\
\end{array}$ & $\begin{array}{c}\text { FA } \\
8 \\
\end{array}$ & $\begin{array}{c}\text { FA } \\
10 \\
\end{array}$ & $\begin{array}{c}\text { FA } \\
15 \\
\end{array}$ & $\begin{array}{c}\text { FA } \\
20 \\
\end{array}$ & $\begin{array}{c}\text { FA } \\
\mathbf{3 1} \\
\end{array}$ & $\begin{array}{c}\text { FA } \\
\text { 32 } \\
\end{array}$ & $\begin{array}{c}\text { FA } \\
36 \\
\end{array}$ & $\begin{array}{c}\text { FA } \\
\text { 39 } \\
\end{array}$ & $\begin{array}{c}\text { FA } \\
40 \\
\end{array}$ & $\begin{array}{l}\text { FA } \\
\mathbf{1 0 0} \\
\end{array}$ & $\begin{array}{l}\text { FA } \\
101 \\
\end{array}$ & $\begin{array}{l}\text { FA } \\
\mathbf{1 0 2} \\
\end{array}$ \\
\hline $\mathrm{SiO}_{2}$ & 60.1 & 53.9 & 60.9 & 46 & 58.9 & 44.8 & 40.4 & 58.7 & NA & 39.6 & 53.9 & 54.1 & 49.5 & 45 \\
\hline $\mathbf{A l}_{2} \mathbf{O}_{3}$ & 29.9 & 27.7 & 25.7 & 23.6 & 6.2 & 23.1 & 18.5 & 29.3 & NA & 20 & 26.3 & 26.6 & 23.9 & 21.2 \\
\hline $\mathrm{Fe}_{2} \mathrm{O}_{3}$ & 2.7 & 8.29 & 4.66 & 22.3 & 4.71 & 9.51 & 4.2 & 5.3 & NA & 12.7 & 6.24 & 5.06 & 4.77 & 4.49 \\
\hline $\begin{array}{c}\text { Total: } \\
\mathrm{SiO}_{2}, \\
\mathrm{Al}_{2} \mathbf{O}_{3}, \\
\mathrm{Fe}_{2} \mathrm{O}_{3}\end{array}$ & 92.7 & 89.6 & 89.3 & 91.9 & 79.8 & 77.4 & 63.1 & 93.3 & NA & 72.3 & 86.4 & 85.7 & 78.2 & 70.6 \\
\hline $\mathrm{CaO}$ & 0.9 & 1.45 & 3.46 & 1.28 & 10.3 & 13.6 & 3 & 0.99 & NA & 9.1 & 4.0 & 1.49 & 2.00 & 2.50 \\
\hline $\mathrm{SO}_{3}$ & NA & 0.08 & 0.29 & 0.77 & 0.86 & 0.96 & 0.6 & 0.03 & NA & 1.1 & 0.2 & 0.17 & 0.32 & 0.46 \\
\hline MgO & NA & 1.15 & 1.12 & 0.99 & 3.13 & 2.97 & NA & 0.87 & NA & 2.28 & 0.86 & 0.65 & 0.44 & 0.22 \\
\hline Alkali & 0.61 & 0.64 & 0.69 & 0.77 & 0.73 & 0.89 & NA & $\mathrm{NA}$ & NA & NA & $\mathrm{NA}$ & NA & $\mathrm{NA}$ & $\mathrm{NA}$ \\
\hline LOI & 0.87 & 2.25 & 0.17 & 1.26 & 1.5 & 0.39 & 23.3 & 6.06 & 21.3 & 10.5 & 3.35 & 10.4 & 14.7 & 19 \\
\hline
\end{tabular}

Although LOI is not a completely reliable measurement for either the carbon content or the adsorption capacity, it is the test currently used in specifications to infer adsorption potential. Therefore, the results of the fly ash iodine number test have been correlated with the LOI results for each ash source analyzed. The results of the fly ash iodine number test were also correlated with foam index test results. Figure 2.2 displays the foam index test results as a function of LOI for the selected samples. The foam index test results are correlated well with the LOI results at higher LOI values. At lower values of LOI, typical of fly ash used in concrete, inconsistencies between the LOI and foam index results can be easily seen. In Figure 2.2, two data points are darkened (i.e. LOI $=2.25$ and foam index $=0.012 ; \mathrm{LOI}=1.5$ and foam index $=0.029)$ that illustrate this point. Other data points for LOI $<7 \%$ show similar inconsistencies. Given the relative scatter in both tests, it is difficult to attribute the error to either test 
without additional information. However, assuming the LOIs of the selected fly ash samples reasonably represent the carbon content, and the foam index test is sensitive to adsorption, Figure 2.2 illustrates how LOI alone cannot be used to predict adsorption capacity.

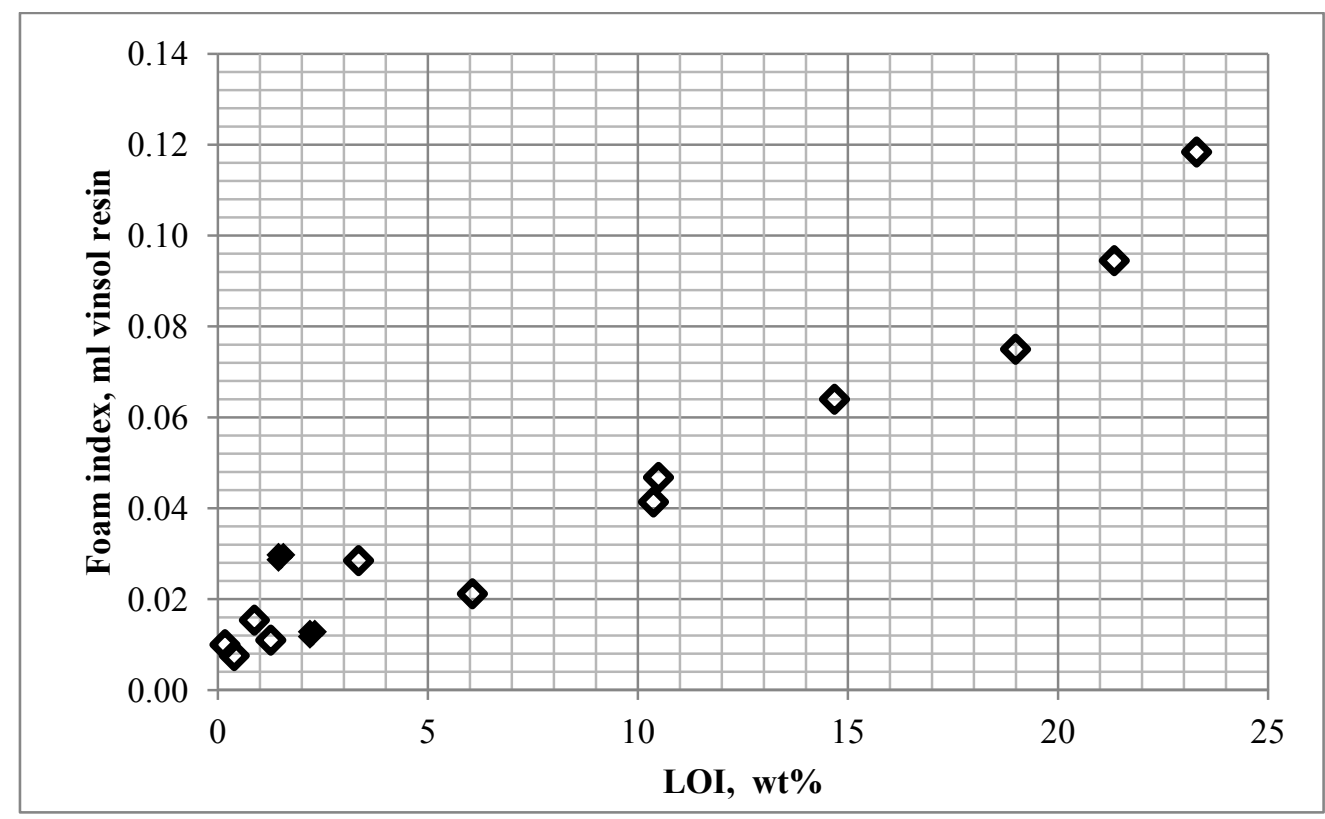

Figure 2.2 Correlation between LOI and foam index tests results for the fourteen fly ash types studied. Filled data points were chosen to illustrate inconsistencies between the LOI and foam index test results

\section{Initial concentration of iodine}

The initial concentration of the iodine solution is critical and is dependent on the required range of adsorption capacity measurements. Higher initial adsorbate concentrations are required for adsorbents with high adsorption capacities, and vice versa. Due to their low adsorption capacities, typical fly ashes can adsorb very limited amounts of iodine. Therefore, the initial iodine concentration used in the test needs to be adjusted with respect to the published ASTM test method (53) to represent the low adsorption capacities encountered 
in fly ash. The initial concentration should be such that when the iodine solution is mixed with a fly ash, that mass of fly ash can produce a measurable reduction in the concentration of the iodine solution. There is a practical range for the fly ash mass used since the test is done with only $100 \mathrm{ml}$ of iodine solution, and only a certain amount of fly ash can be added without compromising the liquid nature of the mixture.

Although more mass of iodine can be adsorbed onto fly ash at higher solution concentrations, the abundance of adsorbate compared to the available adsorption sites makes the change in aqueous phase concentration insignificant. This produces a very steep isotherm slope with a $1 / \mathrm{n}$ value greater than one, which indicates an unfavorable adsorption isotherm as defined by Freundlich isotherm theory (57) (56) and shown in Figure 2.3 for a $0.1 \mathrm{~N}$ iodine concentration with a $6.06 \%$ LOI fly ash (FA32).
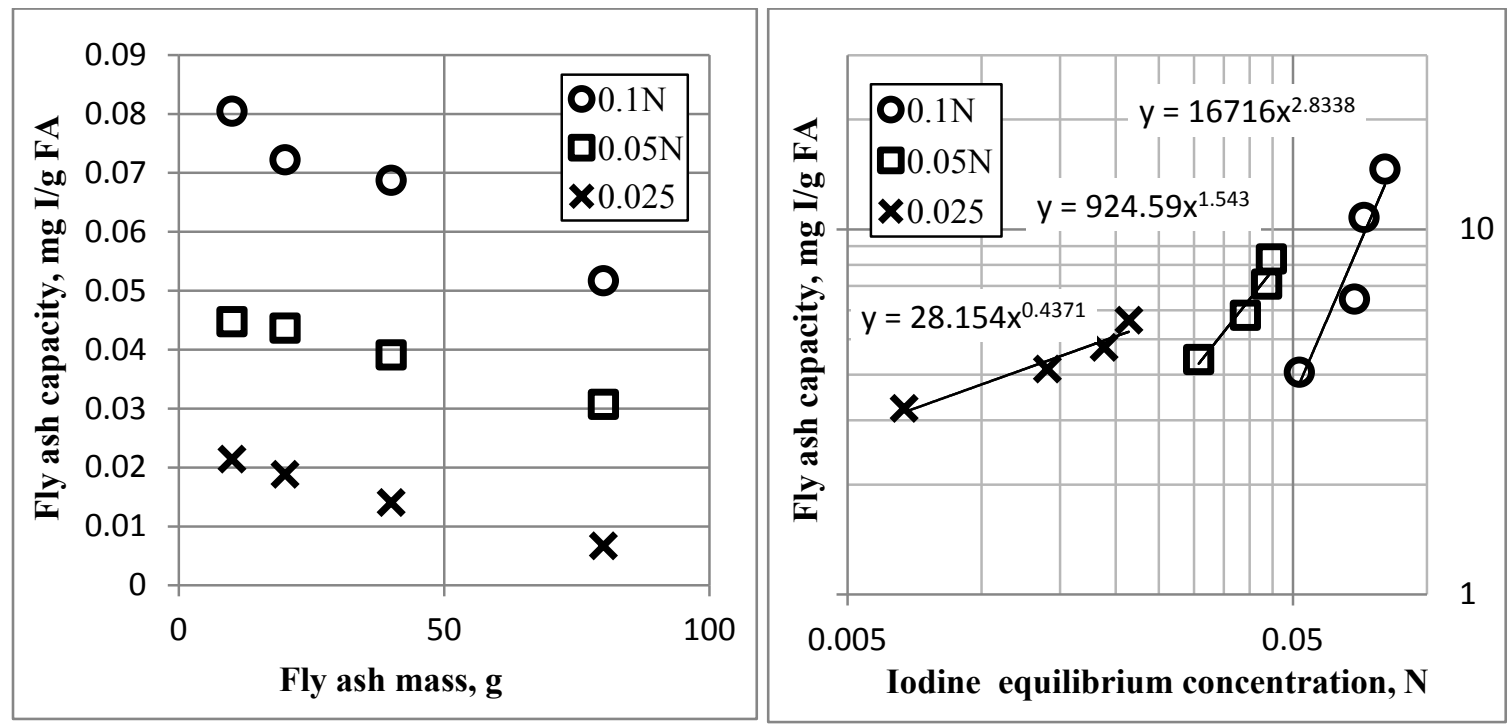

Figure 2.3 Effect of iodine solution concentration on the adsorption isotherm results for the $6.06 \%$ LOI fly ash 
Reducing the iodine solution initial concentration to $0.05 \mathrm{~N}$ produced a $1 / \mathrm{n}$ of 1.543 , which also indicates an unfavorable adsorption isotherm but better than the case of the $0.1 \mathrm{~N}$ iodine solution. Finally a favorable adsorption isotherm was obtained by reducing the iodine solution initial concentration to $0.025 \mathrm{~N}$. A $1 / \mathrm{n}$ value of 0.437 indicates a favorable adsorption process in which most of the iodine was adsorbed by the fly ash. Further reduction of the initial iodine concentration may result in better sensitivity for fly ashes with very low carbon content but it is challenged by the accuracy of the analytical method of measuring iodine concentration. These results were verified by performing the full set of experiments on 10 fly ash samples with both $0.05 \mathrm{~N}$ and $0.025 \mathrm{~N}$ iodine solution initial concentrations.

\section{Iodine adsorption isotherms}

In the case of low carbon fly ash, isotherms performed using a $0.05 \mathrm{~N}$ iodine solution showed a limited resolution, as presented in Figure 2.4a. To better represent the lower adsorption capacities of lower carbon content ashes, it is necessary to expand the range of measurements. By reducing the initial concentration of iodine solution to $0.025 \mathrm{~N}$, the resolution of the fly ash iodine number test was improved considerably and the test became more sensitive to low carbon contents as shown in Figure 2.4b.

In the case of low carbon fly ash, the liquid-phase iodine concentration does not decrease significantly when increasing the mass of fly ash. Therefore, the isotherm in Figure 2.5 has a low slope that shows favorable adsorption in that concentration range. In the case of a high carbon fly ash, the concentration decreases drastically with the increase of fly ash mass (i.e. increased carbon content) and as shown in Figure 2.4, the fly ash exhibits a typical activated carbon behavior where the isotherm starts to exhibit a log shaped trend. This is 
attributed to the dramatic change in the equilibrium liquid phase concentration. In other words, because the fly ash has a low adsorption capacity its maximum adsorption potential is reached using a low initial liquid-phase concentration. If the initial concentration for the isotherm is increased beyond the point of maximum adsorption capacity, the equilibrium liquid-phase concentration does not decrease significantly but the solid-phase concentration decreases in some proportion to the mass of fly ash added. Isotherms that characterize their equilibrium capacity up to the maximum adsorption capacity of the AEA display a favorable isotherm and plotting it in log-log scale will make it a straight line with a $1 / \mathrm{n}$ less than one.
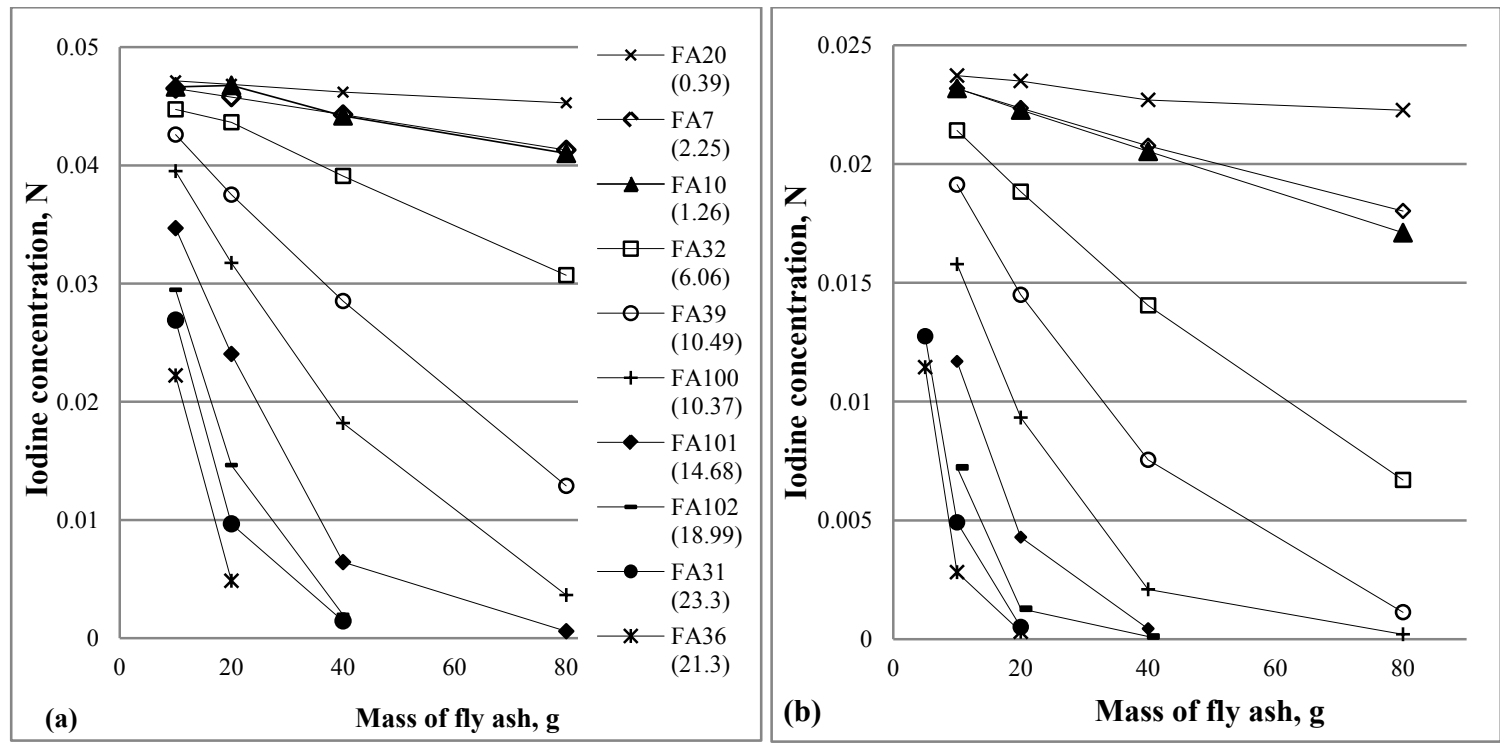

Figure 2.4 Aqueous phase iodine concentration versus fly ash mass for (a) $0.05 \mathrm{~N}$ and (b) $0.025 \mathrm{~N}$ initial iodine solution concentration. LOIs are shown in parentheses

Adsorption isotherms describe the partitioning of solutes between solid and liquid phases at equilibrium. The solid phase concentration at equilibrium is the capacity, and the capacity, as shown in the adsorption isotherms in Figure 2.5, 
is a function of the aqueous phase concentration. The isotherm results shown in Figure 2.5 exhibit the same tendency as shown in Figure 2.4, where the initial iodine concentration of $0.025 \mathrm{~N}$ provided a better measure of the adsorption capacities of low carbon content fly ash materials than did the $0.05 \mathrm{~N}$ solution. Therefore, $0.025 \mathrm{~N}$ was adopted as the initial iodine concentration for the rest of the study.
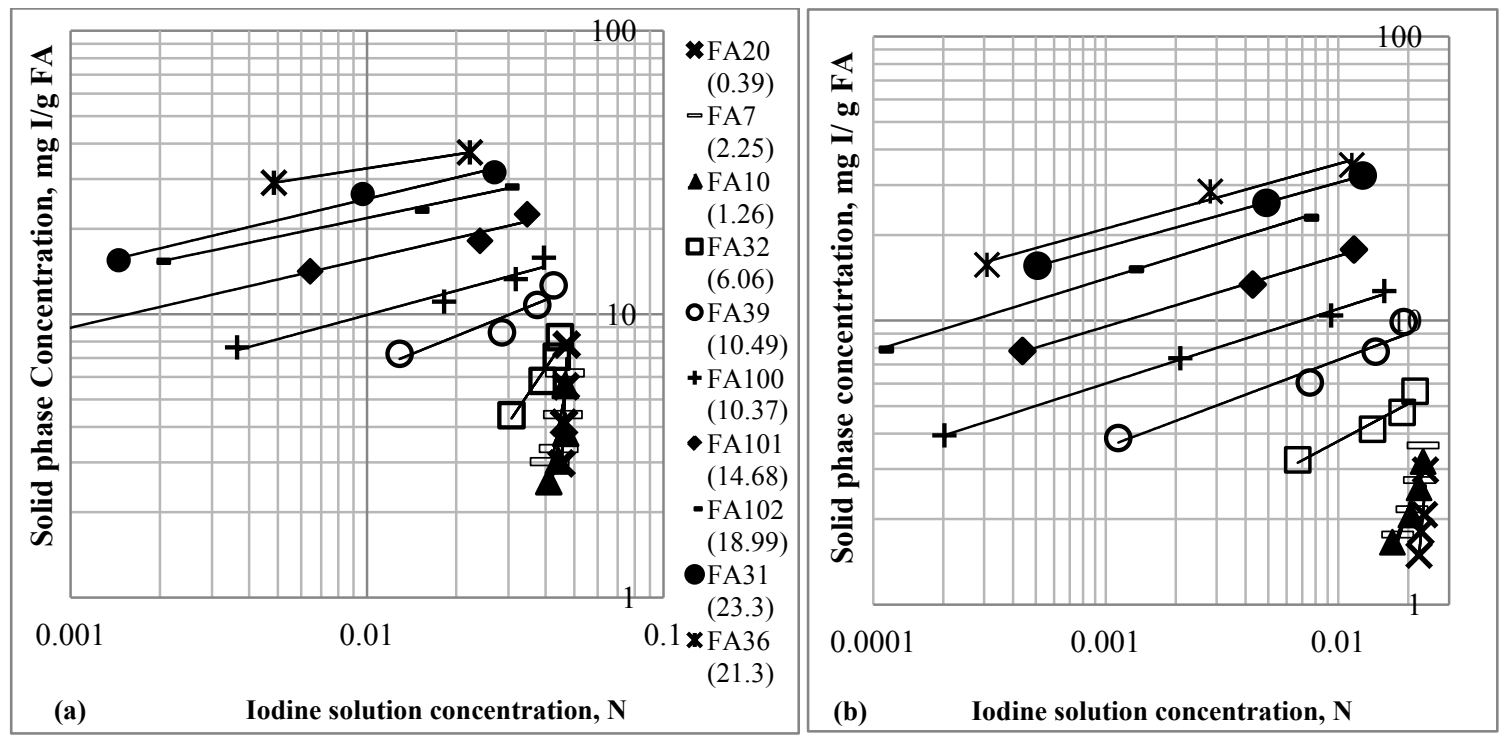

Figure 2.5 Adsorption isotherms for (a) $0.05 \mathrm{~N}$ and (b) $0.025 \mathrm{~N}$ iodine with 10 of fly ash types. LOIs are shown in parentheses

For the 14 fly ash sources tested, the Freundlich isotherm parameters, $\mathrm{K}$ and $1 / \mathrm{n}$, were determined from the $\mathrm{y}$ - axis intercepts and the slopes of the isotherms respectively. Table 2.2 summarizes the Freundlich isotherm parameters for the fourteen fly ash types determined using an initial iodine solution concentration of $0.025 \mathrm{~N}$. 
Table 2.2

Freundlich isotherm parameters for $0.025 \mathrm{~N}$ iodine isotherms with 14 types of fly ash

\begin{tabular}{|l|c|c|c|}
\hline Sample ID & LOI, wt $\%$ & $\begin{array}{c}\mathbf{K} \\
(\mathbf{m g} / \mathbf{g})(\mathbf{L} / \mathbf{m g})^{\mathbf{1} \mathbf{n}}\end{array}$ & $\mathbf{1 / n}$ \\
\hline FA8 & 0.17 & $1.00 \mathrm{E}+12$ & 7.2008 \\
\hline FA 20 & 0.39 & $1 \mathrm{E}+15$ & 9.0601 \\
\hline FA 1 & 0.87 & $6.00 \mathrm{E}+10$ & 6.3356 \\
\hline FA 10 & 1.26 & 5209.4 & 1.9902 \\
\hline FA 15 & 1.5 & 4831.3 & 1.978 \\
\hline FA 7 & 2.25 & 64030 & 2.6286 \\
\hline FA 40 & 3.35 & 62.8 & 0.6899 \\
\hline FA 32 & 6.06 & 28.154 & 0.4371 \\
\hline FA 100 & 10.37 & 36.827 & 0.2626 \\
\hline FA 39 & 10.49 & 29.944 & 0.3075 \\
\hline FA 101 & 14.68 & 52.793 & 0.2479 \\
\hline FA 102 & 18.99 & 81.338 & 0.2544 \\
\hline FA 36 & 21.34 & 101.74 & 0.228 \\
\hline FA 31 & 23.3 & 86.833 & 0.2266 \\
\hline
\end{tabular}

As shown in Table 2.2, the Freundlich adsorption intensity parameters (1/n) appear to numerically correlate with LOI values. However, neither $1 / \mathrm{n}$ nor K can separately represent the adsorption capacity results. The iodine number is the adsorption capacity (i.e. adsorbent phase iodine concentration) measured at a specific target solution concentration. The iodine number defined in the existing ASTM test method utilizes the point of $80 \%$ reduction from the initial iodine solution concentration. For this study $60 \%$ as well as $80 \%$ reduction from the initial iodine concentration were examined, which corresponds to iodine solution concentrations of $0.01 \mathrm{~N}$ and $0.005 \mathrm{~N}$, respectively. 


\section{The target iodine concentration selection}

Selection of the target concentration does not affect the isotherm correlation itself. Rather, it affects how the isotherm is applied by establishing a numerical representation of the adsorption capacity for comparison purposes. The correlation between fly ash iodine number and LOI values, as well as the foam index results, are presented in Figure 2.6. As shown, the fly ash iodine number obtained by both target concentrations exhibited a similar relationship with LOI and the foam index test results. A difference in the values of the fly ash iodine number between the two target concentrations can be seen, particularly for high capacity fly ashes. However, the adsorption capacity of the ash remains exactly the same. That is, for a given ash, when changing the target concentration the only change is the number used to represent the fly ash iodine adsorption capacity for comparison to other ashes.
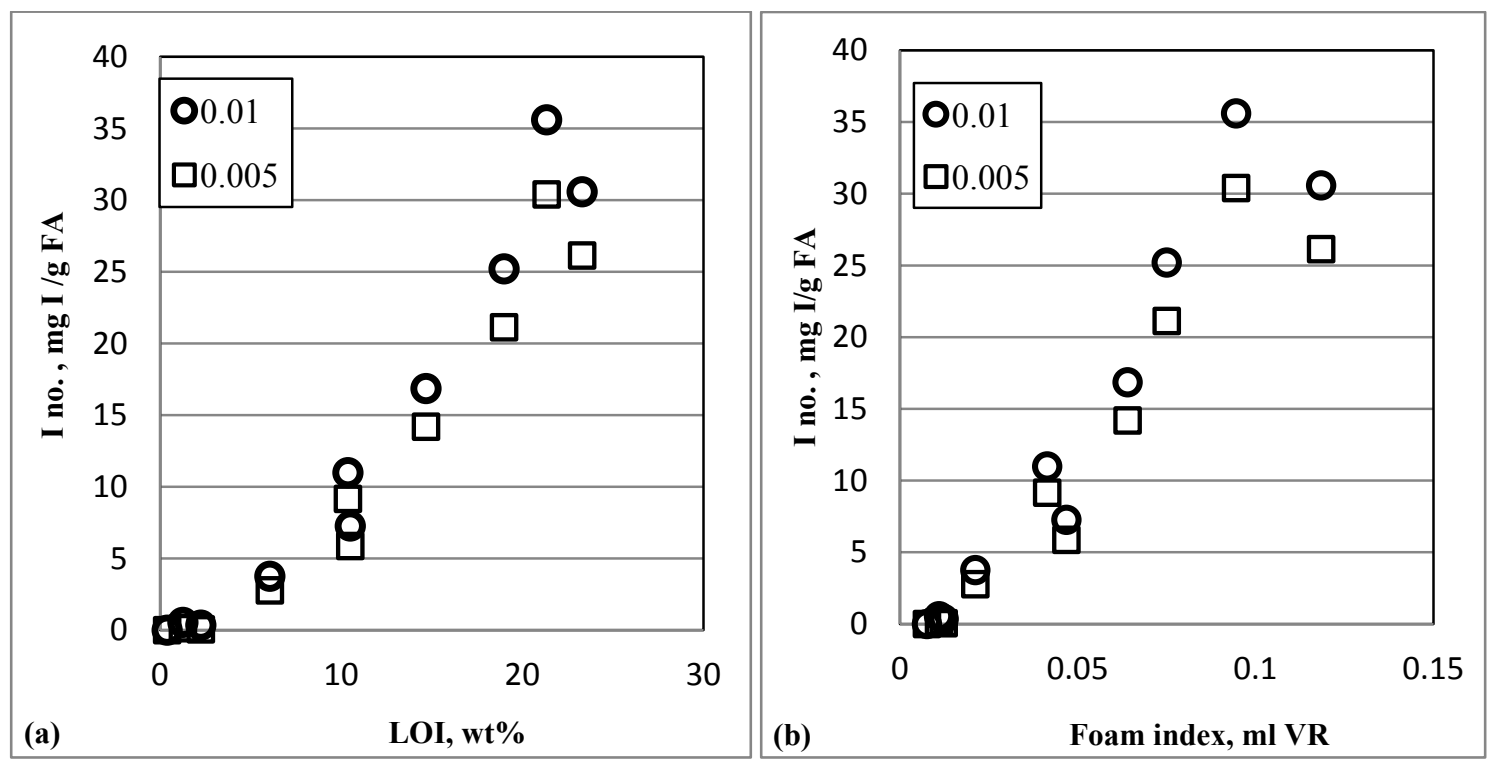

Figure 2.6 The fly ash iodine number with target concentrations of $0.01 \mathrm{~N}$ and $0.005 \mathrm{~N}$ versus (a) LOI and (b) foam index for 10 types of fly ash 
As seen in Figure 2.5, the slopes of the low carbon isotherms are not steep. Therefore, for low carbon ashes, the capacities determined using a target concentration of $0.005 \mathrm{~N}$ are very low resulting in very low fly ash iodine number values. The capacities determined at $0.01 \mathrm{~N}$ are higher and produce commensurately higher values of fly ash iodine numbers. For example, the fly ash iodine number for FA20 at $0.005 \mathrm{~N}$ is $1.4 \mathrm{E}-06 \mathrm{mg} / \mathrm{g}$ and at $0.01 \mathrm{~N}$ its $0.00076 \mathrm{mg} / \mathrm{g}$. A better representation for low carbon fly ash iodine numbers is to plot the results from Figure 2.6 using a log scale as shown in Figure 2.7.

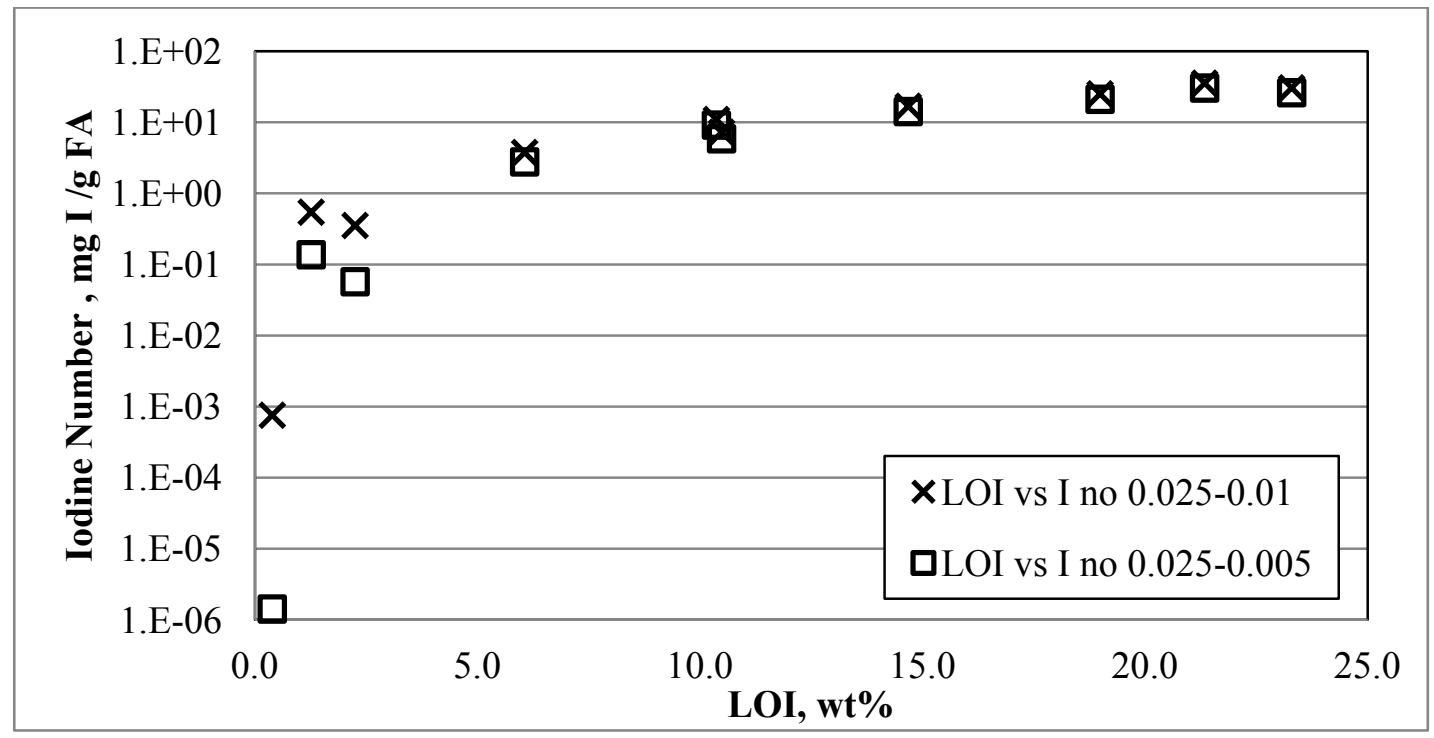

Figure 2.7 Fly ash iodine number at $0.01 \mathrm{~N}$ and $0.005 \mathrm{~N}$ versus LOI

The range of the fly ash iodine number values determined using a $0.005 \mathrm{~N}$ iodine target concentration was from approximately 0.000001 to $30.4(\mathrm{mg} \mathrm{I} / \mathrm{g}$ FA), while for the $0.01 \mathrm{~N}$ iodine target concentration, it was approximately 0.001 to 35.6 (mg I/g FA). For the purpose of having a better scale of measurement, $0.01 \mathrm{~N}$ was chosen as the target concentration for the fly ash iodine number determination. Accordingly, the fly ash iodine number is defined as the mass of iodine absorbed from a solution of $0.025 \mathrm{~N}$ iodine concentration 
by one gram of fly ash at an equilibrium iodine concentration of $0.01 \mathrm{~N}$. Table 2.3 summarizes the fly ash iodine number, LOI, and the foam index test results for the studied fly ashes. Figure 2.8 shows the relationships between the LOI and the fly ash iodine numbers for the fourteen fly ash samples. Note in Figure 2.8 some slight inconsistencies in the LOI-fly ash iodine number relationship. Again, this points out the fly ash iodine number test is measuring adsorption and the LOI test is not. Although LOI may increase, adsorption capacity does not always follow.

Table 2.3

Results of the fly ash iodine number, LOI, and the foam index for the 14 types of fly ash

\begin{tabular}{|l|c|c|c|}
\hline $\begin{array}{l}\text { Fly Ash } \\
\text { ID }\end{array}$ & $\begin{array}{c}\text { LOI } \\
\text { (wt\%) }\end{array}$ & $\begin{array}{c}\text { Foam } \\
\text { Index } \\
\text { (ml) }\end{array}$ & $\begin{array}{c}\text { FA Iodine } \\
\text { Number } \\
\text { (mg/g) }\end{array}$ \\
\hline FA 8 & 0.17 & 0.010 & 0.004 \\
\hline FA 20 & 0.39 & 0.008 & 0.001 \\
\hline FA 1 & 0.87 & 0.015 & 0.013 \\
\hline FA 10 & 1.26 & 0.011 & 0.545 \\
\hline FA 15 & 1.5 & 0.029 & 0.535 \\
\hline FA 7 & 2.25 & 0.012 & 0.354 \\
\hline FA 40 & 3.35 & 0.029 & 2.619 \\
\hline FA 32 & 6.06 & 0.021 & 3.761 \\
\hline FA 100 & 10.37 & 0.041 & 10.989 \\
\hline FA 39 & 10.49 & 0.047 & 7.266 \\
\hline FA 101 & 14.68 & 0.064 & 16.857 \\
\hline FA 102 & 18.99 & 0.075 & 25.205 \\
\hline FA 36 & 21.34 & 0.095 & 35.603 \\
\hline FA 31 & 23.30 & 0.118 & 30.583 \\
\hline
\end{tabular}




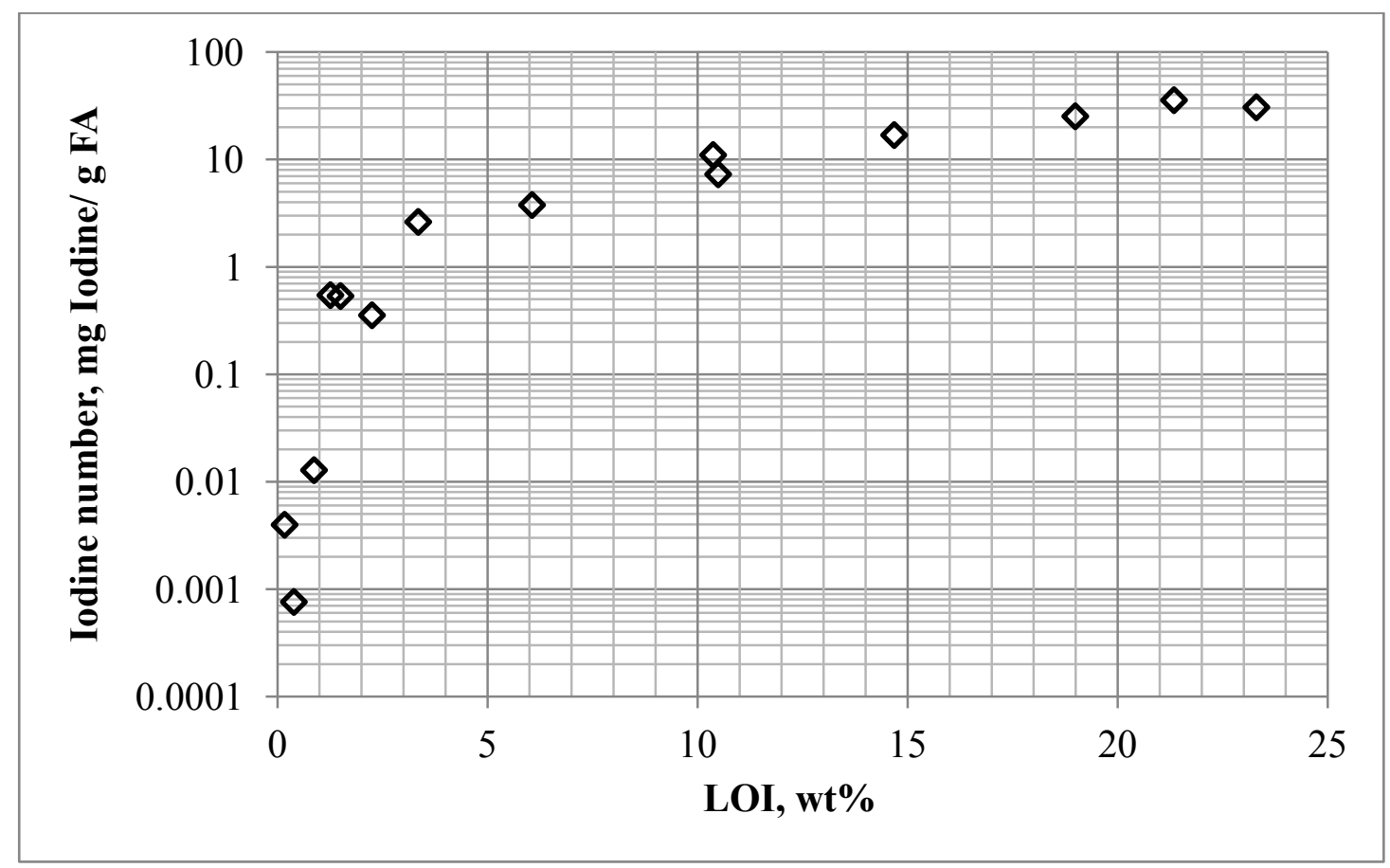

Figure 2.8 Correlation between LOI and fly ash iodine number

According to ASTM C618-08a (13), in general, a fly ash meets the specification if it has a LOI value less than $6 \%$. Class $\mathrm{F}$ ash with a LOI up to $12 \%$ meets the specification if approved by the user and "...acceptable performance records or laboratory test results are made available". Generally, these high LOI ashes are accepted only after numerous test mixtures are prepared and performance in a concrete mixture is demonstrated. This process requires significant time and expense. Alternatively, the fly ash iodine number test can serve as the laboratory test to demonstrate performance. If the high LOI fly ash has a fly ash iodine number similar to a fly ash with a lower LOI, the high LOI fly ash will perform similar to the low LOI fly ash with respect to air entrainment. 
Although ASTM C618-08a specifies $6 \%$ as a general maximum LOI content, problems with air entrainment have been reported for fly ashes with carbon content less than 3\% wt (26). Although a LOI based classification is known to have flaws, it does represent a general trend and historical LOI limits can be used to establish limits for the fly ash iodine number test. Accordingly, a fly ash with a fly ash iodine number less than $0.1 \mathrm{mg} / \mathrm{g}$, corresponding to LOI of approximately $1-2 \%$, can be considered a fly ash with low adsorption capacity. A fly ash iodine number of 0.1 to $1 \mathrm{mg} / \mathrm{g}$, corresponding to LOI of approximately $3-4 \%$, indicates the fly ash has a moderate adsorption capacity. Finally, a fly ash iodine number of more than $1 \mathrm{mg} / \mathrm{g}$ indicates a high adsorption capacity fly ash. Although this seems to be a reasonable approximation, the researchers are not in favor of using LOI based classification of fly ash for the reasons discussed earlier. Rather, the researchers recommend correlating the fly ash iodine number with the direct measurement of adsorption. Then, the fly ash number can be used for a quantitative estimate of AEA dosage (55).

Finally, as the use of powdered activated carbon (PAC) increases for pollution control at power plants, the fly ash iodine number test will become indispensible. Power plants using PAC to treat stack emissions typically cause a small increase in LOI values as very little PAC is required to accomplish the pollution control goals. However, because PAC has such a high adsorption capacity, even this small increase in LOI may cause problems with air entrainment. The fly ash iodine number test will detect the significant increase in adsorption capacity associated with the PAC, while the LOI test will show a negligible change. A test such as the fly ash iodine number test is one of the few options to help characterize and specify fly ash that includes PAC. 


\section{2-4 Conclusions}

The fly ash iodine number is a direct measurement of the adsorption capacity of fly ash. The fly ash iodine number correlates very well with other fly ash characteristic tests such as LOI and the foam index test. However, unlike the LOI and the foam index tests, the fly ash iodine number provides an accurate and non-subjective measurement of the adsorption capacity based on iodine adsorption. The test is a simple procedure and can be done in a simple laboratory that is equipped with a hot plate, burette and a stirring plate.

Direct use of the fly ash iodine number for the characterization, classification, and specification of fly ash for use in concrete is recommended. Empirically, as the method is used broadly, correlation between AEA performance and the fly ash iodine number will be established. In addition, the fly ash iodine number test can be combined with the direct adsorption isotherms presented in the next sections and used to predict the adsorption capacity fly ash to various AEAs. 


\section{3 - Air Entraining Admixtures (AEAs) Partitioning and Adsorption by Coal Fly Ash in Concrete}

\section{3-1 Introduction}

The adsorption capacity of air entraining admixtures (AEAs) on coal fly ash in concrete was evaluated and quantified using adsorption isotherm experiments. The interaction between AEAs and aggregate, cement, and fly ash were studied and the involved physical/chemical processes were identified and quantified. As a result, a method of fly ash adsorption capacity determination was developed in order to estimate the residual AEA concentration in concrete mixtures taking into account the adsorption by fly ash. Fly ash adsorption capacity can be used for the purpose of characterization and specification of fly ash and to assess the suitability of fly ash for use in concrete. Based on that, AEA dosage adjustments can be estimated to compensate for the AEA adsorbed by fly ash. This chapter presents the conceptual development of the test. A simpler and more applicable form of the test will be presented in the next chapter.

When AEAs are added to a concrete mixture containing fly ash, chemisorption of the AEA compounds will occur with the cement while both physical and chemisorption adsorption will occur on the fly ash. The remaining AEA compounds will stay in solution to participate in the formation of the air void system. The objective of this work is to characterize the chemisorption of AEA compounds onto cement, and chemisorption and physical adsorption of AEA compounds on fly ash, in order to determine the remaining AEA concentration in the water. Isotherm tests were developed to characterize the chemisorption and physical adsorption processes on several cement and fly ash 
samples. The isotherms were used to quantify the amount of AEA material adsorbed by fly ash. This procedure can be used on any fly ash/AEA combination to determine the AEA adsorption capacity of fly ash. Consequently, an AEA dosage adjustment can be made to account for the amount of AEA adsorbed by the fly ash.

An adsorption isotherm consists of several individual Erlenmeyer flasks containing various masses of adsorbent (i.e. fly ash) and various concentrations of adsorbate (i.e. AEA) equilibrated at a constant temperature. The results of an isotherm provide a correlation between the adsorbent capacity (i.e. mass adsorbate per unit mass adsorbent) and the adsorbate aqueous phase concentration. In this case, an adsorption isotherm characterizes the mass of AEA adsorbed per mass of fly ash as a function of the AEA equilibrium liquidphase concentration.

In the past, researchers have reported it is not possible to perform isotherms on fresh concrete mixtures because AEAs are usually composed of various unknown organic materials and concrete mixtures are semisolid systems that have a very limited amount of water (22). It is important to emphasize, the adsorption tests developed below are not designed to mimic the conditions of a concrete mixture. Rather, they were designed to quantify the AEA adsorbed onto the carbon portion of the fly ash as a function of the AEA liquid-phase concentration. The resulting adsorption isotherms were fit with the Freundlich isotherm equation to obtain a relationship that can be used to predict the AEA concentration adjustment required to compensate for the adsorbed portion of the AEA for a range of AEA concentrations (i.e. mixture dosages). 


\section{3-2 Materials and methods}

\section{Fly ash and AEAs}

In this study, a low carbon coal fly ash with a LOI of $0.39 \%$ and a high carbon coal fly ash with a LOI of $10.49 \%$ were used. The properties of these ashes are listed in Table 3.1. Six AEAs from various types and manufacturers were utilized in this study and are presented, with their chemical classification (59) in Table 3.2. The AEAs chosen for this study are widely used by the concrete industry and they are preapproved for use in many states in the United States.

\section{Table 3.1}

Fly ash specimens and their properties, $w \mathrm{t} \%$

\begin{tabular}{|c|c|c|c|c|c|c|c|c|}
\hline Fly ash & $\mathbf{S i O}_{2}$ & $\mathbf{A l}_{2} \mathbf{O}_{3}$ & $\mathbf{F e}_{2} \mathbf{O}_{3}$ & $\mathbf{T o t a l}_{:} \mathbf{S i O}_{2}, \mathbf{A l}_{2} \mathbf{O}_{3}, \mathbf{F e}_{2} \mathbf{O}_{3}$ & $\mathbf{C a O}$ & $\mathbf{S O}_{3}$ & $\mathbf{M g O}$ & $\mathbf{L O I}$ \\
\hline Low carbon & 44.81 & 23.08 & 9.51 & 77.4 & 13.58 & 0.96 & 2.97 & 0.39 \\
\hline High carbon & 39.6 & 20 & 12.7 & 72.3 & 9.1 & 1.1 & 2.28 & 10.49 \\
\hline
\end{tabular}

Table 3.2

AEAs used in this study

\begin{tabular}{|c|c|c|l|}
\hline No. & Brand Name & Type of Admixture & Manufacturer \\
\hline $\mathbf{1}$ & MicroAir & Alpha olefin sulfonate admixtures & BASF (Master Builders) \\
\hline $\mathbf{2}$ & EuconAir30 & Benzene sulfonate admixtures & Euclid Chemical Co. \\
\hline $\mathbf{3}$ & DaravAir 1000 & Resin/Rosin and fatty acids admixtures & Grace Concrete Products \\
\hline $\mathbf{4}$ & MB AE90 & Resin/Rosin and fatty acids admixtures & BASF (Master Builders) \\
\hline $\mathbf{5}$ & MB VR & Vinsol resin admixture & BASF (Master Builders) \\
\hline $\mathbf{6}$ & DaravAir AT60 & Combination admixtures & Grace Concrete Products \\
\hline
\end{tabular}




\section{Measurement of AEA concentration}

The measurement of AEA concentrations is problematic since AEAs are composed of a mixture of complex organics. Spectroscopic methods were used by many researchers to describe the concentration of AEAs; the results were always characterized with low accuracy due to the dilution of the sample and the phase instability of the AEA compounds in water. Total organic carbon (TOC) measured by the UV/chemical (persulfate) oxidation method were also considered for the measurement of AEA concentration, but numerous attempts failed to measure AEA concentrations. Results of many test samples for various dilutions showed that because UV/chemical (persulfate) is a relatively weak oxidant, it failed to fully oxidize the complex organic polymers in the AEA mixtures.

The chemical oxygen demand (COD) test uses extreme oxidation conditions including a strong oxidizing agent (potassium dichromate $\mathrm{K}_{2} \mathrm{Cr}_{2} \mathrm{O}_{7}$ ), strong acid (sulfuric acid $\mathrm{H}_{2} \mathrm{SO}_{4}$ ), and high temperature $\left(150^{\circ} \mathrm{C}\right)$. Nearly all organic compounds are oxidized to $\mathrm{CO}_{2}$ and measured as the mass of oxygen consumed per liter of solution. Serial dilutions of three types of AEAs were made and tested with the HACH COD kit (TNT821 and TNT822) and HACH DR 5000 UV-Vis spectrophotometer. The results of the correlation between AEAs concentrations and COD are illustrated in Figure 3.1. 


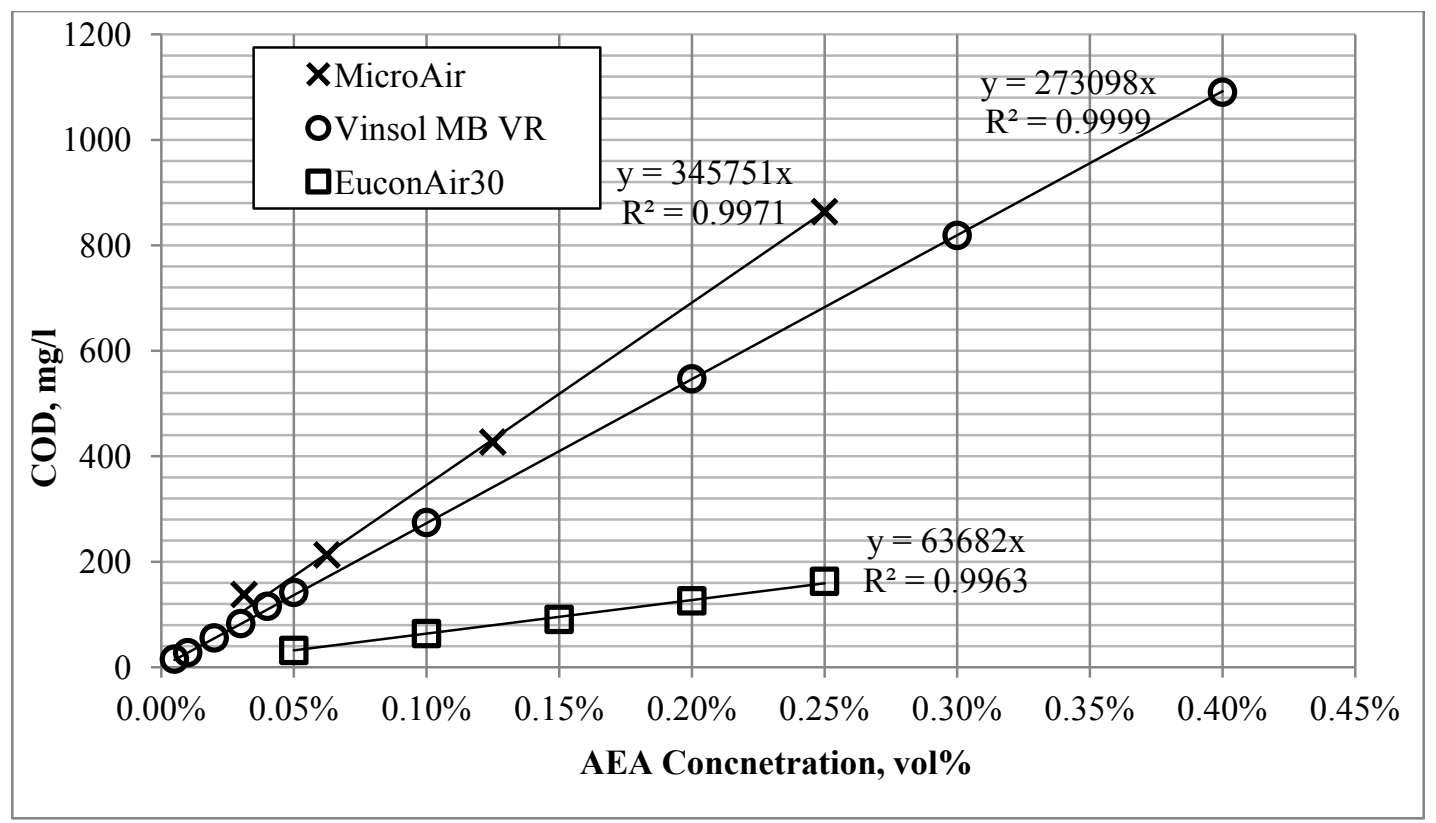

Figure 3.1 The correlation between AEA concentration in \% Vol. and COD (mg/L)

The COD test was able to accurately represent the concentration of the various AEAs. Therefore, it was used in this study for the measurement of AEA concentrations. At least three different concentrations were tested for each AEA used in this research, all AEA testing results showed 100\% sample recoveries and linear correlations between COD and AEA concentrations.

\section{Isotherm setup}

All isotherms were equilibrated for one hour in $250 \mathrm{ml}$ Erlenmeyer flasks at $20{ }^{\circ} \mathrm{C}$. The flasks were covered during the equilibration to minimize the possibility of AEA volatilization. The AEA solution volume was measured using a $200 \mathrm{ml}$ volumetric flask prior to its addition to the solid materials. A magnetic stirrer was used to keep the contents of the isotherm flask mixed for the entire time of equilibration. The equilibrated solution was filtered using grade $1,11 \mu \mathrm{m}, 90 \mathrm{~mm}$ diameter, cellulose, Whatman qualitative filter paper in a 
vacuum apparatus. The filtrate volume was measured using a $200 \mathrm{ml}$ graduated cylinder. COD measurements were performed on the initial solution concentration and filtrate and used to determine the AEA liquid phase concentration and the adsorption capacity at that point. The COD released by the cement or fly ash was subtracted from the COD measurement to determine the net COD of the AEA. The one hour time period was selected because initial kinetic tests showed that fly ash-AEA systems reach near equilibrium state in less than 30 minutes.

\section{3-3 Results and discussions}

To understand and ultimately quantify the interaction between fly ash and AEAs in concrete, it is crucial to understand how AEAs partition among the various materials that make-up concrete. AEA equilibration with aggregate, sand, cement, and various types of fly ash were used to assess the interaction between these materials and AEAs. In this work, the fate of the AEAs was studied; chemisorption and adsorption were quantified to determine the net amount of AEA adsorbed onto the fly ash carbon.

The basic chemical nature of an AEA is shown schematically in Figure 1.3. Typically, an AEA contains two parts, the first which is represented as the head, is the ionic part that has a strong attraction to the solvent (i.e. water) and is therefore hydrophilic. The second part, which is referred to as the tail, is nonionic and has little or no attraction to the water therefore, is hydrophobic (22).

When an AEA is added to the concrete mixture, the hydrophilic anionic polar groups sorb strongly to the ionic cement particles leaving the hydrophobic non-polar end of the surfactant molecule toward the solution as shown in Figure 1.4. Air bubbles are formed during agitation and mixing of the 
concrete mixture and the hydrophobic non-polar ends of the surfactant molecules form micelles to stabilize these air bubbles and prevent them from coalescing into large bubbles (4) (20) (23). The entrained air bubbles have diameters less than $0.25 \mathrm{~mm}$ but not less than $10 \mu \mathrm{m}$ (20). Bruere (24) studied air entrainment in cement and silica pastes and concluded that for sufficient air entrainment two conditions must be satisfied. The first condition is the AEA should be adsorbed on the solid particles with the non-polar ends pointing toward the water to give a hydrophobic character to the cement particles and make them adhere to the air bubbles. The second condition is the cement mixture must maintain enough AEA liquid phase concentration to entrain air during mixing. Another important observation of stable foam formation was that even though AEAs visually precipitate from the solution, it retained its ability to form stable foam. However, after filtration the filtrate lost this ability to form stable foam, which means the precipitated portion of AEA still actively contributes to the foam formation (24) (20).

\section{AEA interaction with aggregate}

Aggregate and sand were equilibrated for an hour with $0.4 \%$ vol. MB VR and $0.4 \%$ vol. MicroAir. No significant changes in AEA liquid phase concentration were measured which indicates there is negligible interaction between AEAs and aggregate materials. This is an important finding and it means the aggregate fraction does not change the liquid phase concentration of AEA. Because the aggregate is electrochemically neutral, and it is carbon free, it can therefore be excluded from the isotherm testing.

\section{AEA interaction with cement}

Air entraining admixtures interact strongly with cement by binding to the cement particles, leaving only a portion in the liquid phase. This type of 
sorption is called chemisorption and is characterized by chemical bonding (ionic or covalent) that is stronger than physical adsorption (van der Waals forces) and is irreversible under normal temperatures. Figure 3.2 shows the change of AEA concentration after equilibration with various masses of cement. The results illustrated in Figure 3.2 show that only a few grams of cement are needed to attain steady levels of AEA liquid phase concentration. After that point, the liquid phase concentration remains constant regardless of the increment in cement mass. This indicates the chemisorption process is fully completed and the remainder of the AEA stays in the solution to participate in air entrainment. The ratio of the equilibrium liquid phase concentration after chemisorption to the initial concentration of the AEA is herein called the AEA partitioning coefficient. It is also clear that various AEAs are designed differently; some of them are designed to maintain almost half of their mass in the liquid phase while others are designed to maintain less than $10 \%$ of their mass in the liquid phase. The latter is heavily dependent on the solid phase AEA (i.e. sorbed to cement minerals) to entrain air, but it still needs a small portion of the AEA in the liquid phase to maintain the air bubble system. 


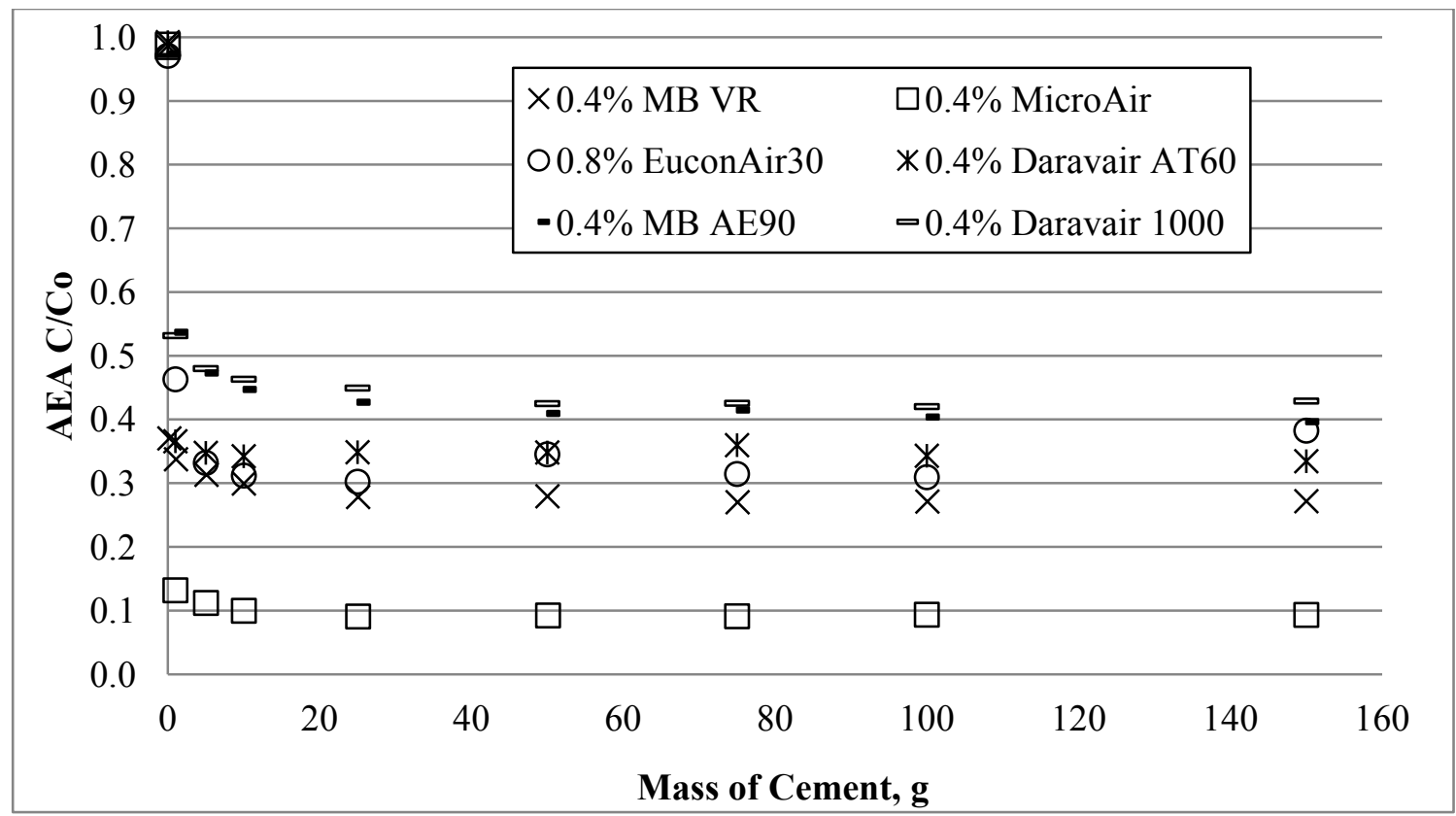

Figure 3.2 AEAs partitioning between cement and water

Although the chemisorption process is very fast (less than a minute), all samples in the test were equilibrated for one hour before measuring the AEA concentration.

\section{Factors affecting AEA partitioning coefficient}

\section{Type of AEA}

The types of AEAs differ in terms of their partitioning in an aqueous solution with cement. Generally, considering the relatively limited adsorption capacity of fly ash, it is expected that an AEA with a high partitioning coefficient, such as DaravAir 1000, is less affected by adsorption because a larger portion of the AEA remains in solution and the adsorbed AEA is therefore a smaller fraction of the total AEA. For an AEA with a low partitioning coefficient, such as MicroAir, a very limited amount of the AEA remains in solution and this amount can easily be adsorbed by fly ash, leaving 
very little AEA in solution to participate in the air void system formation. This is only true if various compounds that make up AEA liquid phase have similar adsorptive properties. However, different AEAs leave different compounds in liquid phase and these compounds vary in their adsorption capacity. For example, DaravAir 1000 may leave $42 \%$ of its mass in solution and these species could have more affinity for adsorption than the $10 \%$ left in solution of MicroAir. Therefore, fly ash adsorption isotherms needed to observe the true AEA liquid phase properties.

\section{AEA concentration}

Another factor affecting AEA partitioning coefficients is the initial concentration of the AEA. Figure 3.3 shows MB VR partitioning between the liquid phase and cement phase for three different initial MB VR concentrations.

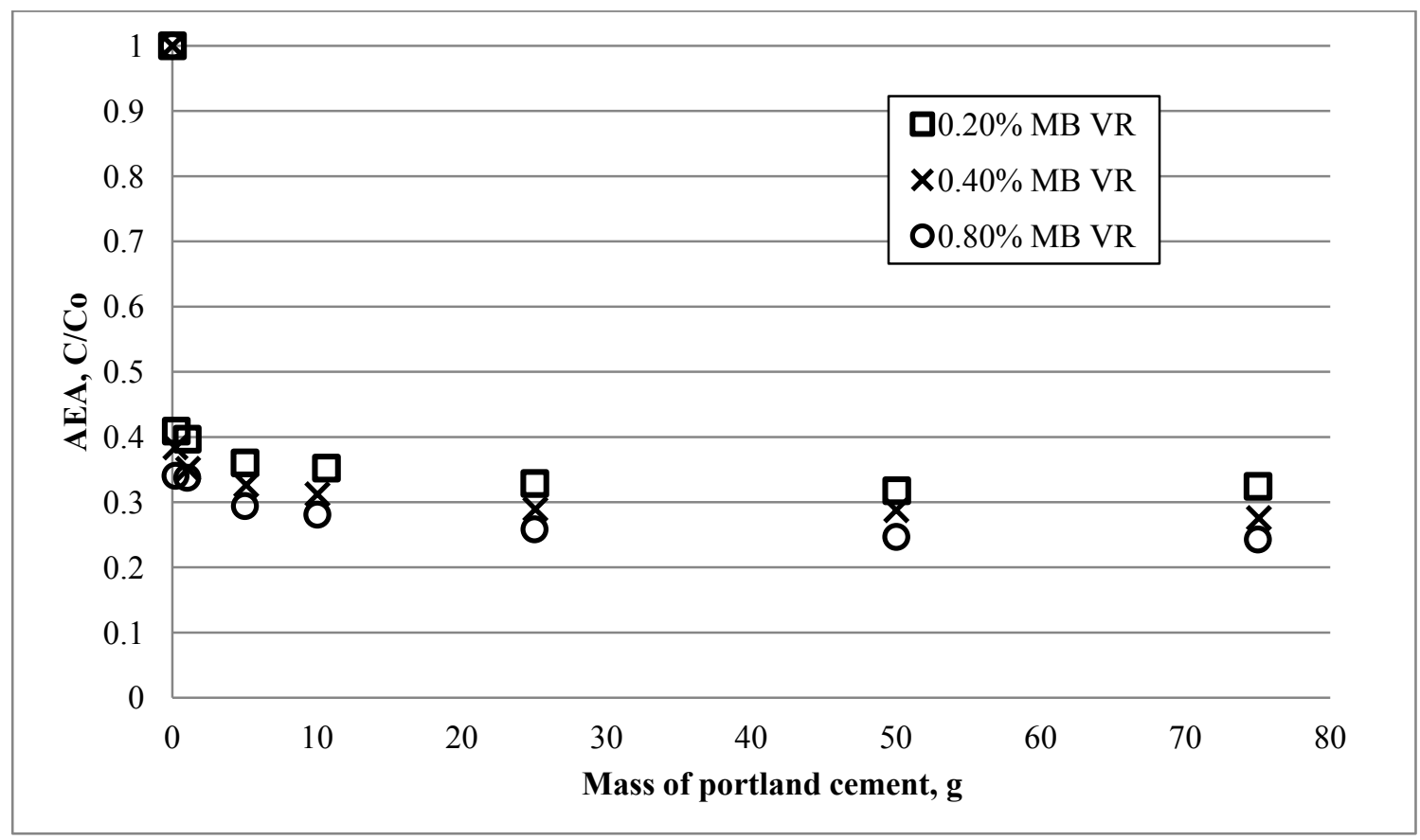

Figure 3.3 AEA partitioning coefficient for various AEA concentrations 
It is clear from Figure 3.3 that the partitioning coefficient is inversely proportional to the AEA concentration. Therefore, it is important to determine the partitioning coefficient for each AEA at the specific initial liquid phase concentration used in the isotherm.

\section{Type of cement}

Two ASTM C130 type I cements from different sources and one type III cement were equilibrated with the same concentration of MB VR to determine the effect that type has on the partitioning coefficient. Figure 3.4 displays the partitioning of MB VR as a function of cement mass for the three cements. The cement type has no significant effect on the AEA partitioning coefficient because all types of cement have an abundance of active chemisorption sites, much more than the amount required to sorb all the chemisorbable portions of any AEA solution under practical AEA concentrations. It is also important to emphasize those different types of cement release different amounts of COD to the solution depending on their composition. The COD results shown in Figures 3.2, 3.3, and 3.4 are for the net COD of the AEA after the COD of the cement was subtracted from the COD measurements of the mixture. 


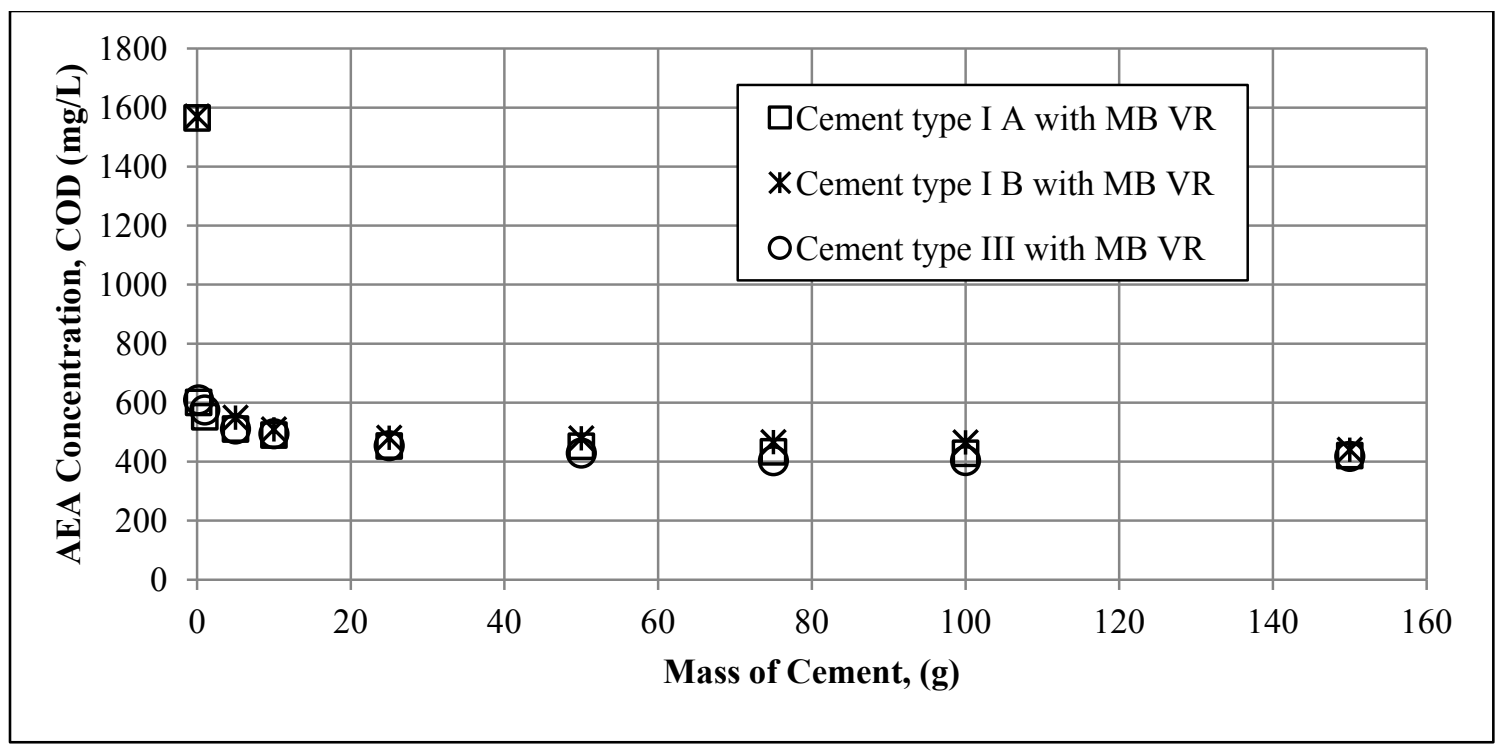

Figure 3.4 Effect of type of cement on the AEA partitioning coefficient

\section{AEA interaction with fly ash}

\section{AEAs interaction with low carbon fly ash}

Low carbon fly ash exhibited a very similar behavior to cement. Figure 3.5 illustrates the results of low carbon fly ash equilibration with three AEAs. Most of the AEA was chemisorbed to the fly ash mineral particles. AEAs partitioned between the liquid and fly ash phase similarly to the way they partitioned with cement. The resulting partitioning coefficients for low carbon fly ash are almost identical to the cement partitioning coefficients. The only difference observed between cement and low carbon fly ash is that more mass of fly ash is required to achieve full chemisorption and attain a steady level of AEA liquid phase concentration. This indicates that cement particles have more chemisorption activity than fly ash particles.

The results of cement and low carbon fly ash suggest that a system of low carbon fly ash, cement, and AEA will exhibit the same behavior as a system of cement and AEA in terms of AEA liquid phase concentration. 


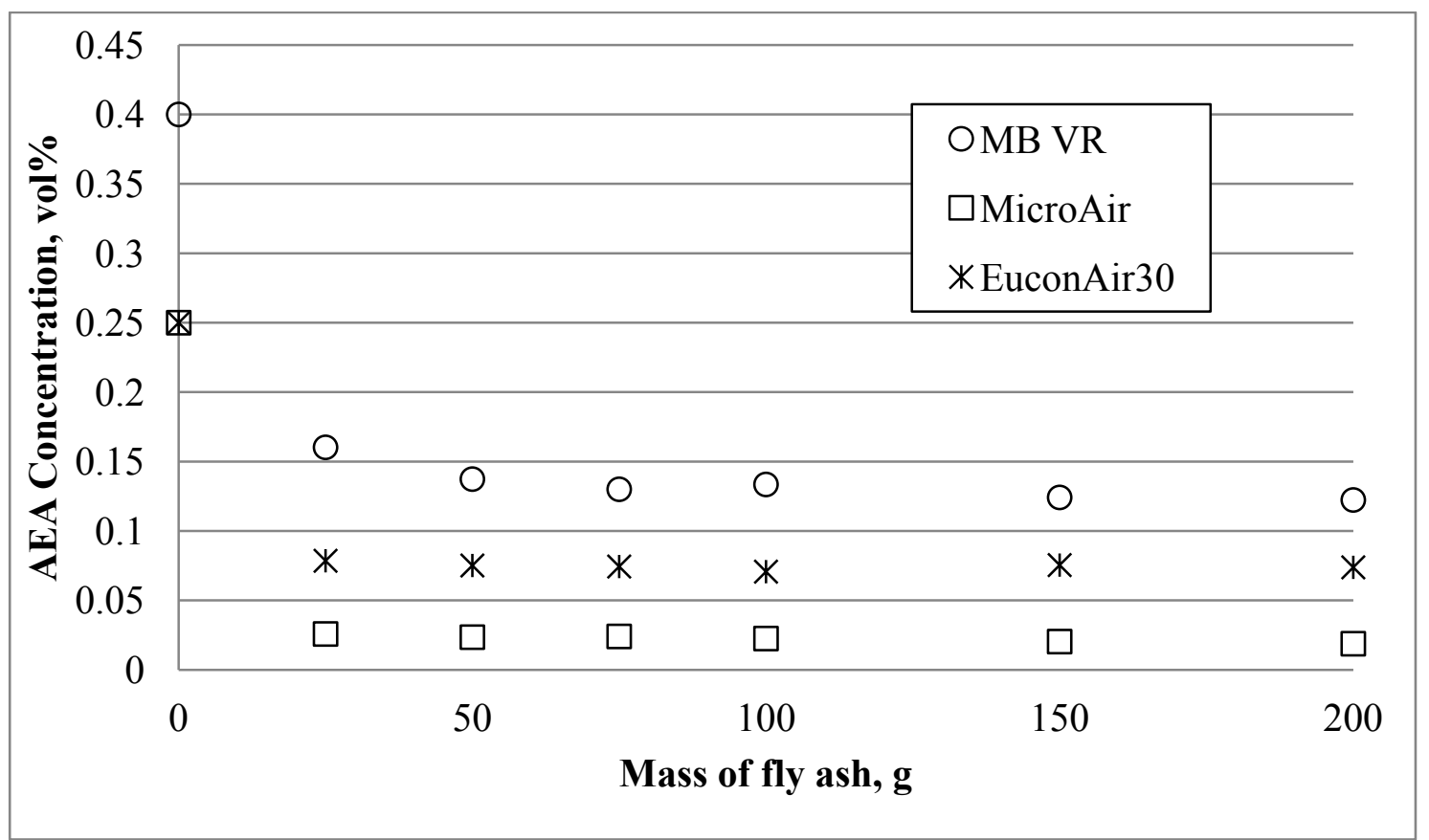

Figure 3.5 Low carbon fly ash $(0.39 \%$ LOI) interaction with three types of AEAs

\section{AEAs interaction with high carbon fly ash}

The carbon in high carbon fly ash adsorbs AEAs in the liquid phase reducing the essential liquid phase AEA concentration. Figures 3.6 and 3.7 show the results of six AEA isotherms equilibrated with high carbon fly ash $(10.45 \%$ LOI). For all AEAs, the observed AEA liquid phase concentrations decreased with increasing mass of fly ash mass and a steady-state level of AEA liquid concentration is never reached. 


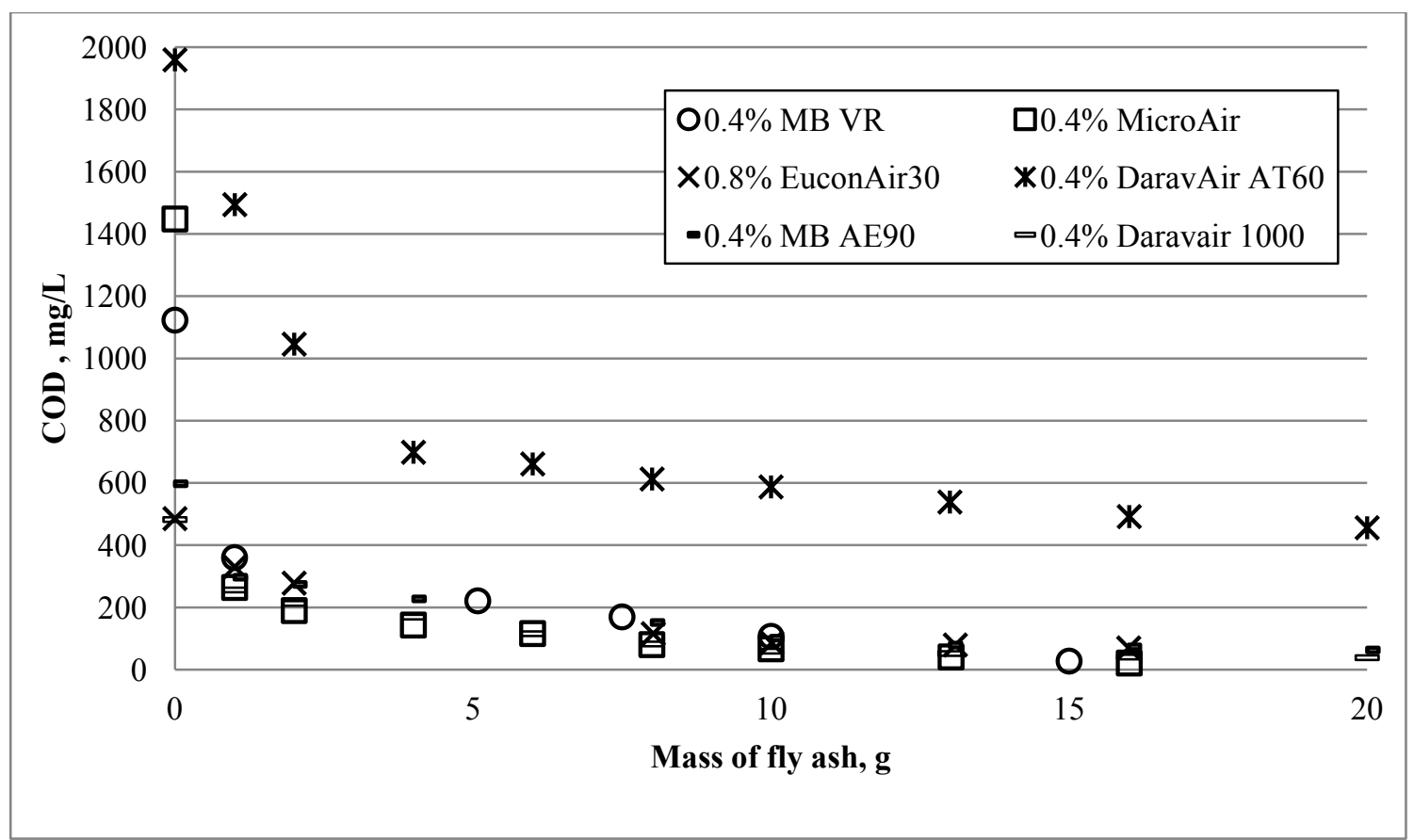

Figure 3.6 Interaction between high carbon fly ash and six different AEAs, AEAs concentrations expressed as $\mathrm{mg} / \mathrm{L}$ of $\mathrm{COD}$

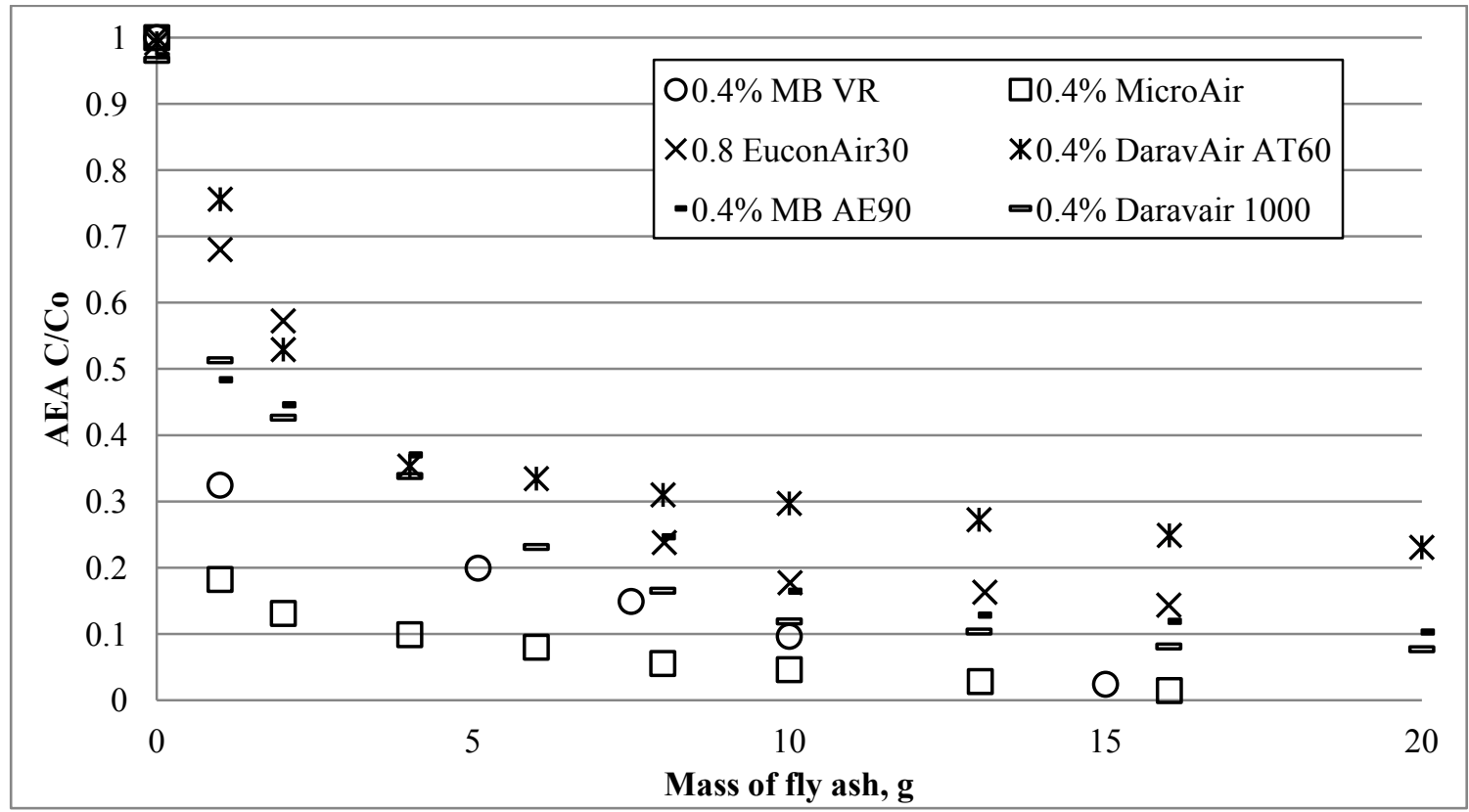

Figure 3.7 Interaction between high carbon fly ash and six different AEAs, AEAs concentrations expressed as ratio to the initial AEA concentration $(\mathrm{C} / \mathrm{Co})$ 
For small amounts of fly ash, large portions of the AEAs were sorbed onto the fly ash, but unlike cement, the loss in the AEA liquid phase concentration continued with the increase of the fly ash added. This indicates the adsorption process is taking place and as more fly ash is added to the system, more adsorbent (carbon) is added causing more AEA adsorption to occur. Eventually, if enough high carbon fly ash is added, all the AEA will be absorbed onto the carbon. Another very important observation is that not all AEAs behaved the same way with high carbon fly ash. The liquid phase of DaravAir AT60 maintained a higher liquid phase concentration than the other AEAs, indicating it is less susceptible to adsorption or has less adsorption potential than the other AEAs. Conversely, MicroAir was the first to lose all its liquid phase concentration with only about 16 grams of fly ash. This is extremely significant because it indicates that some AEAs are more affected than others because their liquid phase concentration is less susceptible to adsorption.

The results presented above show that a preferred AEA for use with high carbon fly ash should have a high partitioning coefficient, while its liquid phase portion should have low absorbability.

Isotherms with cement and fly ash can be used to quantify the amount of AEA adsorbed by fly ash. The goal of the adsorption isotherm is to isolate and measure the reduction in AEA liquid phase concentration due to adsorption by carbon in the fly ash. In order to achieve this goal, the full extent of chemisorption by cement and minerals of fly ash must be quantified. Any reduction in AEA liquid phase concentration beyond chemisorption is considered a loss due to adsorption. 


\section{Adsorption isotherms}

As in every adsorption process, the solid/liquid phase partitioning of the adsorbate is governed by the solid phase capacity of the adsorbent and the initial liquid phase concentration of the adsorbate. Sorption/desorption processes take place until equilibrium is attained. The adsorption isotherm standard test (ASTM D3860-98) (60) provides a procedure to determine the equilibrium solid/liquid phase concentration for various masses of adsorbent. The results of the test describe the two phase equilibrium relationship and provide a measurement of the solute adsorbed phase concentration for any liquid phase concentration, and vice versa. This standard procedure cannot be applied directly in cases of AEA adsorption by fly ash because chemisorption and adsorption are taking place at the same time.

The chemical compositions, as well as the physical properties, of fly ash and cement are inconsistent over time. As a result, there is no standard cement or standard fly ash. Instead, fly ash and cement are classified based on a predefined range for each of their material compositions. This represents a challenge for the task of developing a procedure for measuring the direct adsorption capacity of fly ash. Because of this inconsistency, it is important to develop a procedure that can be performed onsite or in a simple laboratory using the exact material that will be used in the concrete. This will provide a product specific result and eliminate the variation due to the inconsistency of material properties. However, it was proven as discussed earlier that chemisorption, defined by the partitioning coefficient of AEA, is insensitive to the type of cement. This can be attributed to the abundance of minerals in all types of cement. In other words, all cement types have enough charged sites at the mineral particle surfaces to sorb all the chemisorbable portion of the AEA 
compounds. Therefore, the isotherm of any AEA with cement doesn't need to be repeated in every test.

An adsorption isotherm for a given combination of fly ash and AEA provides the equilibrium relationship between the solid and liquid phase concentration of the AEA. The solid phase concentration represents the mass of AEA adsorbed per unit mass of fly ash, while the liquid phase concentration represents the mass of AEA left per unit volume of water. An adsorption isotherm test involves performing separate isotherms: (1) a cement isotherm to define the limit of chemisorption and (2) a fly ash isotherm to measure adsorption. The cement isotherm is used to determine the chemisorption partitioning coefficient for a given AEA concentration while the fly ash isotherm is used to quantify the adsorption of the AEA onto the fly ash.

\section{Cement isotherms and AEA liquid phase determination}

The first step in a direct adsorption isotherm is to perform a cement isotherm with the AEA of interest. Separate measured masses of cement are equilibrated using a magnetic stirrer with $200 \mathrm{ml}$ of water with a known concentration of AEA. After one hour of equilibration, the mix is filtered and COD measurements are performed on the filtrate. This produces an isotherm data point for each mass of cement. The COD contribution of the cement is subtracted from the COD measurement of the filtrate to determine the COD attributable to the AEA for each data point. The mass of cement plotted against the corresponding AEA concentration (COD) produces a graph similar to Figure 3.2. The COD decreases with increasing mass of cement until it reaches a constant COD. That constant concentration provides the initial AEA concentration, in terms of COD, that is available for adsorption. 
The constant COD level from the graph divided by the initial AEA concentration used in the isotherm yields the partitioning coefficient at that given AEA initial concentration. It was shown in a previous section that AEAs behave similarly with all types of cement. Consequently, if an excess amount of cement is used, the partitioning coefficient for each individual AEA is only a function of the initial concentration of that AEA. The need to run a cement isotherm could be eliminated if the partitioning coefficient of the AEA of interest is known at the AEA concentration of interest. Therefore, Figure 3.8 can be used to obtain the cement partitioning coefficient without performing a cement isotherm. For example, the partitioning coefficient for $0.8 \% \mathrm{MB}$ VR is 0.26 , therefore $26 \%$ of the COD value of the $0.8 \%$ MB VR will remain in solution and can be considered the initial concentration for adsorption in the fly ash isotherm.

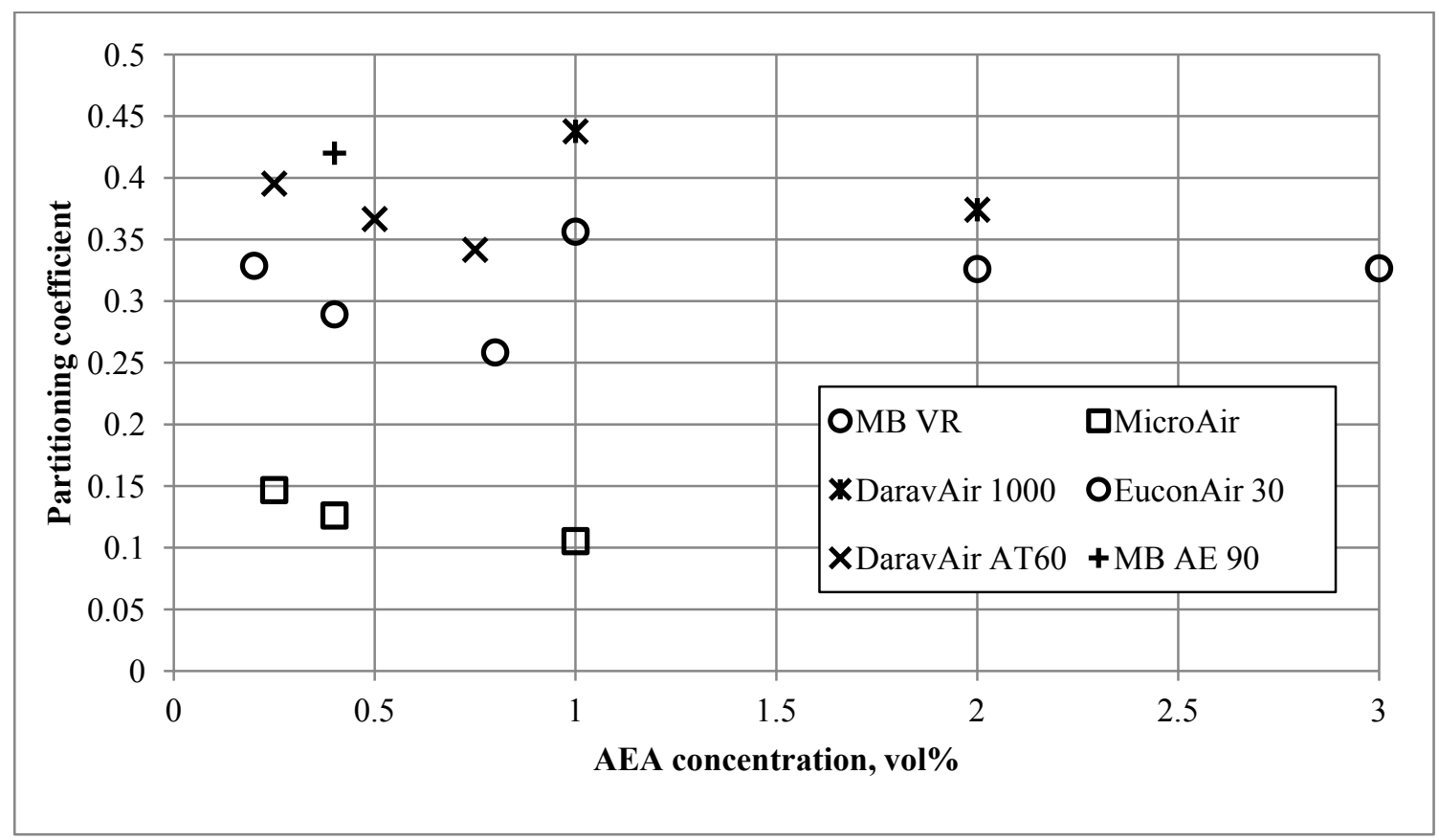

Figure 3.8 AEA cement partitioning coefficients for six AEAs at various concentrations equilibrated with $20 \mathrm{~g}$ of portland cement. 


\section{Fly ash isotherm}

After determining the AEA liquid phase concentration using the partitioning coefficient, various masses of fly ash are equilibrated with the AEA solution to measure adsorption. Each mass represents an isotherm data point and is equilibrated with the AEA solution for one hour. After equilibration, the solution is filtered and COD measurements are taken for the filtrate. All COD values that exceed the AEA liquid phase concentration determined from the partitioning coefficient should be ignored because it indicates incomplete chemisorption, and the amount of fly ash added was insufficient to achieve complete chemisorption in these isotherm points.

Data points with COD values less than $80 \%$ of the initial AEA liquid phase concentration determined from the cement isotherms are preliminarily considered good isotherm data points and can be used for the isotherm calculations. In other words, these are the isotherm data points where the chemisorption has most likely been satisfied.

\section{Isotherm calculations}

The initial AEA liquid phase concentration available for adsorption can be determined from the COD of the AEA solution and the partitioning coefficient:

$$
\mathrm{COD}_{\mathrm{o}, \mathrm{aq}}=\mathrm{COD}_{\mathrm{i} \text { AEA }} \times \text { Partitioning Coefficient ..............Equation } 3.1
$$

Where:

$\mathrm{COD}_{\mathrm{o}, \mathrm{aq}}=$ Initial AEA liquid phase concentration available for adsorption, $\mathrm{mg} / \mathrm{L}$

$\mathrm{COD}_{\mathrm{i}_{\mathrm{AEA}}}=\mathrm{AEA}$ solution concentration measured as $\mathrm{COD}, \mathrm{mg} / \mathrm{L}$.

The final AEA concentration after equilibration with fly ash can be determined using Equation 3.2: 


$$
\mathrm{COD}_{f, a q}=\mathrm{COD}_{\text {Filtrate }}-\mathrm{COD}_{\text {Fly Ash }}-\mathrm{COD}_{c}
$$

Where:

$\mathrm{COD}_{\mathrm{f}, \mathrm{aq}}=$ Equilibrated AEA liquid phase concentration obtained from the filtrate, $\mathrm{mg} / \mathrm{L}$

$\mathrm{COD}_{\text {filtrate }}=$ Equilibrated filtrate $\mathrm{COD}, \mathrm{mg} / \mathrm{L}$

$\mathrm{COD}_{\text {Fly Ash }}=$ Soluble COD released from the mass of fly ash in the isotherm point. $\mathrm{mg} / \mathrm{L}$

$\mathrm{COD}_{\text {cement }}=$ Soluble COD released from the mass of cement in the isotherm point. $\mathrm{mg} / \mathrm{L}$

The soluble COD released from the fly ash or cement can be determined from equilibrating the fly ash or cement mass with $200 \mathrm{ml}$ of distilled water and determine the soluble COD released. A mass balance is performed on each isotherm point and the amount of AEA adsorbed can be determined from Equation 3.3:

$$
\mathrm{M}_{\mathrm{AEAad}}=\mathrm{V}_{\mathrm{O}} \times \mathrm{COD}_{\mathrm{o}, \mathrm{aq}}-\mathrm{V}_{\mathrm{f}} \times \mathrm{COD}_{\mathrm{f}, \mathrm{aq}}
$$

Where:

$\mathrm{M}_{\mathrm{AEA}, \mathrm{ad}}=$ Mass of AEA adsorbed, mg COD

$\mathrm{V}_{\mathrm{O}}=$ Initial volume of AEA solution for the isotherm point, $\mathrm{L}$ $\mathrm{V}_{\mathrm{f}}=$ Volume of the filtrate, $\mathrm{L}$

The mass of AEA adsorbed is then divided by the mass of fly ash used in the isotherm point to determine the solid phase concentration.

$$
\mathrm{q}_{\mathrm{Fly} \mathrm{Ash}}=\mathrm{M}_{\mathrm{AEAd}} \div \mathrm{M}_{\mathrm{Fly} \mathrm{Ash}} \ldots \ldots \ldots \ldots \ldots \ldots \ldots \ldots \ldots \ldots \ldots \ldots \text { Equation } 3.4
$$

Where:

$\mathrm{q}_{\text {Fly Ash }}=$ Capacity of fly ash, or fly ash phase AEA concentration, mg COD/ g fly ash. 
Solid phase concentrations $\left(\mathrm{q}_{\mathrm{Fly}}\right.$ Ash $)$ for all isotherm points are plotted versus the corresponding liquid phase concentrations of $\mathrm{AEA}\left(\mathrm{COD}_{\mathrm{f}, \mathrm{aq}}\right)$ for each data point on a log-log scale. A power line data fit produces coefficients for the Freundlich equation (Equation 3.5) that describes the equilibrium partitioning between the AEA solid phase concentration (capacity of fly ash) and the AEA liquid phase concentration (57) (56).

$\mathrm{q}=\mathrm{K} \times \mathrm{C}^{\frac{1}{n}}$ Equation 3.5

Where:

$\mathrm{K}=$ Freundlich capacity parameter, $\frac{m g}{g} \times\left(\frac{L}{m g}\right)^{\frac{1}{n}}$

$\frac{1}{n}=$ Freundlich intensity parameter, unitless

Figure 3.9 displays the results of two sets of isotherms for the high carbon fly ash with $0.8 \%$ vol. MB VR. The curvature of the data at high COD values indicates an error caused by incomplete chemisorption. At the curved region of the graph, both adsorption and chemisorption are taking place at the same time. The straight line part of the correlation can be considered the adsorption isotherm and can be used to determine $(\mathrm{K})$ and $(1 / \mathrm{n})$. 


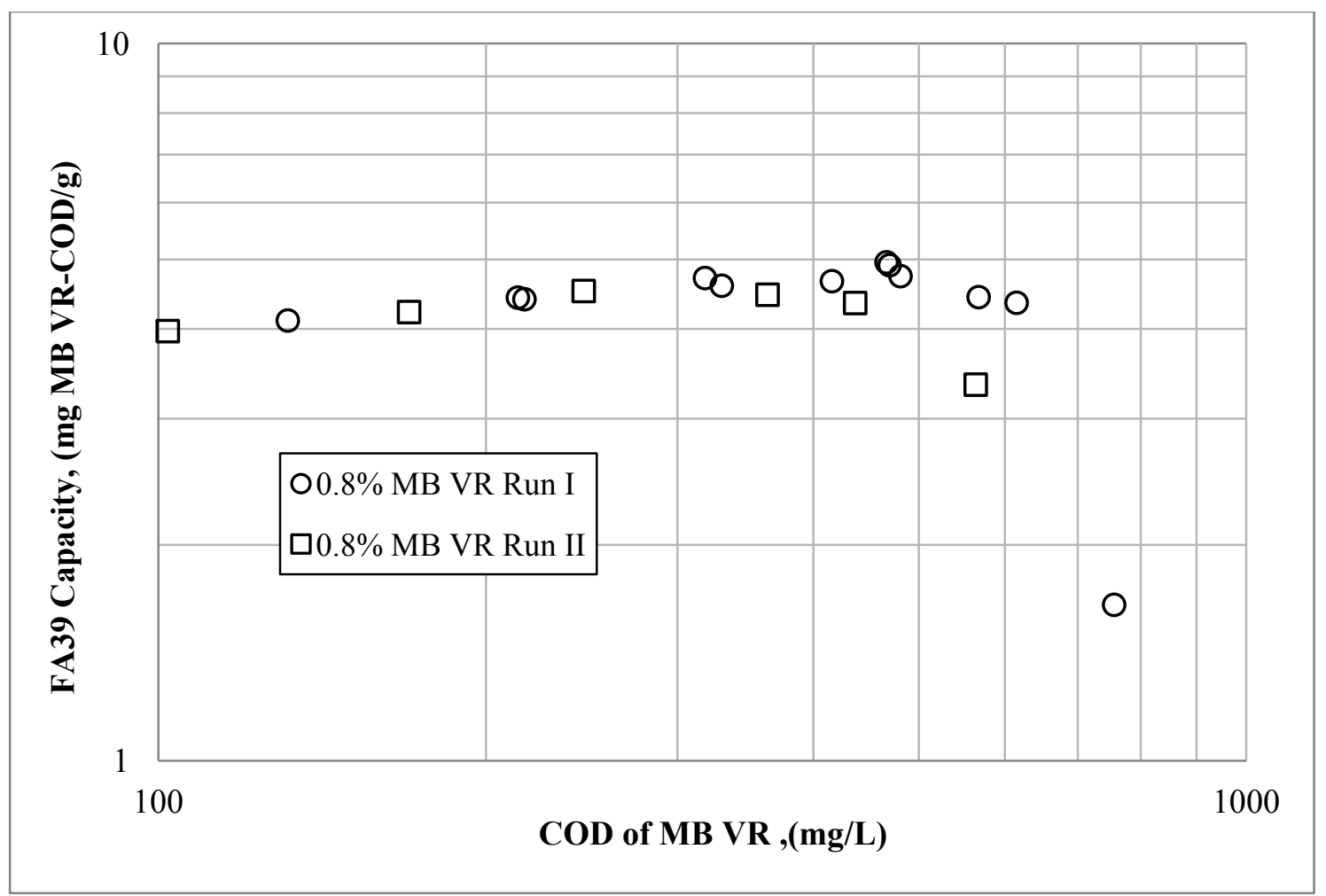

Figure 3.9 High carbon fly ash isotherm with $0.8 \%$ MB VR

Figure 3.10 illustrates the results of adsorption isotherms of the six AEAs with the high carbon fly ash as obtained from COD tests and the mass balance equation. However, it is difficult to directly relate these values to the concrete mix. In order for these isotherms to be usable in the concrete industry it is important to express the capacity and concentration of AEAs in more practical units. 


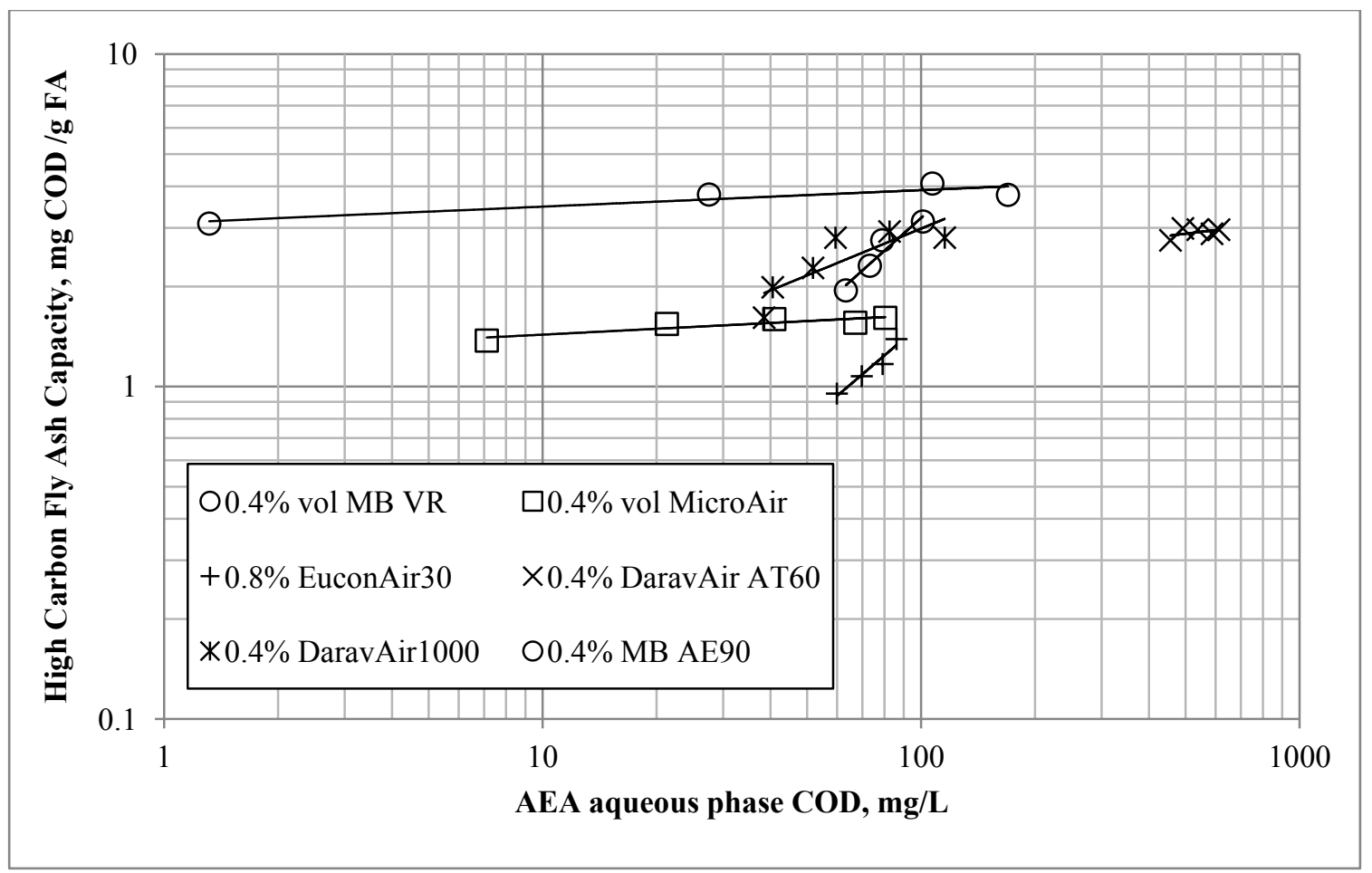

Figure 3.10 High carbon fly ash isotherm results with six AEAs

To convert the capacity from mg COD adsorbed/ $\mathrm{g}$ FA to ml AEA adsorbed/ g FA the capacity has to be divided by the values of COD per ml of AEA. This value can be obtained from the COD measurement of the initial AEA solution.

$\mathrm{q}_{F A}\left(\frac{\mathrm{ml}_{\mathrm{AEA}}}{\mathrm{g}_{\mathrm{FA}}}\right)=\mathrm{q}_{F A}\left(\frac{\mathrm{mg}_{\mathrm{COD}}}{\mathrm{g}_{\mathrm{FA}}}\right) \div$ Partitioning Coefficient $\div \frac{\mathrm{COD}_{\mathrm{iAEA}}}{\text { AEA conc. }}$ ....Equation 3.6

Where,

AEA conc. $=$ the initial concentration of the AEA, $\mathrm{ml} / \mathrm{L}$

To convert the AEA liquid phase COD to \%vol. of AEA in water the concentration should be divided by the partitioning coefficient and by the COD value of $1 \%$ vol. AEA of the AEA solution. 
AEA conc., $\%$ vol. $=\mathrm{COD}_{\mathrm{f}, \mathrm{aq}} \div\left[\right.$ Partitioning Coefficient $\left.\times \frac{\mathrm{COD}_{\mathrm{iAEA}}}{\mathrm{AEA} \text { conc. }}\right]$

....Equation 3.7

Where,

AEA conc. $=$ the initial concentration of the AEA, \% vol.

The values of high carbon fly ash capacity and AEA concentration units were converted using Equation 3.6 and Equation 3.7 and the resulting isotherms are illustrated in Figure 3.11. Figure 3.11 is presented in the final form of the isotherm and can be used to determine the amount of AEA adsorbed by the specific fly ash under the required AEA concentration. This capacity multiplied by the mass of fly ash used in the mixture provides the AEA dosage adjustment required to compensate for the AEA lost due to the adsorption capacity of the fly ash.

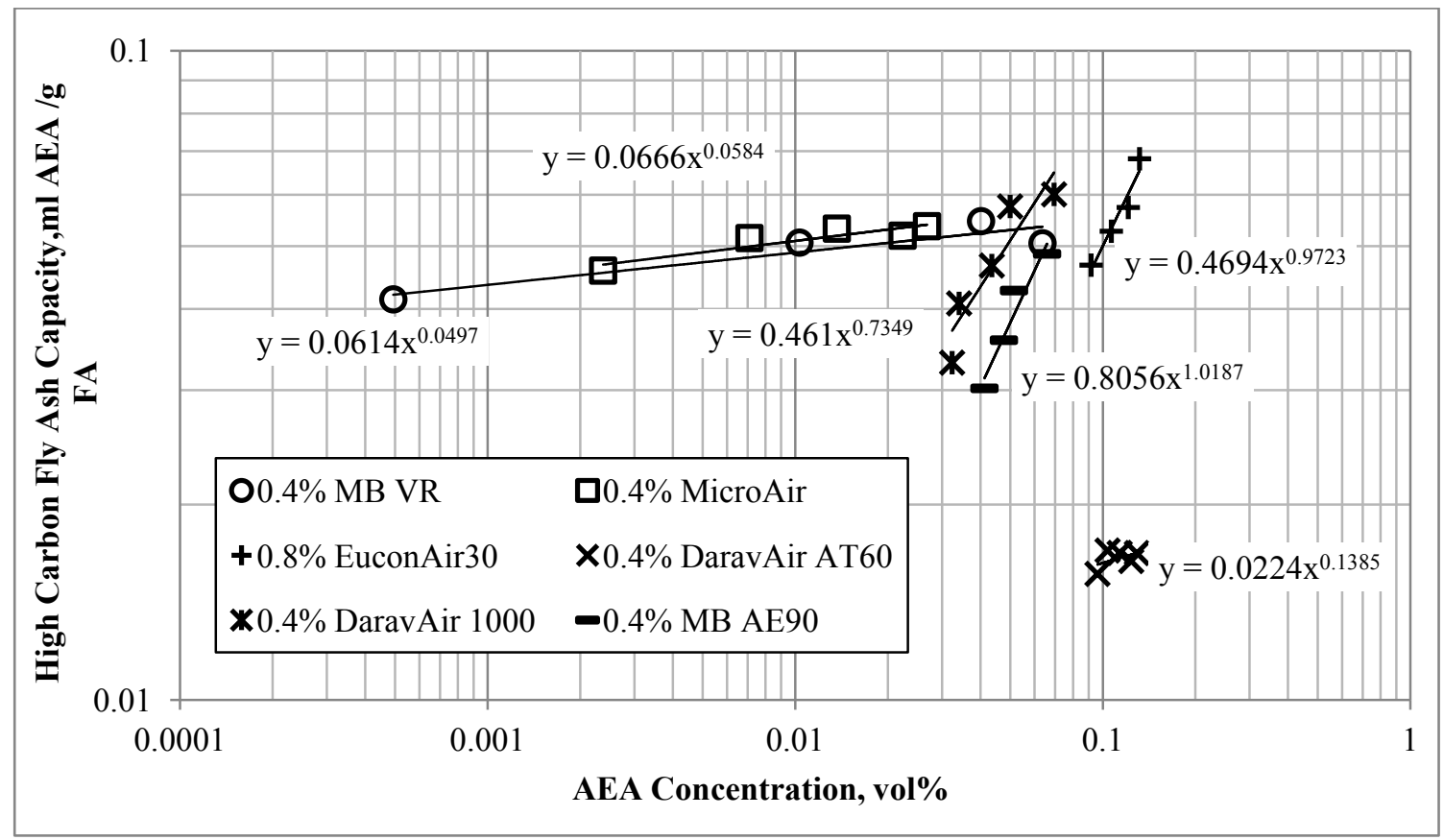

Figure 3.11 High carbon fly ash isotherm results with six AEAs. Capacity expressed as ml AEA per $\mathrm{g}$ fly ash and concentration as \%vol. in water 


\section{3-4 Conclusions}

Fly ash adsorption isotherms provide an accurate and much needed tool for the direct measurement of the adsorption capacity of fly ash and the amount of AEA adsorbed by fly ash. Fly ash adsorption isotherms provide a correlation between the fly ash capacity and the AEA concentration in water. Therefore, users can determine the capacity at the specific concentration of the AEA required for achieving the desired air void system. Consequently, the required dosage adjustment can be determined by multiplying the measured capacity by the mass of fly ash used in the mixture. This dosage adjustment is the volume of AEA required to compensate for the adsorption capacity of the fly ash. 


\section{4 - Combined Adsorption Isotherms for the Quantification of Air Entraining Admixtures Adsorption by Fly Ash in Concrete}

\section{4-1 Introduction}

The adsorption capacity measurement of fly ash for the purpose of characterization and specification can be accurately determined using the fly ash iodine number test (61). Although useful, this test utilizes iodine for measurement and therefore, it is unable to directly quantify the adsorption of AEAs by fly ash. The first AEA adsorption isotherm procedure for use with fly ash was presented in the previous chapter (62). These isotherms provide a direct measurement of the fly ash adsorption capacity, and enable users to determine the volume of AEAs adsorbed by the fly ash in a concrete mixture. Consequently, a dosage adjustment can be made to compensate for the AEA lost due to adsorption. The procedure requires performing two sets of isotherms. The first set is for the AEA and cement to determine the AEA partitioning coefficient, and the initial aqueous phase of the AEA that is available for adsorption by fly ash. The second set of isotherms is for the AEA with fly ash to determine the adsorption capacity based on the initial AEA aqueous concentration determined from the first set.

In this chapter a simplified and more accurate fly ash adsorption isotherm procedure is presented. The simplification resulted from the use of one set of combined cement-fly ash isotherms. The better accuracy results from the elimination of the need to make a judgment regarding the completion of the chemisorption process and the start of the adsorption process.

Instead of performing two separate isotherms for cement and fly ash, a mass of cement is added to all fly ash isotherm points to achieve full chemisorption. 
A blank sample of the AEA and cement is used to determine the initial concentration of AEA available for adsorption. This approach reduced the fly ash adsorption isotherm test procedure to one isotherm instead of two. This approach also provides a more robust form of testing since it eliminates the need to use judgment in determining the AEA partitioning coefficient from a multipoint cement isotherm. This section presents the test development and application using a vinsol resin admixture with eight fly ashes. The results obtained from these isotherms can be used to make AEA dosage adjustment predictions to compensate for fly ash adsorption.

\section{4-2 Materials and methods.}

\section{Fly ash and AEA}

Eight Class F, coal fly ashes, with LOIs ranging from $0.17 \%$ to $10.49 \%$ were used to develop these isotherms. Table 4.1 summarizes the properties of the fly ashes used in this study. MB VR, a vinsol resin AEA, manufactured by BASF (Master Builders) was utilized to develop the combined isotherm experimental procedure.

\section{Table 4.1}

Fly ash specimens and their properties, $\% \mathrm{wt}$

\begin{tabular}{|c|c|c|c|c|c|c|c|c|c|}
\hline Fly ash & $\mathbf{S i O}_{\mathbf{2}}$ & $\mathbf{A l}_{\mathbf{2}} \mathbf{O}_{\mathbf{3}}$ & $\mathbf{F e}_{\mathbf{2}} \mathbf{O}_{\mathbf{3}}$ & $\begin{array}{l}\mathbf{T o t a l}_{\mathbf{2}} \mathbf{S i O}_{\mathbf{2}}, \\
\mathbf{A l}_{\mathbf{2}} \mathbf{O}_{\mathbf{3}}, \mathbf{F e}_{\mathbf{2}} \mathbf{O}_{\mathbf{3}}\end{array}$ & $\mathbf{C a O}$ & $\mathbf{S O}_{\mathbf{3}}$ & $\mathbf{M g O}$ & Alkali & LOI \\
\hline $\mathbf{1}$ & 60.1 & 29.9 & 2.7 & 92.7 & 0.9 & NA & NA & 0.61 & 0.87 \\
\hline $\mathbf{7}$ & 53.94 & 27.66 & 8.29 & 89.89 & 1.45 & 0.08 & 1.15 & 0.64 & 2.25 \\
\hline $\mathbf{8}$ & 60.85 & 25.7 & 4.66 & 91.2 & 3.46 & 0.29 & 1.12 & 0.69 & 0.17 \\
\hline $\mathbf{1 0}$ & 45.95 & 23.61 & 22.31 & 91.88 & 1.28 & 0.77 & 0.99 & 0.77 & 1.26 \\
\hline $\mathbf{1 5}$ & 58.92 & 16.17 & 4.71 & 79.81 & 10.24 & 0.86 & 3.13 & 0.73 & 1.5 \\
\hline $\mathbf{2 0}$ & 44.81 & 23.08 & 9.51 & 77.4 & 13.58 & 0.96 & 2.97 & 0.89 & 0.39 \\
\hline $\mathbf{3 9}$ & 39.6 & 20 & 12.7 & 72.3 & 9.1 & 1.1 & 2.28 & NA & 10.49 \\
\hline $\mathbf{4 0}$ & 53.9 & 26.3 & 6.24 & 86.4 & 4 & 0.2 & 0.86 & NA & 3.35 \\
\hline
\end{tabular}




\section{Measurement of AEA concentration}

The chemical oxygen demand test (COD) was used to measure the concentration of the AEA. A HACH COD kit (TNT821 and TNT 822) along with HACH spectrophotometer DR5000 were utilized for this purpose.

\section{Isotherm points setup}

All isotherm points were performed in a $250 \mathrm{ml}$ Erlenmeyer flask. For each isotherm point, a volume of $200 \mathrm{ml}$ of the solution (water, AEA), was equilibrated with the adsorbent (cement, fly ash) for one hour at $20{ }^{\circ} \mathrm{C}$. The contents of the flask were mixed using a magnetic stirrer. After equilibration, the mixture was filtered using grade $1,11 \mu \mathrm{m}, 90 \mathrm{~mm}$ diameter, cellulose, Whatman qualitative filter paper in a vacuum apparatus. The volume of filtrate was measured using a graduated cylinder and the COD measurements of the filtrate were taken. The same procedure was followed for the cement blank samples prepared with the three AEA concentrations, and for the COD of solid materials (fly ash or cement) prepared with distilled water.

\section{Cement blanks}

At least two blanks with 20 grams of cement and no fly ash were performed for each initial AEA concentration. The goal of these blanks was to quantify the chemisorption demand and to determine the AEA aqueous phase concentration left in solution after chemisorption. This AEA aqueous phase concentration is considered the initial AEA concentration available for adsorption.

\section{COD of solid materials}

Cement as well as fly ash may contribute to the COD values of the isotherm points. To determine the background COD caused by the presence of cement 
and fly ash, the same mass of fly ash or cement used in the cement blank or the isotherm point was equilibrated with distilled water for one hour as in any other isotherm point. The measured filtrate COD represents the background COD released by the solid materials. This background COD was subtracted from the COD value of any AEA solution wherever fly ash and/or cement were present, to obtain the net AEA COD (i.e. concentration).

\section{Fly ash isotherm points}

Three different AEA concentrations were used to generate a three point isotherm. For each concentration, at least two fly ash isotherm points, prepared with $20 \mathrm{~g}$ of cement and $40 \mathrm{~g}$ of fly ash, were used to determine the change in AEA concentration due to adsorption by the fly ash. If adsorption by fly ash occurs, the AEA concentration of the fly ash isotherm point filtrate will be less than the AEA concentration of the cement blank filtrate. If the AEA concentration of the fly ash isotherm point drops near to the lower detection limit of the COD test, the isotherm point must be repeated using less mass of fly ash.

\section{4-3 Results and discussions}

This method is based on providing enough mass of cement to chemisorb all the chemisorbable portion of the AEA solution in every isotherm point. A blank of every AEA solution concentration utilized is required to determine the AEA aqueous phase concentration after chemisorption at that specific AEA solution concentration. Any reduction of the AEA aqueous phase concentration in any fly ash-cement isotherm point, below the blank concentration, is then considered loss due to adsorption by that mass of fly ash. 


\section{Test development and optimization}

\section{AEA Solution Concentrations}

Due to the relatively low adsorption capacity of fly ash, it is sometimes impossible to obtain a good representative isotherm by using only one initial AEA concentration. Therefore, this combined isotherm procedure requires the utilization of three different AEA concentrations in order to obtain an isotherm that represents a wide range of practical AEA concentrations. It is recommended to use the average practical AEA concentration used by the concrete industry for the first set of isotherms, then to use $50 \%$ of that for the second set and $200 \%$ for the third set of isotherms. This will produce a three point isotherm that covers all the possible practical concentrations.

\section{Mass of cement in isotherm points}

It was shown that for all AEAs tested, a few grams of cement were enough to achieve full chemisorption and bring the AEA aqueous phase concentration to a constant level (62). Fly ash adsorption isotherms with 10, 20, and 30 grams of cement combined with various masses of fly ash were performed to determine the appropriate mass of cement that can fulfill the chemisorption requirements of cement-fly ash isotherm points.

The results of these combined isotherms are illustrated in Figure 4.1. MB VR at a concentration of $0.8 \% \mathrm{vol}$, which is a relatively high concentration, was utilized in this set of isotherms to confirm the mass of cement utilized can achieve full chemisorption at high AEA concentrations. The three masses of cement exhibited the same behavior and produced identical results within the experimental error of the COD test at this AEA concentration, which confirms the findings of Ahmed et. al. (62) However, as a conservative measure, 20 
grams of cement was chosen to be the standard amount of cement added to each isotherm point to ensure the availability of at least twice the amount of cement needed to achieve full chemisorption. Twenty grams of cement was used with all remaining isotherms in this study.

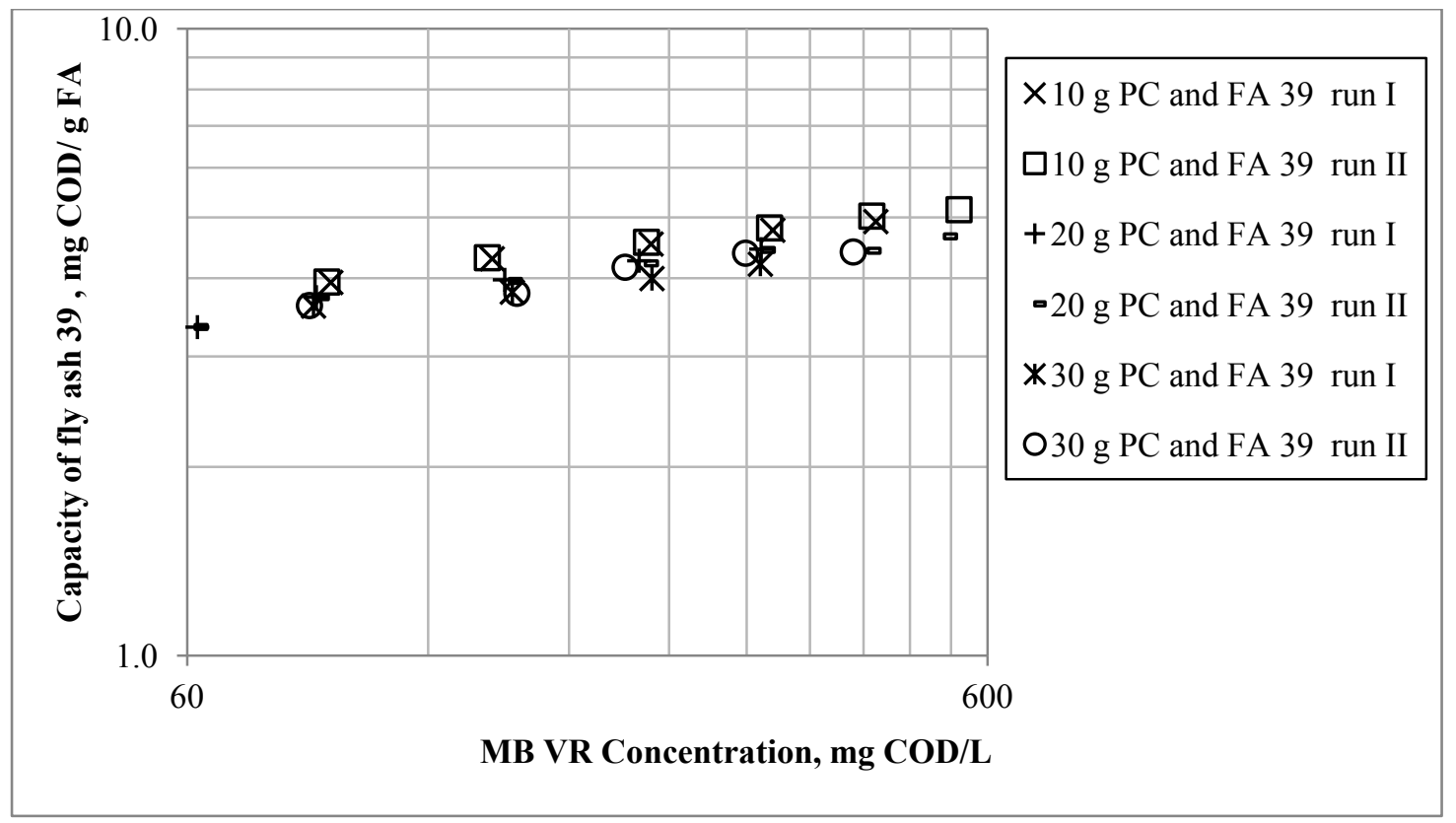

Figure 4.1 Combination isotherm results of $0.8 \% \mathrm{MB}$ VR, fly ash 39 , and various masses of portland cement

\section{Mass of fly ash}

The mass of fly ash in any isotherm point has to be large enough to adsorb some of the AEA and produce a measurable reduction in the AEA aqueous phase concentration. Also fly ash absorbs water and even though this absorbed water is considered in the calculations, it is important to minimize the water volume change to minimize the consequent impact on the AEA concentration. A fly ash mass of $10-40 \mathrm{~g}$ was found to be sufficient to produce measurable change in the aqueous AEA concentrations. An adequate mass of fly ash is 
dependent on two factors, the carbon content of the fly ash and the concentration of the AEA solution. For example, $40 \mathrm{~g}$ of fly ash $20(0.39 \%$ LOI) is enough to produce a change in MB VR solution concentrations of $2 \%$, $4 \%$, and $8 \%$ vol. without reducing the MB VR concentration to near the COD test lower detection limit. On the other hand, $40 \mathrm{~g}$ of fly ash 40 (3.35\% LOI) will reduce the $0.2 \% \mathrm{MB}$ VR concentration near the lower detection limit of the COD test and therefore, $20 \mathrm{~g}$ should be used with this concentration and $40 \mathrm{~g}$ can be used with $0.4 \%$ and $0.8 \%$ vol. MB VR concentrations. For high carbon fly ash such as fly ash $39(10.49 \%$ LOI $), 5 \mathrm{~g}$ should be used with the $2 \%, 10 \mathrm{~g}$ with the $4 \%$ and $20 \mathrm{~g}$ can be used with the $0.8 \%$ vol. MB VR concentration. In general, if the equilibrated concentration of the AEA drops to near the lower detection limits of the COD test, the isotherm point should be repeated using less mass of fly ash.

\section{Combination isotherm calculations}

The amount of AEA available for adsorption, for each initial AEA concentration, can be determined from the cement blanks using Equation 4.1.

$$
\mathrm{COD}_{\text {available, } \mathrm{i}}=\mathrm{COD}_{\text {blank }, \mathrm{i}} \times \mathrm{V}_{\text {fblank, } \mathrm{i}}-\mathrm{COD}_{\text {s cement }} \times \mathrm{M}_{\text {cement }}
$$

Where,

COD available, $i=$ Available mass of AEA for adsorption for the $i^{\text {th }}$ initial concentration. mg COD

COD blank, $\mathrm{i}=\mathrm{COD}$ of the cement blank for the $\mathrm{i}^{\text {th }}$ initial concentration, $\mathrm{mg} / \mathrm{L}$

$\mathrm{V}_{\mathrm{f} \text { blank, } \mathrm{i}}=$ Volume of the filtrate of the cement blank for the $\mathrm{i}^{\text {th }}$ initial concentration, $\mathrm{L}$

$\mathrm{COD}_{\mathrm{s} \text { cement }}=\mathrm{COD}$ released by cement in water, $\mathrm{mg}(\mathrm{COD}) / \mathrm{g}$ cement.

$\mathrm{M}_{\text {cement }}=$ Mass of the cement used in the blank, $\mathrm{g}$ 
The COD released by cement in water can be determined by equilibrating 20 grams of cement with $200 \mathrm{ml}$ of distilled water, this produces COD cement, then $\mathrm{COD}_{\mathrm{s} \text { cement }}$ can be determined using equation 4.2. The same method is applied to determine the COD released into solution by the fly ash ( $\left.\mathrm{COD}_{\mathrm{s} \text { FA }}\right)$.

$$
\mathrm{COD}_{\text {s cement }}\left(\frac{\mathrm{mg}}{\mathrm{g}}\right)=\mathrm{COD}_{\text {cement }}\left(\frac{\mathrm{mg}}{\mathrm{L}}\right) \times 200(\mathrm{ml}) \div 20(\mathrm{~g})
$$

For each fly ash isotherm point, the remaining mass of AEA in solution after equilibration with cement and fly ash can be determined from Equation 4.3.

$$
\mathrm{COD}_{\text {final, } \mathrm{i}}=\mathrm{COD}_{\text {eq } \mathrm{i}} \times \mathrm{V}_{\mathrm{f}, \mathrm{i}}-\mathrm{COD}_{\mathrm{sFA}} \times \mathrm{M}_{\mathrm{FA}}-\mathrm{COD}_{\text {s cement }} \times \mathrm{M}_{\text {cement }}
$$

Where,

$\mathrm{COD}_{\text {final, } \mathrm{i}}=$ Mass of AEA COD remaining in solution after equilibration with cement and fly ash, mg

$\mathrm{COD}_{\text {eq, } \mathrm{i}}=\mathrm{COD}$ of the equilibrated isotherm point, $\mathrm{mg} / \mathrm{L}$

$\mathrm{V}_{\mathrm{f}, \mathrm{I}} \quad=$ Volume of equilibrated isotherm point filtrate, $\mathrm{L}$

$\mathrm{COD}_{\mathrm{s} \mathrm{FA}}=\mathrm{COD}$ released into solution by the fly ash, $\mathrm{mg} / \mathrm{g}$

$\mathrm{M}_{\mathrm{FA}} \quad=$ Mass of fly ash used in the isotherm point, $\mathrm{g}$

The capacity at each fly ash isotherm point can be determined from Equation 4.4 .

$$
\mathrm{q}_{\mathrm{FA}, \mathrm{i}}=\left(\mathrm{COD}_{\text {available, } \mathrm{i}}-\mathrm{COD}_{\text {final, } \mathrm{i}}\right) / \mathrm{M}_{\mathrm{FA}}
$$

Where,

$\mathrm{q}_{\mathrm{FA}, \mathrm{i}}=$ The fly ash capacity for the isotherm point, $\mathrm{mg}$ (COD)/g (FA)

The partitioning coefficient for each initial concentration can be determined from the COD of the blank and the COD of the AEA solution using Equation 4.5 .

Partioning Coefficient ${ }_{\mathrm{i}}\left(\mathrm{PC}_{\mathrm{i}}\right)=\frac{\mathrm{COD}_{\text {blank } \mathrm{i}}-\mathrm{COD}_{\text {Cement }}}{\mathrm{COD}_{\mathrm{AEA}, \mathrm{i}}} \ldots \ldots \ldots . .$. Equation 4.5 
Where,

$\mathrm{COD}_{\mathrm{AEAi}}=$ The COD of the AEA solution for the $\mathrm{i}^{\text {th }}$ initial concentration, $\mathrm{mg} / \mathrm{L}$

$\mathrm{COD}_{\text {cement }}=$ The COD of $20 \mathrm{~g}$ cement in $200 \mathrm{ml}$ distilled water. $\mathrm{mg} / \mathrm{L}$

Equation 4.6 can be used to convert the capacity form $\mathrm{mg} \mathrm{COD/g} \mathrm{FA} \mathrm{to} \mathrm{ml}$ AEA/ g FA. The conversion factor can be obtained from the COD measurement of the AEA solution (62).

$$
\mathrm{q}_{F A i}\left(\frac{\mathrm{ml}_{\mathrm{AEA}}}{\mathrm{g}_{\mathrm{FA}}}\right)=\mathrm{q}_{F A i}\left(\frac{\mathrm{mg}_{\mathrm{COD}}}{\mathrm{g}_{\mathrm{FA}}}\right) \div\left[\mathrm{PC}_{i} \times \frac{\mathrm{COD}_{\mathrm{AEAi}}}{\mathrm{AEAi}^{\text {th }} \text { conc. }}\right]
$$

Where,

$A E A i^{\text {th }}$ conc. $=$ the $i^{\text {th }}$ initial concentration of the AEA, ml/L

The AEA aqueous phase concentration, represented as \% vol. in water, can be obtained from Equation 4.7 in which the $i^{\text {th }}$ initial concentration of the AEA is represented as \% vol. $(62 ; 61)$.

AEA conc., \% vol. $=\left(\mathrm{COD}_{\text {eq, } \mathrm{i}}-\mathrm{COD}_{\text {cement }}-\mathrm{COD}_{F A}\right) \div\left[\mathrm{PC}_{i} \times \frac{\mathrm{COD}_{A E A, i}}{\mathrm{AEA} \mathrm{it}^{\text {th }} \text { conc. }}\right]$

Equation 4.7

Where,

AEA $i^{\text {th }}$ conc. $=$ The $i^{\text {th }}$ initial concentration of the AEA, $\%$ vol.

$\mathrm{COD}_{\mathrm{FA}} \quad=$ The COD of the fly ash used in the isotherm point in $200 \mathrm{ml}$ distilled water, $\mathrm{mg} / \mathrm{L}$ 


\section{Combined Cement and Fly Ash Isotherm Results Analysis}

The adsorption isotherm can be obtained by plotting the fly ash capacity of all isotherm points versus their corresponding final equilibrated aqueous phase AEA concentration on a log-log scale, as shown in Figure 4.2. A power line data fit produces a Freundlich equation (Equation 4.8) that describes the equilibrium partitioning between the AEA solid phase concentration (capacity of fly ash) and the AEA aqueous phase concentration (56).

$$
\mathrm{q}=\mathrm{K} \times \mathrm{C}^{1 / n}
$$

Where:

$\mathrm{K}=$ Freundlich capacity parameter, $\frac{\mathrm{ml}}{\mathrm{g}} \times\left(\frac{1}{\% \mathrm{vol}}\right)^{1 / \mathrm{n}}$

$1 / n=$ Freundlich intensity parameter, unitless

The Freundlich equation as well as the graph by itself can be used to determine the capacity at any AEA concentration. This isotherm procedure was adopted as the final procedure and was used for the rest of this research. This procedure was conducted on MB VR with eight different fly ashes. The results are illustrated in Figure 4.2. 


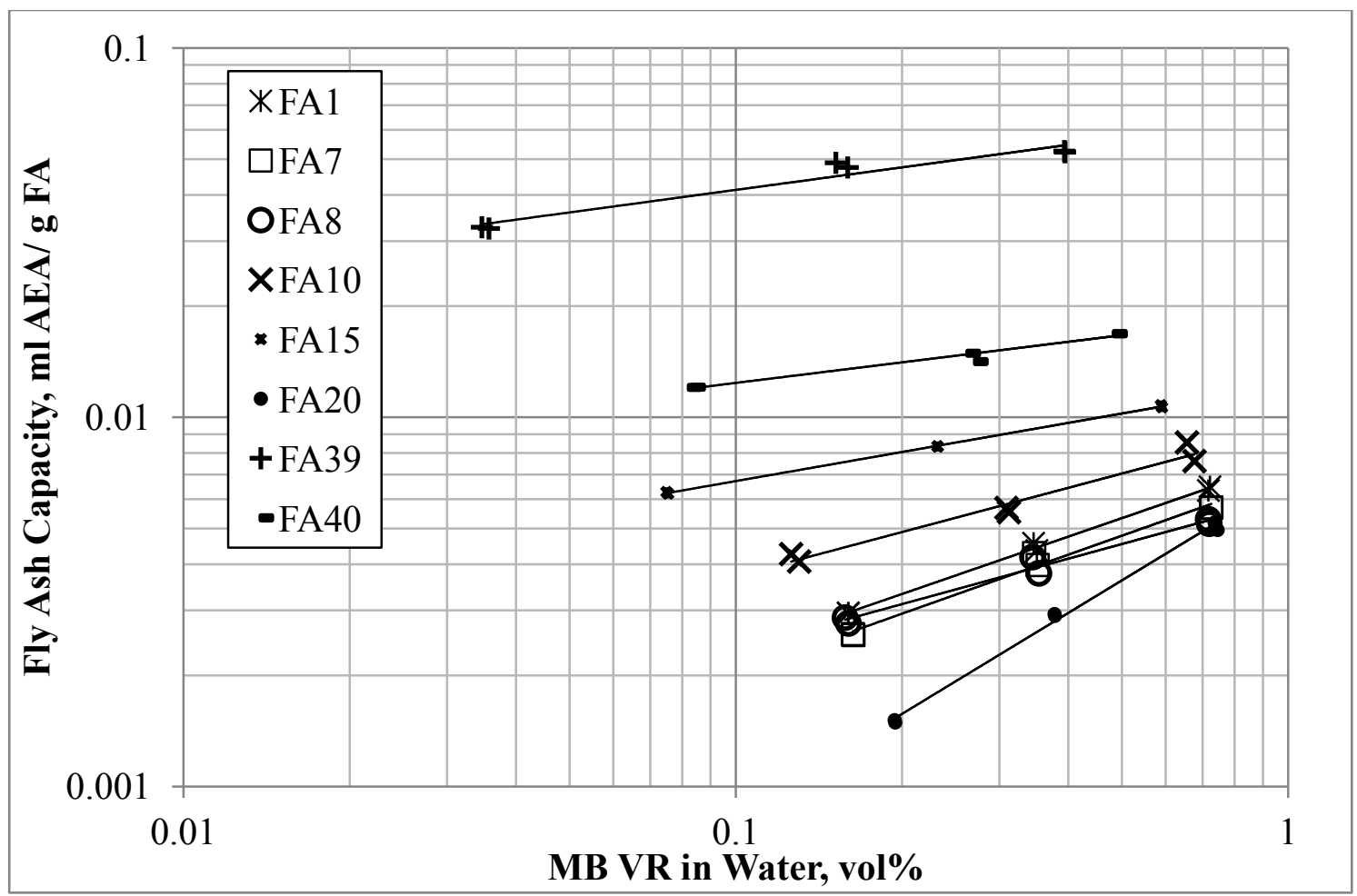

Figure 4.2 Combined adsorption isotherms for MB-VR with eight fly ashes

\section{Adsorption Isotherms Utilization and AEA Dosage Adjustment}

The isotherm results presented in Figure 4.2 provide a precise quantification of the amount of AEA adsorbed by the fly ash as a function of the AEA concentration. To determine the fly ash adsorption capacity specific to the mix condition, an isotherm has to be developed for the specific fly ash and the specific AEA used in the concrete mix. AEA dosages are often specified in terms of volume AEA/100 kg of cement used in the mix. To determine the AEA solution concentration, the volume of AEA used has to be divided by the volume of water used in the base concrete mix. The fly ash capacity at this concentration can be determined from the isotherm graph. For example, the adsorption capacity of FA40 for MB-VR at a concentration of $0.5 \%$ vol. $\mathrm{AEA} /$ water is $0.017 \mathrm{ml} \mathrm{AEA} / \mathrm{g}$ FA. This capacity multiplied by the total mass 
of fly ash used in the mix results in the volume of MB-VR adsorbed by FA40 at this concentration. This volume of AEA is the estimated amount should be added to the initial dosage of AEA to compensate for the adsorption of MB-VR by FA40.

\section{Effect of Temperature on Fly Ash Adsorption Capacity}

Adsorption isotherm tests were conducted at various temperatures to assess the effect of temperature on the adsorption capacity of fly ash. MB VR was tested with $\mathrm{FA} 39$ at $5^{\circ} \mathrm{C}, 20^{\circ} \mathrm{C}, 30^{\circ} \mathrm{C}$, and $40^{\circ} \mathrm{C}$, and the results of these isotherms are presented in Figure 4.3. The results show there is no significant effect of temperature on the adsorption capacity of AEA by fly ash on the temperature range examined. In conventional activated carbon applications, multilayer adsorption, as well as adsorbate condensation, takes place at the surface of the strong adsorbents and also inside the pores where the adsorption potential is extremely high. For activated carbon, the limiting factor for adsorption becomes the solubility limit of the solute since the solute is present in its pure form at the high adsorption potential sites. The solubility limit is very sensitive to temperature and therefore, temperature affects the capacity of activated carbon significantly. Fly ash carbon has very low micro pore volume (16) and it possesses very low adsorption capacity because it is not activated. In addition, AEA molecules are very large and the adsorption is most likely characterized by mono layer coverage. Therefore, the solubility limit is not an issue for fly ash and fly ash capacity is not sensitive to temperature. 


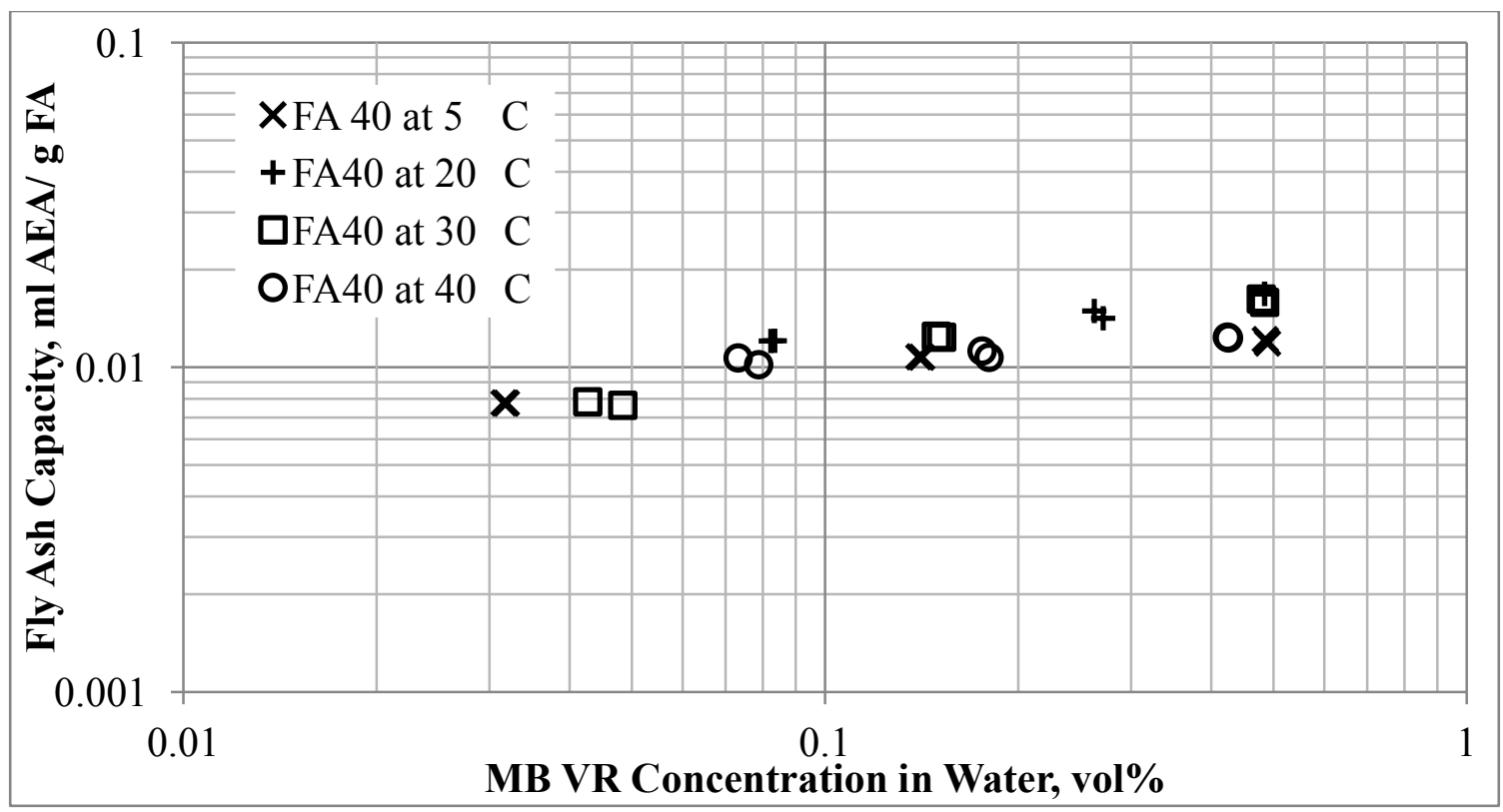

Figure 4.3 The effect of temperature on the adsorption capacity of fly ash

\section{Results Verification}

The combined direct fly ash and cement adsorption isotherm results presented in Figure 4.2 were utilized to determine the dosage adjustments for cement mortars and concrete with 25\% fly ash replacement. All adjusted dosages succeeded in achieving the target air content, and in most cases the adjusted dosages were lower than the adjusted dosages determined using the conventional trial mix approach. A detailed results verification study is presented in Sutter et. al. (55) .

\section{4-4 Conclusions and recommendations}

The newly developed combined adsorption isotherm test provides an accurate and direct measurement of the adsorption capacity of AEAs onto fly ash. This test can be performed in a laboratory that has the capability of measuring COD. The results obtained from this test quantify the adsorption 
capacity of fly ash, which in turn can be used to determine the adjustment of AEA dosage needed to compensate for the adsorbed portion of the AEA. This amount is the dosage adjustment that needs to be added to the base AEA dose to achieve the desired air content in concrete. It is recommended this test be performed on the specific combination of fly ash and AEA utilized in the mixture. This approach provides a product specific dosage that is direct and accurate. 


\section{5 - Summary and conclusions}

\section{5-1 LOI Correlation to the Adsorption Tests}

The correlation between LOI and the fly ash iodine number test, the foam index test, and the fly ash capacity measured by the direct adsorption isotherms for 8 fly ashes is presented in Figure 5.1. The fly ash capacities measured using the direct adsorption isotherms were taken at an AEA concentration of $0.4 \%$ vol.

For all three adsorption testing methods, Figure 5.1 shows that adsorption capacity somewhat correlates to LOI especially at higher LOI values. However, the figure also shows that LOI does not provide a good correlation to adsorption capacity of fly ash at low LOI values. This is obvious in the case of FA15 and FA7. All three adsorption tests showed that FA7 has less adsorption capacity than FA15 in contrary to what LOI suggests since FA7 has LOI of 2.25 and FA15 has LOI of 1.5\%. Similar results are true for FA8 and FA20 where FA8 has more capacity than FA20, as foam index, fly ash iodine number, and adsorption isotherms showed, although FA20 has higher LOI. This agrees with the findings of Brown and Dykstra (42) which reported that depending on the composition of fly ash, use of LOI to measure the carbon content can be as accurate as $99 \%$ or can have up to $75 \%$ error between carbon content and LOI. Based on these results the researchers suggest that LOI is not a reliable test for low carbon fly ash because the non-carbon mass loss might be significant. However, LOI provides a good indication for high carbon fly ashes because the loss in mass due to burning carbon is overwhelmingly higher than the mass loss by other mechanisms. 
Powdered activated carbon (PAC) has increasingly been used to treat the stack emissions in power plants for pollution control. PAC can cause a small increase in LOI, as only small amounts of PAC are needed, and a high increase in the adsorption capacity. In this case, although the LOI test may be able to represent the carbon content, it should not be used as an indication of the fly ash adsorption capacity, because for the LOI test a gram of non-activated, low adsorption capacity fly ash carbon is the same as a gram of high adsorption capacity PAC. However, this huge difference in adsorption capacity can be reflected in the foam index test and can be accurately quantified by using the iodine number test and the direct adsorption isotherms.

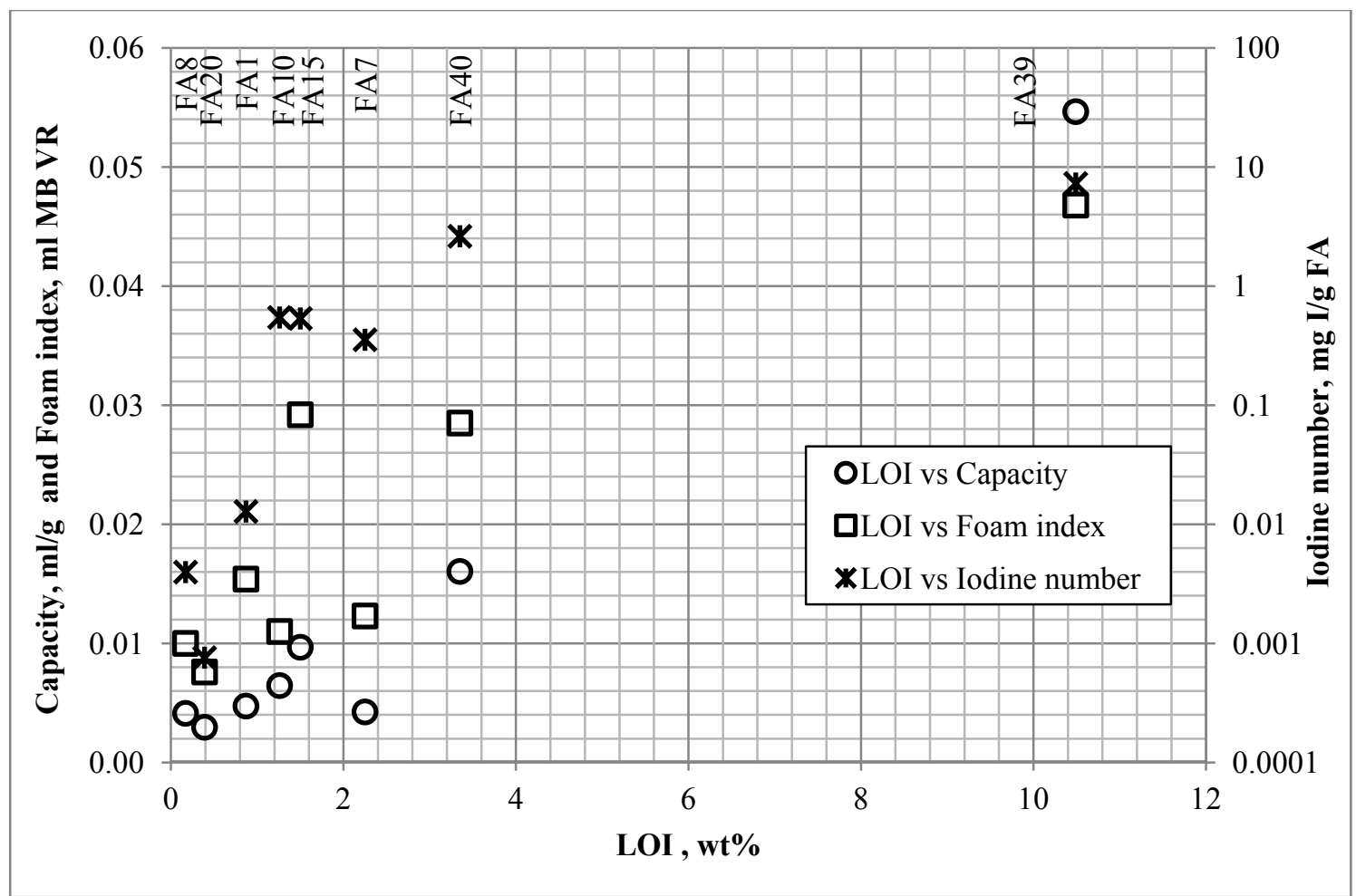

Figure 5.1 LOI correlation to fly ash iodine number, foam index, and fly ash capacity measured using the direct adsorption isotherms. 


\section{5-2 Correlation among the adsorption capacity tests}

The relationship between the direct adsorption isotherms, the fly ash iodine numbers and the foam index results of the eight fly ash specimens is illustrated in Figure 5.2. The results showed that although it is conceptually different, foam index test results showed a clear trend following fly ash iodine number and correlated to the capacity measured using the direct adsorption isotherms.

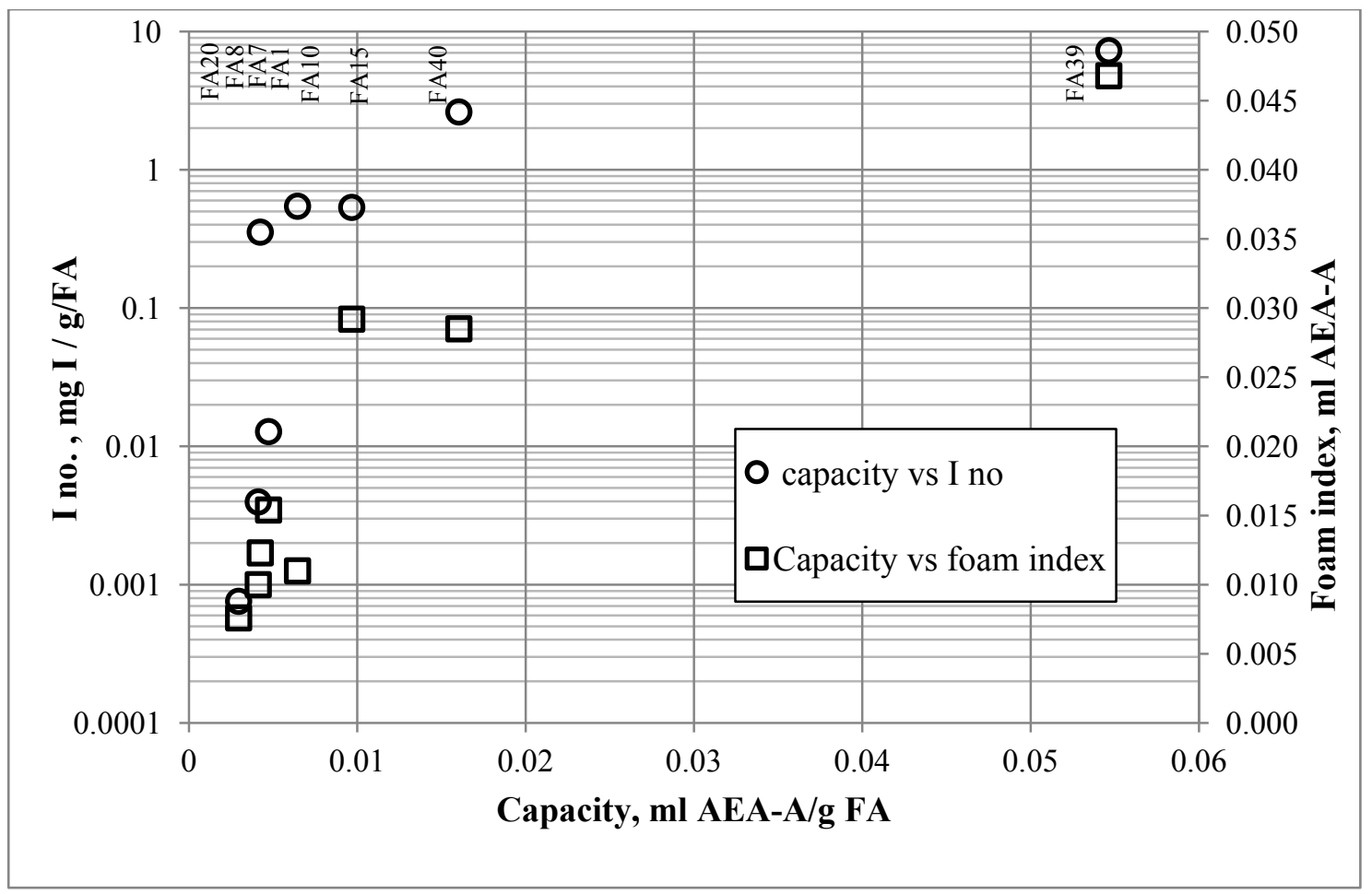

Figure 5.2 The relationship between the fly ash iodine number, the foam index, and the capacity of fly ash at $0.4 \%$ vol. MB VR concentration measured using direct adsorption isotherms 


\section{The foam index and the fly ash capacity}

The foam index test is fundamentally different from the iodine and AEA isotherm methodologies. For the isotherms, fly ash is equilibrated with a higher concentration of solute and the fly ash will adsorb the solute reducing the iodine or AEA aqueous phase concentration. In foam index test the system starts with no AEA, and AEA is introduced in an incremental manner consequently the AEA concentration increases until stable foam is formed. In addition, the foam index test is dynamic and if the system was left to equilibrate the foam may disappear because adsorption is still taking place. On the other hand, isotherms are based on equilibrium or near equilibrium where no significant change in the concentration takes place.

The foam index test provides better representation of the adsorption capacity of fly ash than LOI, especially in its improved form where the total time of the test is considered (63). The fly ash iodine number, however, followed the capacity trend better than the fly ash foam index. This can be seen in the case of FA10 and FA40, where unlike the fly ash iodine number, the foam index decreased although the capacity increased. In addition, the grouping of the fly ash iodine number test looks to be better than the foam index test which can be attributed to the low resolution and the subjective nature of foam index test.

\section{The fly ash iodine number and the fly ash capacity}

Although both are isotherms, the direct adsorption isotherm is different from the fly ash iodine number because the former utilizes AEAs and the later utilizes iodine as adsorbate. Iodine is a single solute and has a much smaller molecular size than the complex organics that AEAs are composed of, therefore they have different adsorbability. 
The direct adsorption isotherm is the only direct measurement for the adsorption of AEAs by fly ash, and the only method to precisely determine the AEA dosage adjustment required to compensate for the adsorbed AEA. However, this test is technically more complicated than the fly ash iodine number, which can be performed in a simple field laboratory. In summary, the relationship between the fly ash iodine number and the adsorption capacity of an AEA presented in Figure 5.2, describes the relative adsorbability of that AEA to iodine. Having this graph developed for the AEA, the concrete producers can perform the simple fly ash iodine number on the fly ash of interest then use the iodine number value and the graph to determine the AEA adsorption capacity, which represent the AEA dosage adjustment needed to compensate for the adsorbed AEA.

The capacity of fly ash to any AEA is a function of the concentration of the AEA (64). The correlation between the fly ash iodine number and the AEA presented in Figure 5.2 was developed using the capacity of MB VR at a concentration of $0.4 \%$ volume. Therefore it is only useful if this AEA is used at this specific concentration. However, AEAs may be used in various concentrations, and in order to develop a useful graph, it is important to develop a graph that illustrates the correlation of fly ash iodine number to the various practical concentrations of the AEA utilized. Such a graph is presented for the vinsol resin admixture MB VR in Figure 5.3. A similar graph has to be developed for other AEAs to be able to predict the capacities of these AEAs using the fly ash iodine number. 


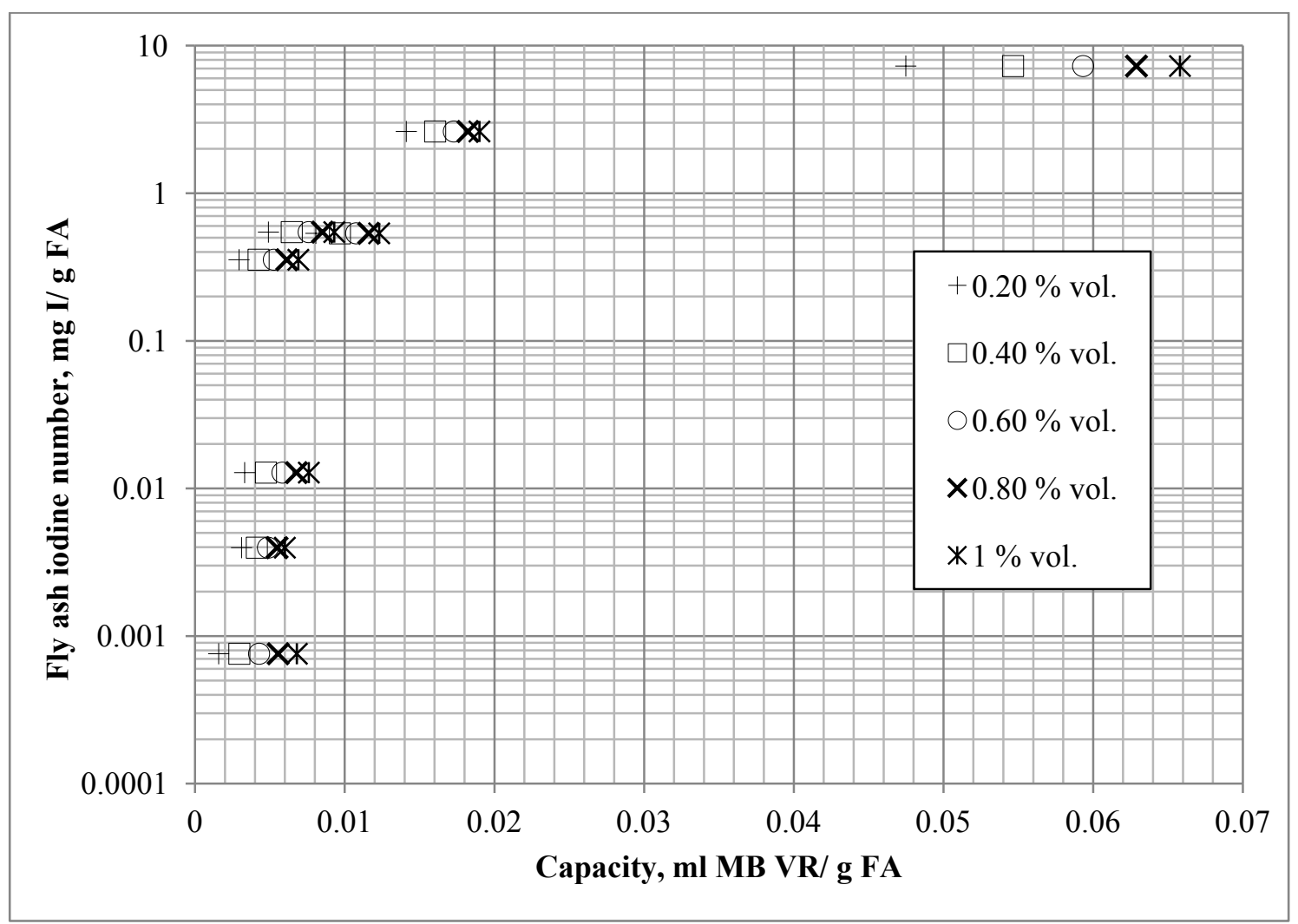

Figure 5.3 The correlation between the fly ash iodine number and various concentrations of the vinsol resin admixture MB VR 


\section{5-3 Conclusions}

The LOI test cannot be used for the quantification of the adsorption capacity of fly ash, especially when the fly ash contains PAC. The Foam index test provides a good indication of the adsorption capacity of fly ash. However, this test is subjective and is not very accurate because it is dynamic and not based on equilibrium.

Direct adsorption isotherms provided a very successful tool for the direct measurement of the adsorption capacity of AEAs onto fly ash. This method can be performed on the specific concrete mixture materials to determine the exact amount of AEA that will be adsorbed by the fly ash. This adsorbed amount is the quantity required to compensate for the adsorbed portion of the AEA and should be added to the initial base mix AEA dose.

Fly ash iodine number also provides a good tool for the quantification of the adsorption capacity of fly ash based on iodine adsorption. The fly ash iodine number can be used for classification of fly ash and determining whether the fly ash is suitable for the use in concrete. Furthermore, the fly ash iodine number can be correlated to the adsorption capacities of various AEAs and used directly to determine the AEA dosage adjustment required. 


\section{References}

1. Energy Information Adminstration (EIA), U.S. DOE, "International Energy Outlook 2011," www.eia.gov. [Cited: May 23, 2012.] http://www.eia.gov/forecasts/ieo/pdf/0484\%282011\%29.pdf.

2. Energy Information Adminstration (EIA), U.S. DOE, "Electricity Generatoin By Energy Source," www.eia.doe.gov. [Cited: May 22, 2012.] http://www.eia.gov/electricity/monthly/epm_table_grapher.cfm?t= epmt_1_1.

3. American Coal Ash Association, "2010 Coal Combustion Product (CCP) Production \& Use Survey Report," http://acaa.affiniscape.com. [Cited: July 16, 2012.] http://acaa.affiniscape.com/associations/8003/ files/19662010_FlyAsh_Prod_and_Use_Charts.pdf.

4. Pederson, K.H., Jensen, A.D., Skjøth-Rasmussen, M.S., and DamJohansen, K., "A review of the interference of carbon containing fly ash with air entrainment in concrete," Progress in Energy and Combustion Science, V. 34, 2008, pp. 135-154.

5. Clendenning, T.G. and Durie, N.D., "Properties and use of fly ash from a steam plant operating under variable load," Proceedings of the American Society for Testing Materials, V. 62, 1963, pp. 1019-1040.

6. Maroto-Valer, M., Taulbee, D., and Hower, J., "Characterization of differing forms of unburned carbon present in fly ash separated by density gradient centrifugation," Fuel, V. 80, 2001, 795-800.

7. Bouzoubaa, N., Zhang, M.H., and Malhotra, V. M., "Laborotary produced high volume fly ash belnded cement:compressive strength and resistance to 
the chloride ion penetration of concrete," Cement and Concrete Research, V. 30, No. 7, 2000, pp. 1037-1046.

8. Zhang, D. S., "Air entrainment in fresh concrete with PFA," Cement and Concrete Composites, V. 18, No. 6, 1996, pp. 409-416.

9. Gebler, S., and Klieger, P., "Effects of fly ash on the air-void stability of concrete," Proceedings of the Canmet/ADI First international conference on the use of fy ash, silica fume, slag and other mineral by-products in concrete, V. 1, 1983, pp. 103-142.

10. Veranth, J. M., Pershing, D.W., Sarofim, A.F., and Shield J.E., "Sources of unburned carbon in the fly ash produced from low-NOx pulverized coal combustion," Proceedings of the Combustion Institute, V. 27, 1998, pp. $1737-1744$.

11. Kuloats, I., Hurt, R. H., and Suuberg, E. M., "Size distribution of unburned carbon in coal fly ash and its implicatoins," Fuel, V. 83, No. 2, 2004, pp. 223-230.

12. Federal Highway Administration, United States Department of Transportation. "Fly Ash Facts for Highway Engineers," Fedral Highway Admistration. July 14, 2006. [Cited: November 19, 2009.] http://www.fhwa.dot.gov/PAVEMENT/recycling/fach01.cfm.

13. ASTM C618 08a. "Standard Specification for Coal Fly Ash and Raw or Calcined Natural Pozzolan for Use in Concrete," American Society for Testing Materials, 2008. 
14. AASHTO M295-05. "Coal Fly Ash and Raw or Calcined Natural Pozzolan for Use in Concrete," The American Association of Stale Highway and Transportation Officials, 2005.

15. Hill, R.L., Sarkar, S.L., Rathbone, F.R., and James C.H., "An Examination of Fly Ash Carbon and its Interaction with Air Entraining Agent," Cement and Concrete Research, V. 27, No. 2, 1997, pp. 193-204.

16. Hwang, J. Y., Sun, X., and Li, Z., "Unburned Carbon from Fly Ash for Mercury Adsorption: I. Separation and Characterization of Unburned Carbon," Journal of Minerals and Materials Characterization and Engineering, V.1, No.1 , 2002, pp. 39-60.

17. Brister, B.S., and Price, L.G., "New Mexico's Energy, Present and Future: Policy, Production, Economics, and the Environment," Second Annual Decision-Maker's Field Conference, New Mexico Bureau of Geology and Mineral Resources, May 2002, p. 84. http://geoinfo.nmt.edu/publications/decisionmakers/2002/dmfg2002_comp1 ete.pdf.

18. Manz, O.E.. "Coal fly ash: a retrospective and future look," Fuel, V. 78, No.2, 1999, pp. 133-136.

19. Dilmore, R. M., and Neufeld, R. D., "Autoclaved aerated concrete produced with low-NOx burner/selective catalytic reduction fly ash," Journal of Energy Engineering, V. 127, No. 2, 2001, pp. 37-50.

20. Rixom, R., and Mailvaganam, N., "Chemical Admixtures for Concrete, third edition," E \& FN SPON, 1999, pp.115-116. 
21. Nasvik, J., and Pistilli, M., "Are we placing too much air in our concrete?," Concrete Construction, V. 49, No. 2, 2004, pp. 51-55.

22. Du, J., and Folliard, K. J., "Mechanisms of air entrainment in concrete," Cement and Concrete Research, V. 35, 2005, pp. 1463-1471.

23. Bruere, G. M., "Air-entraining actions of anionic surfactants in Portland cement paste," Journal of Applied Chemistry and Biotechnology, V. 21 ,1971, pp. 61-64.

24. Bruere, G. M., "Air entrainment in cement and silical paste," Journal of the American Concrete Institute, V. 26, No. 9, May 1955, pp. 905-919.

25. Gao, Y.M., Shim, H.S., Hurt, R.H., and Suuberg E.M., "Effect of Carbon on Air Entrainment in Fly Ash Concrete. The Role of Soot and Carbon Black," Energy and Fuels, V. 11, 1997, pp. 457-462.

26. Freeman, E., Gao, Y.M., Hurt, R., and Suuberg, E., "Interaction of carboncontaining fly ash with commercial air-entraining admixtures for concrete," Fuel, V. 76, No. 8, 1997, pp. 761-765.

27. Yu, J., Külaots, I., Sabanegh, N., Gao, Y., Hurt, R.H., Suuberg, E.S., and Mehta, A., "Adsorptive and optical properties of fly ash from coal and petroleum coke co-firing," Energy and Fuel, V. 14, 2000, pp. 591-596.

28. Veranth, J. M., Fletcher, T.H., Pershing, D.W., and Sarofim, A.F., "Measurment of soot and char in pulverized coal fly ash," Fuel. V. 79, No. 9, 2000, pp. 1067-1075.

29. Hachmann, L., Burnett, A., Gao, Y.M., Hurt, R.H., and Suuberg, E.M., "Surfactant adsorptivity of solid products from pulverized-coal combustion 
under controlled conditions," Proceedings of the Combustion Institute, V. 27, 1998, pp. 2965-2971.

30. Gao,Y., Külaots, I., Chen, X., Suuberg, E.M., Hurt, R.H., and Veranth, J.M., "The effect of solid fuel type and combustion conditions on residual carbon properties and fly ash quality," Proceedings of the Combustion Institute, V. 29, 2002, pp. 475-483.

31. Chen, X., Farber, M., Gao, Y., Külaots, I., Suuberg, E.M., and Hurt, R.H., "Mechanisms of surfactant adsorption on non-polar, air-oxidized and ozonetreated carbon surfaces," Carbon, V. 41, No. 8, 2003, pp. 1489-1500.

32. Gao, Y, Külaots, I., Chen, X. Aggarwal, R., Mehta, A., Suuberg, E.M., and Hurt, R.H., "Ozonation for the chemical modification of carbon surfaces in fly ash," Fuel, V. 80, No. 5, 2001, pp. 765-768.

33. Hurt, R., Suuberg, E., Gao, Y.M., and Burnett, A., "Apparatus and method for deactivating carbon in fly ash," United States Patent No. 6136089 USA, October 2000.

34. Chen, X., Gao, Y., Hurt, R.H., Suuberg, E.M., and Mehta, A.K., "Ozone treatment of fly ash," United States Patent No. 6890507 USA, May 2005.

35. Baltrus, J. P., and LaCount, R. B., "Measurement of adsorption of air entraining admixture on fly ash in concrete and cement"' Cement and Concrete Research, V. 31, No. 5, 2001, pp. 819-824.

36. Kulaots, I., Hsu, A., Hurt, R.H., and Suuberg, E.M., "Adsorption of surfactants on unburned carbon in fly ash and development of a standardized foam index test," Cement and Concrete Research, V. 33, No. 12, 2003, pp. 2091-2099. 
37. Dobson, V. H., "Concrete admixtures," Van Nostrand Reinhold, New York ,1990. pp. 137-162.

38. Dhir, R. K., McCarthy, M.J., Limbachiya, M.C., ElSayad, H.I., and Zhang, D.S., "Pulverized fuel ash concrete: air entrainment and freeze/thaw durability," Magazine of Concrete Research, V. 51, No. 1, 1999, pp. 53-64.

39. ASTM C311-11b, Standard test methods for sampling and testing fly ash or natural pozzolans for use in Portland-cement concrete (C311-04)," American Society for Testing Materials, 2011.

40. Fan, M., and Brown, R. C., "Comparison of the loss-on-ignition and thermogravimetric analysis techniques in measuring unburned carbon in coal fly ash," Energy and Fuels, V. 15, No. 6, 2001, pp. 1414-1417.

41. Zhang, Y, Lu, Z., Maroto-Valer, M.M., Andrėsen, J.M., and Schobert, H.H., "Comparison of high-unburned-carbon fly ashes from different combustor types and their steam activated products," Energy and Fuels, V. 17, No. 2, 2003, pp. 369-377.

42. Brown, R. C., and Dykstra, J., "Systematic errors in the use of loss-onIgnition to measure unburned carbon in fly ash," Fuel, V. 74, No.4,1995, pp. 570-574.

43. Dobson, D.H., LaCount, R. B., and Kern, D.G., "Economical Treatment of High Carbon Fly Ash to Produce a Low Foam Index Product with Carbon Content Retained," Final Project Report, DOE project award no.DE-FC2698FT40028, Waynesburg College, Waynesburg, PA., 1999. 
44. Federal Highway Administration (FHWA), " Identifying Incompatible Combinations of Concrete Materials: Volume II-Test Protocol," Final Project Report, FHWA-HRT-06-080, August 2006.

45. Grace Construction Products, "The Foam Index Test:A Rapid Indicator of Relative AEA Demand," Tecnical Bulletin TB-0202, www.graceconstruction.com, (2006), [Cited: November 25, 2009.] http:/www.na.graceconstruction.com/custom/concrete/downloads/TB_0202 .pdf

46. Gurupira, T. Z., Ochsenbein, M.P., Stencel, J.M.,and Martinus, F., "Development of an Automated Foam Index Test," The proceedings of the 2005 World of Coal Ash (WOCA), Lexington, Kentucky, April 11-15,2005.

47. Harris, N. J., Hover, K.C., Folliard, K.J., and Tyler, L.M., "The Use of the Foam Index Test to Predict AEA Dosage in Concrete Containing Fly Ash: Part I-Evaluation of the State of Practice," Journal of ASTM International, V. 5, No. 7, 2008.

48. Külaots I., Gao,Y.M., Hurt, R.H., and Suuberg E.M., "Surface Characteristics of Unburned Caron on Fly Ash and their Influence on Foam Index Testing," Conference on Unburned Carbon on Utility Fly Ash, Pittsburgh, PA, 1998, pp. 53-54.

49. Külaots, I., Hsu, A., Hurt, R.H., and Suuberg, E.M., "Adsorption of Surfactants on Unburned Carbon in Fly Ash and Development of a Standardized Foam Index Test," Cement and Concrete Research, V. 33, No. 12, 2003, pp. 2091-2099. 
50. Meininger, C. R., "Use of Fly Ash in Concrete," Report of Recent NSGANMRCA Research Laboratory Studies, NSGA-NRMCA, 1980.

51. Stencel, J.M., Song, H., and Cangialosi, F., "Automated foam index test: Quantifying Air Entraining Agent Addition and Interactions with Fly AshCement Admixtures," Cement and Concrete Research, V. 39, 2009, pp. 362-370.

52. Zacarias, P., "Modified Foam Index For Class C Fly Ashes," Unpublished Test Proceedure, LaFarge Canada Inc., Montreal, Quebec, Canada, 2000.

53. ASTM D4607.94. "Standard Test Method for Determination of Iodine Number of Activated Carbon," American Society for Testing Materials, 1994.

54. Sontheimer, H., Crittenden, J.C., and Summers, R.S., "Activated Carbon for Water Treatment," DVGW-Forschungsstelle,Engler-Bunte-Institute, and Karlsruhe Universität, 1988, pp. 102-103.

55. Sutter L., et al., "Specifications and Protocols for Acceptance Tests of Fly Ash Used in Highway Concrete, NCHRP 18-13," Transportation Research Board of The National Academies, project final report under review.

56. Crittenden, J. C., Trussell, R.R., Hand, D.W., Howe, K.J., and Tchobanoglous, G. "MWH's Water Treatment Principles and Design," third edition, John Wiley and Sons,Inc. New York, 2012.

57. Freundlich, H., "šber die Adsorption in Lösungen," The Journal of Physical Chemistry A, V. 57, 1906, pp. 385-470. 
58. Andrew, D. E., Clesceri, L.S., Rice, E.W., and Greenberg, A.E., "Standard Methods for the Examination of Water and Wastewater," $21^{\text {st }}$ edition, $A P H A, A W W A, W E F, 2005$, pp. 4-58 to 4-60.

59. Nagi, M.A., Okamoto, P.A., Kozikowski, R.L., and Hover, K., "NCHRP Report 578: Evaluating Air-Entraining Admixtures for Highway Concrete," National Cooperative Highway Research Program, Transportation Research Board of the National Academies, Washington, D.C., 2007.

60. ASTM D3860-98, "Standard Practice for Determination of Adsorptive Capacity of Activated Carbon by Aqueous Phase Isotherm Technique," American Society for Testing Materials, 2003.

61. Ahmed, Z. T., Hand, D.W., Sutter, L.L., and Kueber, M.J., "Fly Ash Iodine Number For The Measurement of Fly Ash's Adsorption Capacity," Pending, 2012.

62. Ahmed, Z. T., Hand, D.W., Sutter, L.L., and Kueber, M.J., "Air Entraining Admixtures (AEAs) Partitioning and Adsorption by Fly Ash in Concrete," Pending, 2012.

63. Kueber, M J, Sutter, L.L., Hand, D.W., and Ahmed, Z.T., "The 15-Minute Foam Index Test for the Characterization and Specification of Coal Fly Ash," Pending, 2012.

64. Ahmed, Z. T., Hand, D.W., Sutter, L.L., and Kueber, M.J., "Combined Adsorption Isotherms for the Direct Quantification of Air Entraining Admixtures (AEAs) Adsorption by Fly Ash in Concrete," Pending, 2012. 


\section{Appendix A. Direct adsorption isotherms results for various AEAs}

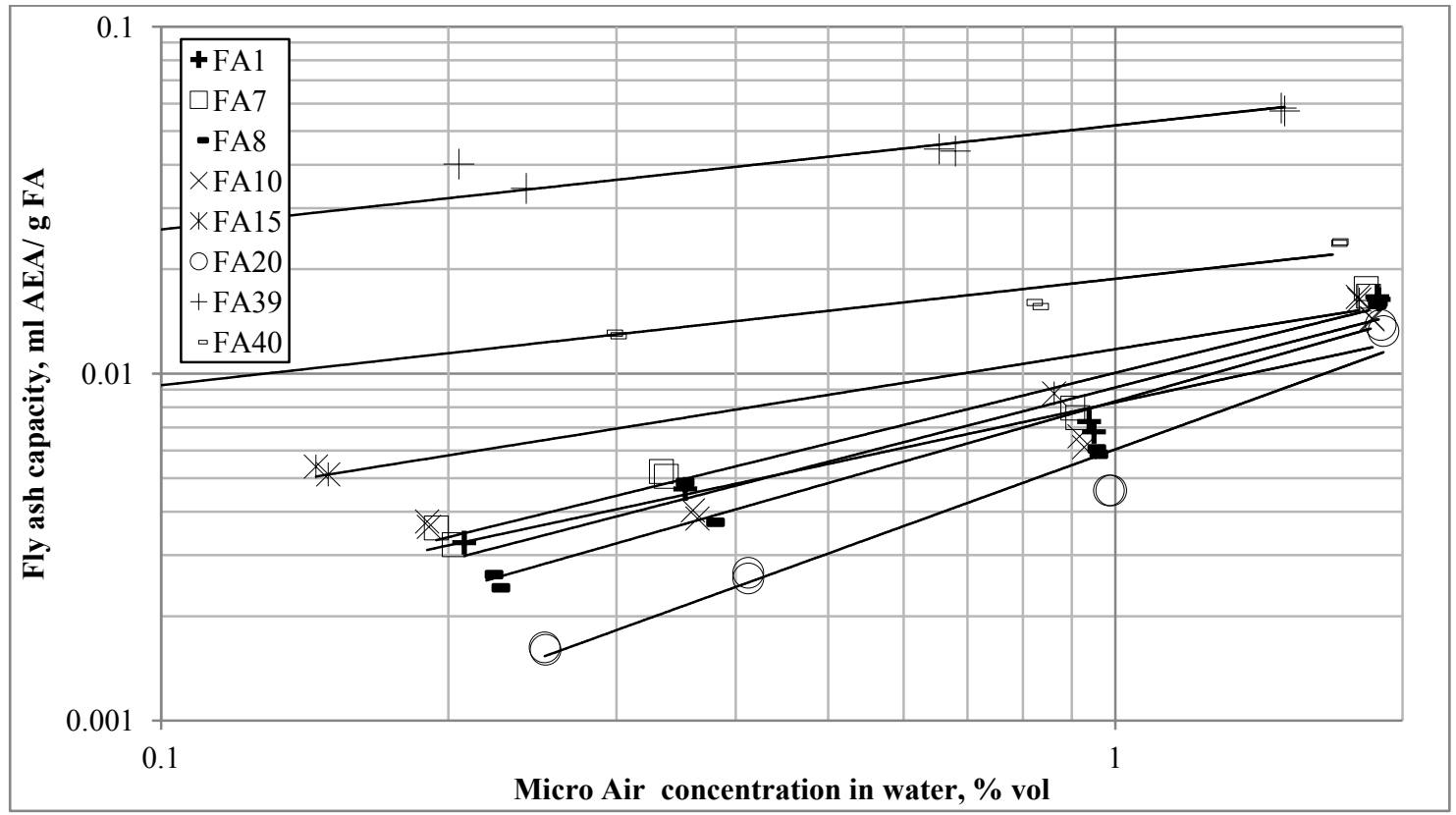

Figure A.1 Direct adsorption isotherm results for the AEA MicroAir

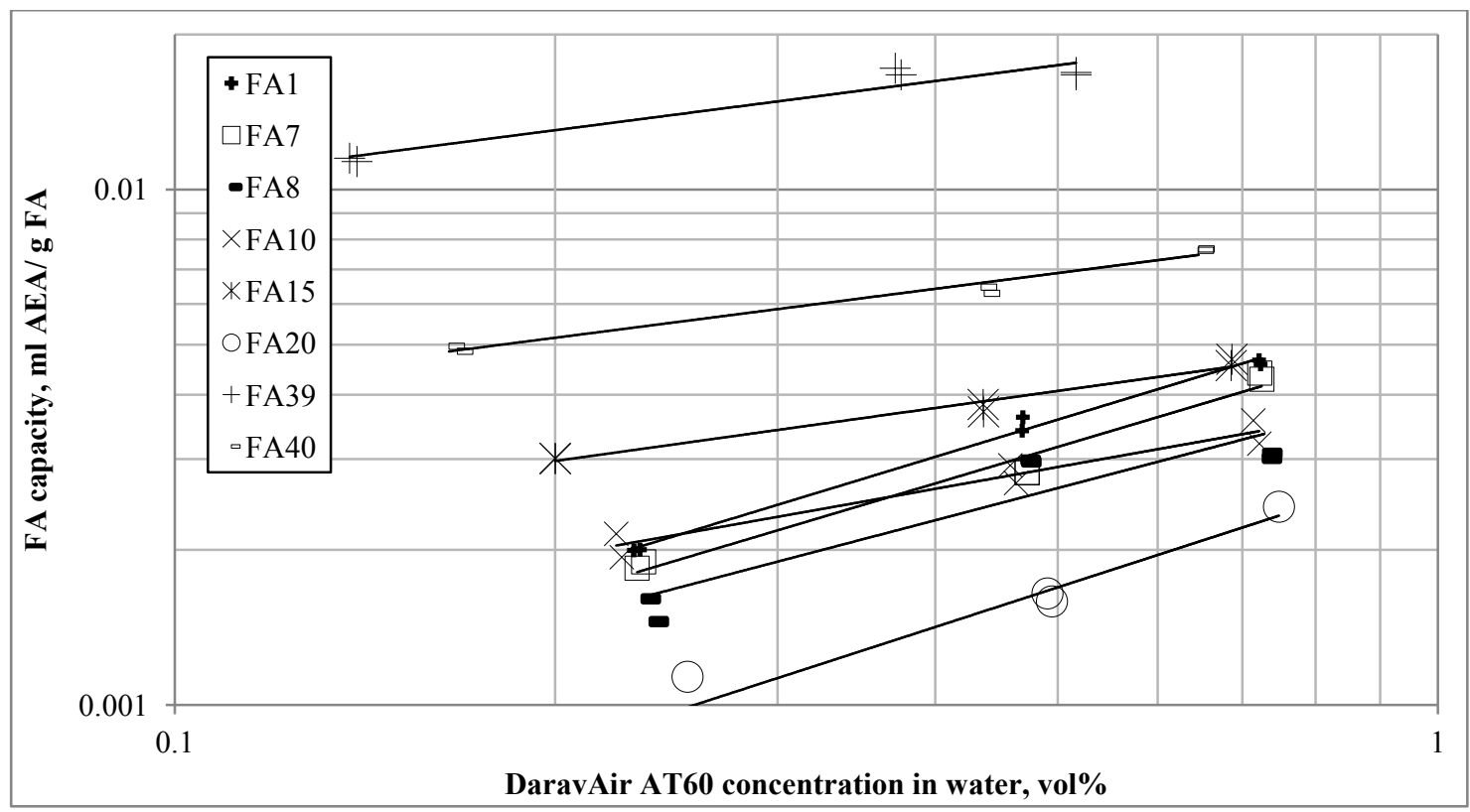

Figure A.2 Direct adsorption isotherms for the AEA Daravair AT60 


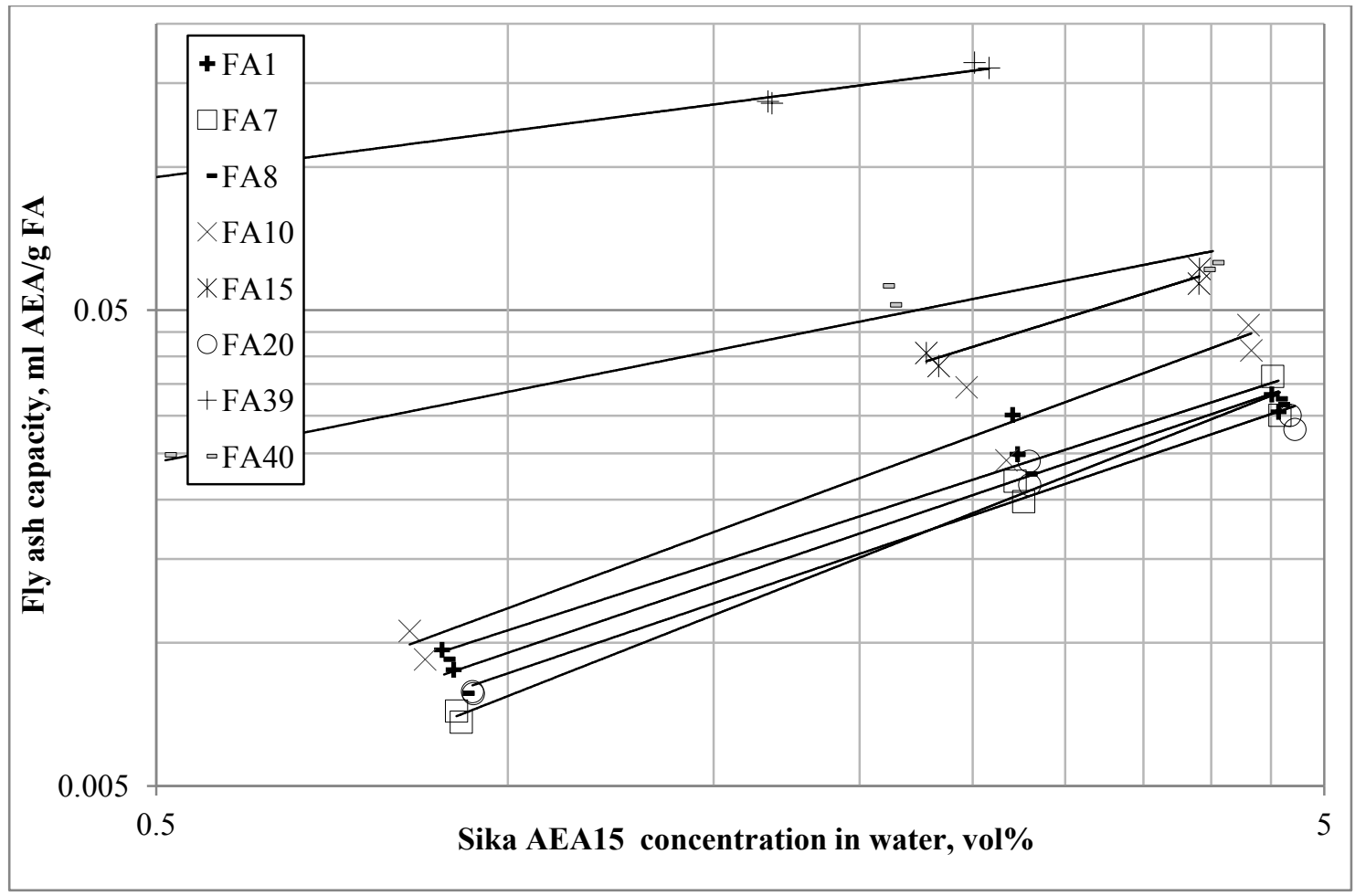

Figure A.3 Direct adsorption isotherms for the AEA SikaAEA15

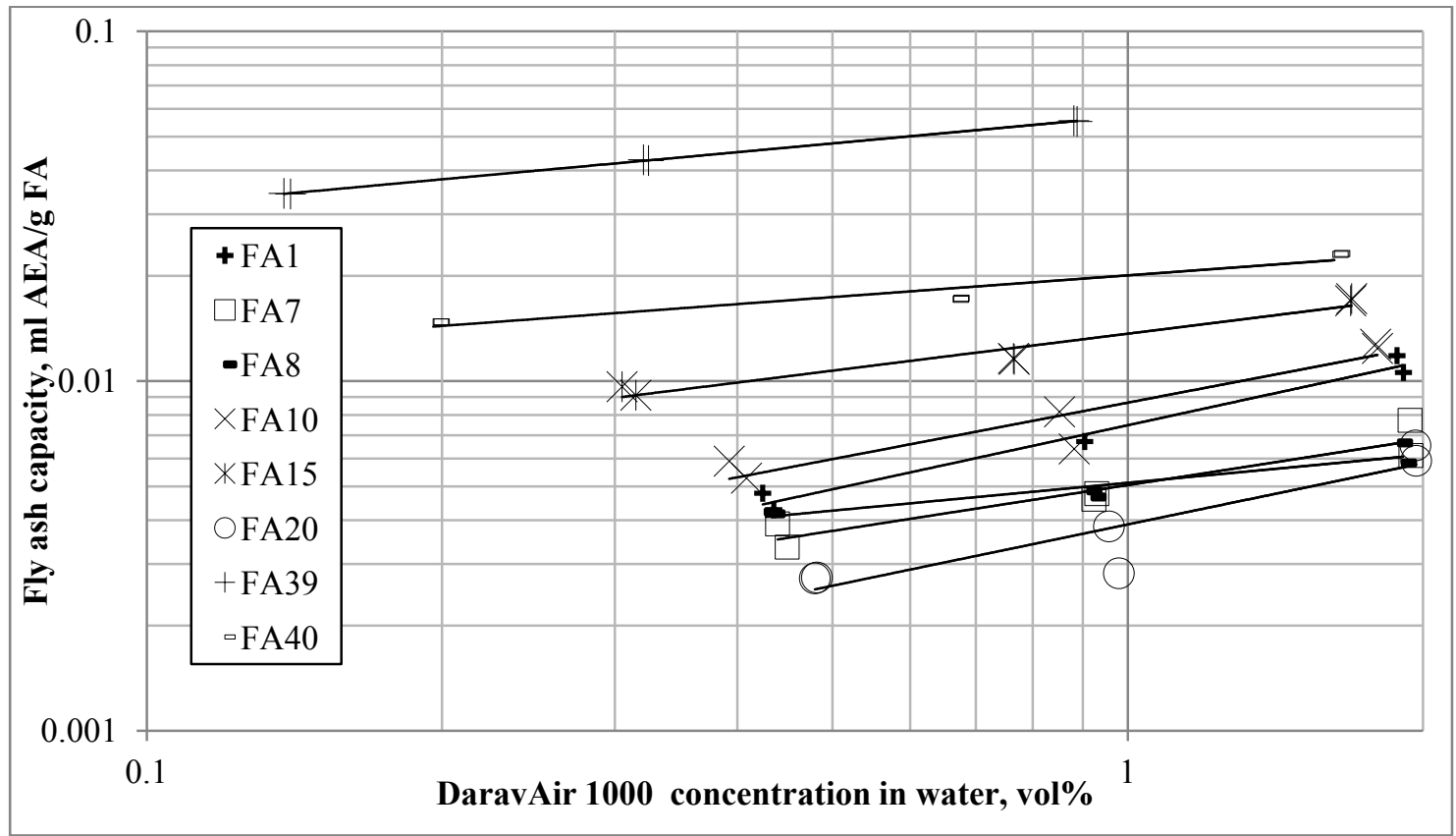

Figure A.4 Direct adsorption isotherms for the AEA Daravair 1000 


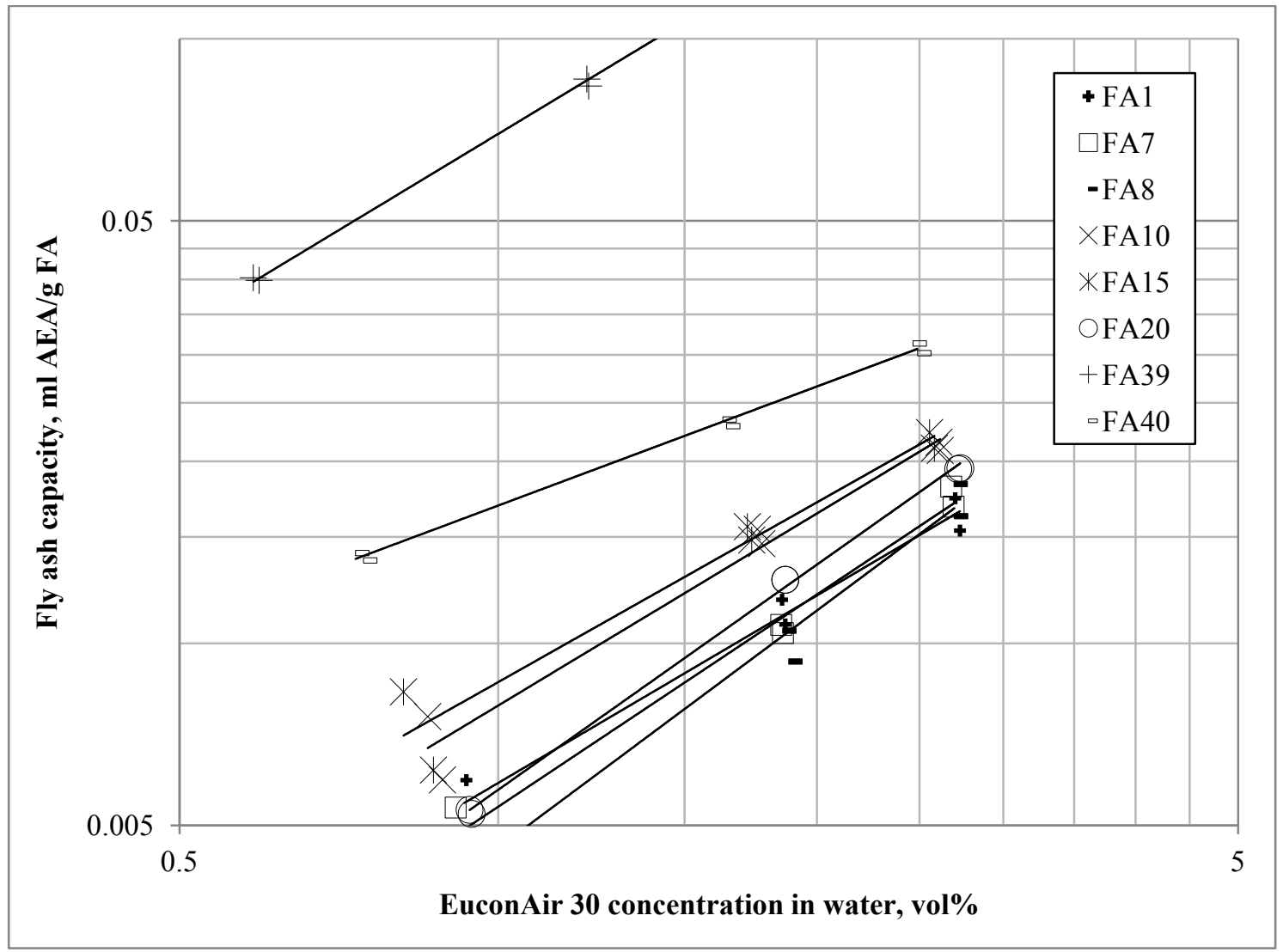

Figure A.5 Direct adsorption isotherms for the AEA EuconAir 30 


\section{Appendix B. Copyright permissions}

\section{ELSEVIER LICENSE TERMS AND CONDITIONS}

This is a License Agreement between Zeyad Ahmed ("You") and Elsevier ("Elsevier") provided by Copyright Clearance Center ("CCC"). The license consists of your order details, the terms and conditions provided by Elsevier, and the payment terms and conditions.

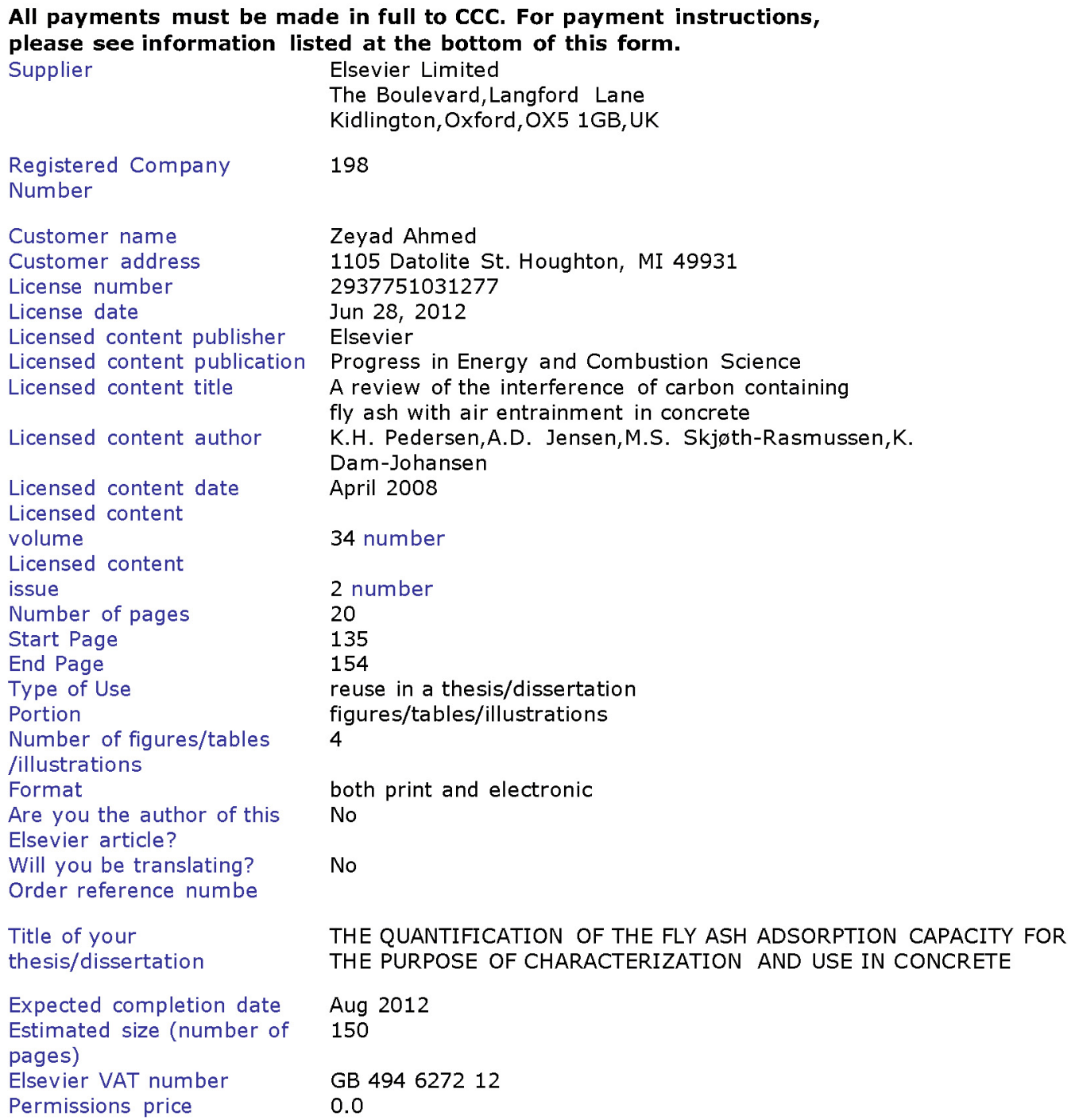

Figure B.1 Copyright permission for Figures 1.1, 1.6, and 1.7 


\section{Fwd Copyright permission}

Zeyad Ahmed <ztmahmou@mtu.edu>

To: ztmahmou@mtu.edu

Wed, Jul 11, 2012 at 10:29 AM

From: <Michael.Rafalowski@dot.gov>

Date: Wed, Jul 11, 2012 at 8:54 AM

Subject: FW: Copyright permission

To: ztmahmou@mtu.edu

Cc: Rosemary.Zaccagnino@dot.gov

Your request for permission has been forwarded to my office for response.

The figure that you have referenced is in the public domain since it is an unattributed picture in a government publication. You have permission to use the figure. We request that a notation such as "Courtesy of the Federal Highway Administration" or other notation that meets your style requirements accompany the figure.

Let me know if you need anything else.

Michael Rafalowski

Highway Materials Engineer

Federal Highway Administration

1200 New Jersey Avenue, SE

E73-448

Washington, DC 20590

email: michael.rafalowski@dot.gov

Phone: 202-366-1571

Fax: 202-493-2070

From: Zeyad Ahmed [mailto:ztmahmou@mtu.edu]

Sent: Tuesday, July 10, 2012 9:58 AM

To: FHWA, ExecSecretariat (FHWA)

Subject: Copyright permission

Dear FHWA Executive Secretariat

I would like to get your permission to use Figure 1-2: Fly ash particles at 2,000x magnification. published in Fly Ash Facts for Highway Engineers, Chapter one, in your website http://www.fhwa.dot.gov/PAVEMENT/recycling/fach01.cfm To use in my PhD dissertation, Below are the dissertation details

Name of Student: Zeyad Tareq Ahmed

Department of Civil and Environmental Engineering

Michigan Technological University

The dissertation Title"THE QUANTIFICATION OF THE FLY ASH ADSORPTION CAPACITY FOR THE PURPOSE OF CHARACTERIZATION AND USE IN CONCRETE "

This permission is required according to our graduate program policy.

I appreciate your help and timely response,

Yours,

Zeyad Ahmed

1105 Datolite St. , Apt D

Houghton, MI, 49931

Figure B.2 Copyright permission for Figure 1.2 